\title{
WestVirginiaUniversity
}

THE RESEARCH REPOSITORY @ WVU

Graduate Theses, Dissertations, and Problem Reports

2016

\section{Attachment, Coping Style, and Perceived Stress in University Students}

\author{
Erin L. Higgenbotham
}

Follow this and additional works at: https://researchrepository.wvu.edu/etd

\section{Recommended Citation}

Higgenbotham, Erin L., "Attachment, Coping Style, and Perceived Stress in University Students" (2016). Graduate Theses, Dissertations, and Problem Reports. 5800.

https://researchrepository.wvu.edu/etd/5800

This Dissertation is protected by copyright and/or related rights. It has been brought to you by the The Research Repository @ WVU with permission from the rights-holder(s). You are free to use this Dissertation in any way that is permitted by the copyright and related rights legislation that applies to your use. For other uses you must obtain permission from the rights-holder(s) directly, unless additional rights are indicated by a Creative Commons license in the record and/ or on the work itself. This Dissertation has been accepted for inclusion in WVU Graduate Theses, Dissertations, and Problem Reports collection by an authorized administrator of The Research Repository @ WVU.

For more information, please contact researchrepository@mail.wvu.edu. 
Attachment, Coping Style, and Perceived Stress in University Students

Erin L. Higgenbotham

Dissertation submitted to the College of Human Resources and Education at West Virginia University in partial fulfillment of the requirements of the degree of

Doctor of Philosophy in

Counseling Psychology

James W. Bartee, Ph.D., Chair

Jeffrey Daniels, Ph.D.

George Mamboleo, Ph.D.

John Blake, Ph.D.

Lisa Hamilton, Ph.D

Department of Counseling, Rehabilitation Counseling, and Counseling Psychology

Morgantown, West Virginia

2015

Keywords: attachment, coping, perceived stress, university students Copyright 2015 Erin L. Higgenbotham 


\title{
ABSTRACT \\ Attachment, Coping Style, and Perceived Stress in University Students
}

Erin L. Higgenbotham

\begin{abstract}
Attachment theory suggests that previous experiences direct one's interpretations of potentially stressful events and one's reaction to these events. As university students interact with a novel environment and face new demands, they may experience elevated levels of stress. Dependent on what resources they feel are available to them, they might feel confident in addressing these challenges, or they may believe they cannot meet the demands of the college environment. This perception of ability or inability can affect personal and academic success. Using attachment theory as a foundation, this study investigated the relationships among students' attachment dynamics, coping styles, and perceived stress in a sample 174 West Virginia University students. Based on attachment theory and previous research, it was expected that both students' attachment dynamics and coping styles would explain variance in perceived stress. As predicted, using hierarchical multiple regression analyses, both attachment dynamics and coping styles were observed to explain a significant amount of variance $(26.8-45.5 \%$ variance explained) in the perception of stress, after accounting for demographic variables. Results of this study are explored with regard to how they can inform clinical work and future research with the university student population.
\end{abstract}




\section{DEDICATION}

This dissertation is dedicated to my parents. Your love and support has been immeasurable throughout this process. You have stood by me and behind me through every step I have taken in this life and continue to encourage me every day. I am the woman I am today, because of all you have taught me. I love you both more than I can say. Thank you. 


\section{ACKNOWLEDGEMENTS}

I want to express my gratitude to several people integral to the completion of this dissertation. First, I would like to recognize my dissertation chair and training director, Dr. James Bartee for his support, time and effort throughout the dissertation and doctoral process. I deeply appreciate the time you took to help with my professional development. I would also like to acknowledge my former supervisor and dissertation committee member Dr. Lisa Hamilton who was the first to give me the opportunity to work with college students, helping me discover the passion I have for working with this population. Additionally, thank you to Dr. Daniels for taking the time to be a part of my committee, and for pushing me, both in this process and in the classroom, to challenge myself in the research process. A special thank you to Drs. John Blake and George Mamboleo, who both stepped in during the course of this research and provided their time, input, and suggestions, helping this project come to fruition. Also, thank you to former committee members, Drs. Roy Tunick and Richard Walls, for initially being a part of this journey.

I would also like to acknowledge the faculty and staff in the Department of Counseling, Rehabilitation Counseling, and Counseling Psychology. Thank you to all of the faculty in the Counseling Psychology program at West Virginia University, who trained and challenged me to become a better clinician and professional in our field. Special thanks to Vicki Railing, who has been exceedingly helpful throughout my time in the program, and particularly in navigating the logistics of the dissertation process from a distance. I am grateful for the lessons you shared in my journey and your contributions to my professional development. 
To the supervisors who encouraged and cajoled me throughout this process, I thank you. From my time at the West Virginia University Carruth Center for Psychological and Psychiatric Services, to my two years at The Ohio State University's Counseling and Consultation Service, and now at the University of Mary Washington's Talley Center for Counseling Services, I have felt an immense amount of support that I can never repay, but hope to one day pay forward. Thank you for giving me such amazing examples of what it is to be a clinician, and a supervisor. Finally, to my family and friends, I cannot say thank you enough. You have stuck with me through the thick and thin of this process, and have never lost faith. Your trust and cheerleading has helped me make it to the end, and I am proud to share this with y'all. 


\section{TABLE OF CONTENTS}

Page

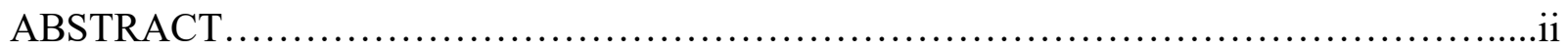

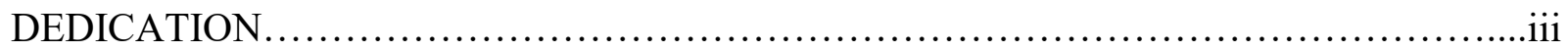

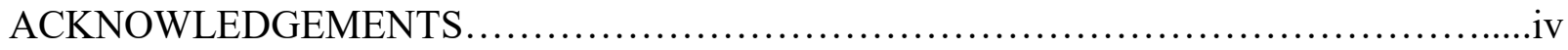

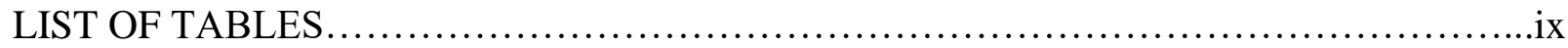

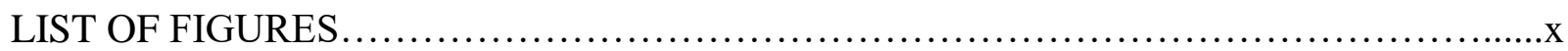

\section{CHAPTER}

I. INTRODUCTION

Statement of Problem........................................................

Attachment Theory and Stress Research......................................

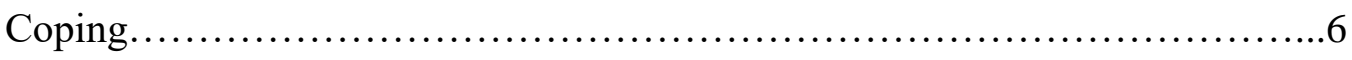





II. REVIEW OF LITERATURE

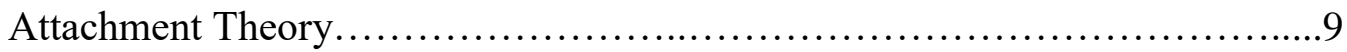

Limitations of Attachment Theory.........................................14

Conceptualization and measurement of adult attachment.......................17





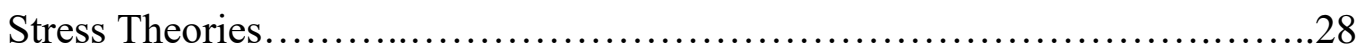

Measurement of Stress....................................................








Empirical Research in Attachment Theory and Stress........................37

Stress, Coping and Attachment Relationships in College........................38

Summary and Research Questions........................................44

III. METHODOLOGY

Research Design........................................................ 47

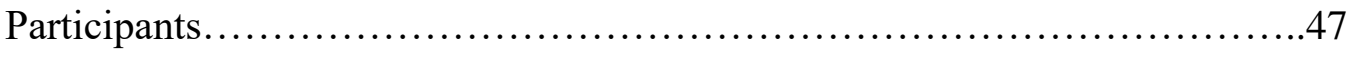

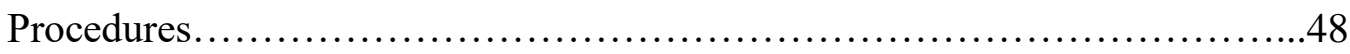

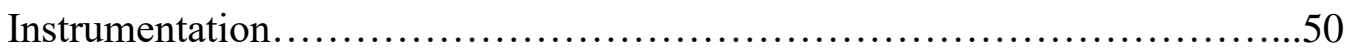

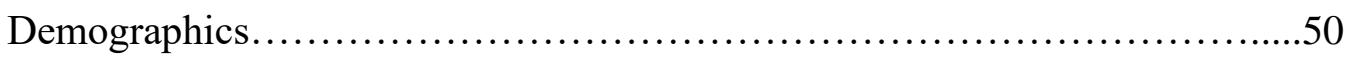

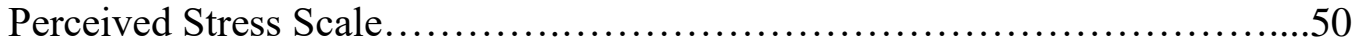

Experiences in Close Relationships......................................,51

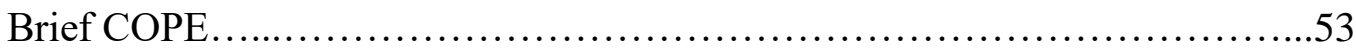

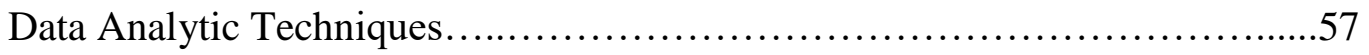

IV. RESULTS



Missing Data............................................................. 61

Tests for Univariate and Multivariate Assumptions............................62

Descriptive Statistics...................................................63



Hierarchical Multiple Regression Analyses.................................,71

Additional Regression Analyses...............................................

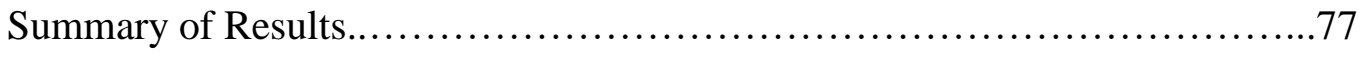


V. DISCUSSION

Summary of Results.................................................. 79

Attachment and Perceived Stress........................................ 79



Coping Style and Perceived Stress.....................................86

Hierarchical Regression Analyses......................................88

Exploratory Regression Analyses.....................................89

Clinical Implications and Future Research.............................91

Strengths....................................................93

Limitations................................................... 95

Conclusion......................................................97

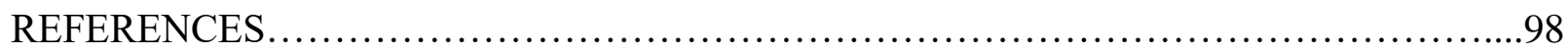

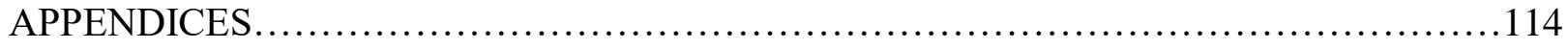

APPENDIX A: STUDY ADVERTISEMENTS.................................115

APPENDIX B: ADDITIONAL RECRUITMENT MATERIALS $\ldots \ldots \ldots \ldots \ldots \ldots \ldots \ldots 117$

APPENDIX C: WILLING PARTICIPANT INFORMATION ..................... 120

APPENDIX D: DEMOGRAPHIC QUESTIONNAIRE............................. 122

APPENDIX E: PERCEIVED STRESS SCALE...............................123

APPENDIX F: EXPERIENCES IN CLOSE RELATIONSHIPS SCALE...............125

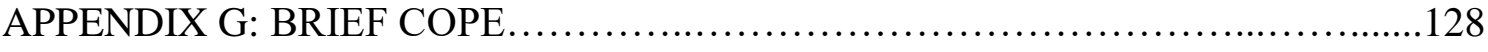




\section{LIST OF TABLES}

Table Page

3.1. Higher Order Coping Subscales for the Brief COPE.................................55

3.2. Hierarchical Multiple Regression Model 1 Variable Entry..............................59

3.3 Hierarchical Multiple Regression Model 2 Variable Entry..............................59

4.1 Participant Demographic Characteristics.........................................63

4.2 Descriptive Statistics for Criterion and Predictor Variables............................66

4.3 Correlations of Predictor and Criterion Variables for Coping Styles........................68

4.4 Research Question 2 Observed Relationships.....................................69

4.5 Research Question 3 Observed Relationships......................................70

4.6 Summary of First Hierarchical Regression Analysis of Perceived Stress..........................72

4.7 Summary of Second Hierarchical Regression Analysis of Perceived Stress...,,,,,,,,,,,,,,,,,,,..74 


\section{LIST OF FIGURES}

Figure $\quad$ Page

1. Hazan and Shaver (1987) Descriptions of Adult Attachment............................ 18

2. Model of Adult Attachment, Adapted from Bartholomew \& Horowitz (1991).....................19 


\section{CHAPTER I}

This study examined perceived stress variables within the context of the university student experience. Specifically, this study was used to examine the relationships between perceived stress (perceived environmental demands exceeding perceived available resources of the person; Cohen, 1986), coping style (i.e., problem-focused coping, emotion-focused coping, and avoidance coping), and attachment (i.e., anxious, avoidant; Brennan, Clark, \& Shaver, 1998) in a sample of university students.

\section{Statement of the Problem}

The study of stress has been an ongoing focus within the field of counseling psychology since the 1930s, when the terms general adaptation syndrome, or stress syndrome, first became an area of study (Selye, 1976). Initially, researchers understood stress as "the state manifested by a specific syndrome which consists of all the nonspecifically-induced changes within a biologic system" (Selye, 1976, p.64). Essentially, stress occurs when an individual experiences

pressure to adapt his or her behaviors and cognitions to accommodate environmental changes. In response to this change in homeostasis, unconscious biological processes in the body activate and the body becomes alert to the potential of a threat; following this initial response, appraisal of the stimulus begins in effort to determine which coping mechanisms will need to be utilized (Lok \& Bishop, 1999; Lopez \& Gormley, 2002). The person assesses the situation and any available coping resources while also becoming increasingly aware of the underlying physiological changes occurring in response to the change. When the individual determines that the perceived demands of the environmental changes exceed available resources, the person subjectively feels stress (Cohen, 1986). 
Subjective, or perceived, stress varies among individuals; some people are more vulnerable to stress, as posited in the diathesis-stress theory (Lazarus \& Folkman, 1984; Moos \& Schaefer, 1993). This theory proposes that psychological and physiological vulnerabilities make some individuals more sensitive to stress, more likely to interpret environmental events as threatening, and therefore more likely to react to perceived stress or threats in their environment. However, in all persons, there is an ongoing interaction process between people and their environments: as the environment impacts the individual, the individual also interacts with and affects the environment (Lazarus \& Folkman, 1987). This reciprocal interaction is characteristic of college students, who face many life changes in response to an environment that places demands upon students to adapt (Salas, Driskell, \& Hughes, 1996). Ross, Niebling, and Heckert (1999) found that, when undergraduate students interact with the college environment, they experience many new demands; these include an increased workload, perceived higher pressure to maintain grades and earn a degree, establishing relationships with new faculty and peers, increased responsibilities for time-management, and increased independence from their families. Andrews and Wilding (2004) and Chemers, Hu, and Garcia (2001) have found that elevated stress levels are associated with lowered academic achievement among undergraduate college students, as well as other difficulties in student success. If individuals believe they cannot meet the demands of the college environments, they might experience perceived stress that could result in lowered self-esteem, poor self-management decisions, decreased healthy behaviors (Hudd et al., 2000), impaired memory (Vondras et al., 2005), and impaired information processing (Lok \& Bishop, 1999). Additionally, studies of undergraduate students demonstrate the relationship between elevated subjective stress, poor academic performance and lower gradepoint average (Andrews \& Wilding, 2004; Chemers, Hu, \& Garcia, 2001; De Meuse, 1985; 
Shields, 2001; Struthers, Perry, \& Menec, 2000). Struthers and colleagues (2000) provided further evidence, finding that stress inversely predicted course grades at the end of the academic year.

As students react to the demands in their environment, they assess what resources are available to them to meet these requirements. Lazarus and Folkman (1984) posited that this appraisal includes not only classifying the different demands, but also evaluating the specific resources on hand to meet those demands. An individual's resources can include the support and adult relationships in their lives (Howard \& Medway, 2004). Communicating with others, receiving comfort, advice, and counsel from those to whom the individual is attached may be a mediating factor in the perception of and reaction to stress (Bernier, Larose, Boivin, \& Soucy, 2004; Soucy \& Larose, 2000). Attachment in adulthood occurs when individuals seek the adult attachment figure, particularly when under duress; when individuals seek security and comfort in the adult attachment relationship; and when individuals protest when the adult attachment figure becomes or threatens to become inaccessible (Colin, 1996). Positive responses to stress that might lead to the alleviation of stress over time include seeking support from adult attachment figures, communicating with these attachment figures, and perceiving environmental demands as challenging as opposed to threatening (Bernier et al., 2004; Hammen, et al., 1995; Howard \& Medway, 2004). To frame the investigation of students' perceived stress and individuals' response to perceived stressful events, Attachment Theory was utilized, as it has been identified and supported as a strong way to represent real differences in peoples' behaviors and attitudes.

\section{Attachment Theory and Stress Research}

One can trace the origins of attachment research back to the work of ethnologist Konrad Lorenz, and his studies on animal imprinting (Hess, 1973). Lorenz (1937), in examining the 
behaviors of newly hatched ducklings and goslings, observed that they became socially bonded to the first moving creature they encountered within about 13-16 hours after hatching, which became known as the critical period, rather than instinctively connecting to adult members of their own species as previously believed. Over time, this immediate form of social learning was found to be long-term and irreversible (Hess, 1973). Lorenz' work with imprinting was instrumental in establishing an understanding that instinctive behaviors play a central role in the social adaptation of animals. In an effort to expand on the idea of imprinting, John Bowlby (1969/1982) asserted that the primary formation of social bonds in infant animals, imprinting, was not only an instinctive process, but also one activated in effort to avoid perceived threats in the environment. Bowlby, and later researchers, expanded on one area in studying imprinting in human children: the critical period. Researchers determined that human infants experienced a more extended period of development time during which these social bonds form, known as the sensitive period. He examined this through his work studying the mother-child bond and maternal deprivation, leading to the development of Attachment Theory (Bowlby, 1988).

Attachment Theory (Bowlby, 1969/1982, 1988) describes the way in which individuals' early experiences with caregivers impact their behavior in relationships. Early empirical work in the arena of attachment includes Mary Ainsworth's observations of infants and their mothers in Uganda, during the Strange Situation Protocol (Ainsworth, 1978). The focus of these studies was to assess individual infant behaviors in response to the presence and absence of the identified caregiver. While the development of attachment theory initially focused on the behavior of children and caregivers and/or parents, recent extensions to adult relationships have found ample empirical support (Mikulincer \& Shaver, 2003). With specific bearing on this research, Attachment Theory has been proposed as a framework to integrate the multiple 
psychological theories that inform research and practice in psychology as the theory comprehensively accounts for cognitive processes, relationship dynamics, and systemic contexts that impact behavior (Lopez, 1995). For example, Attachment Theory can help us understand such diverse phenomena as satisfaction within romantic relationships (Feeney, 1999), coping with relationship stressors (Alexander, Feeney, Hohaus, \& Noler, 2001; Seiffge-Krenke, 2006), conflict resolution behaviors (Corcoran \& Mallinckrodt, 2000; Pistole \& Arricale, 2003), general psychological adjustment (Seiffge-Krenke, 2006), and affect regulation (Feeney, 1999; Mikulincer, 1998). Feeney and Noller (1996) theorized that secure attachment helps an individual respond to stress in a more constructive manner, as researchers have found the protective mechanisms characteristic of secure attachments active during stressful experiences (Solberg \& Villarreal, 1997). Furthermore, McCarthy, Moller, and Fouladi (2001) and Perrine (1998) posited that attachment styles modify the ways that individuals perceive and respond to stress. Specifically, the interaction effect between attachment and stress in a sample of college students suggested that students with secure attachment perceived less stress. Researchers have found secure adult attachments provide trust and self-confidence in finding and using support (Bernier et al., 2004); therefore, when experiencing stress, individuals identified with attachment security assess themselves as closer to and more trusting of others, and they interpret stress as challenging, rather than threatening (Hammen et al., 1995; Perrine, 1998). Conversely, individuals with elevated attachment avoidance or attachment anxiety might experience altered appraisal of life events. Feelings of mistrust, insecurity, and lack of self-confidence that are characteristic of insecure adult attachments can prevent optimal performance and increase vulnerability to stress (Bernier et al., 2004). Therefore, non-secure attachment is considered a vulnerability or reactivity factor. 
Stress activates the attachment system by impacting one of three general categories of threat: personal factors (i.e., hunger, fatigue, pain), environmental factors (i.e., challenging or frightening events), and relationship factors (i.e., relationship conflict, or the separation from or death of an attachment figure) (Mikulincer, Birnbaum, Woodis, \& Nachmias, 2000). The individual's attachment system, informed by previous experiences, determines how the individual reacts to stress in one or more of these areas (Collins \& Feeney, 2004; Larose \& Soucy, 2005). Dependent on the individual's history and experience with caregivers, he or she may feel more equipped to deal with stress themselves, as well as to access support from others in addressing the stress.

\section{Coping}

Coping is understood as a complex, multidimensional process defined as "constantly changing cognitive and behavioral efforts designed to manage specific external and/or internal demands that are appraised as taxing or exceeding the resources of the person" (Lazarus \& Folkman, 1984; p. 141). In the stress appraisal and coping model developed by Lazarus and Folkman, the origin of how individuals cope with stress is known as the primary appraisal process. In this process, the individual initially perceives the threat to him or herself. Once threat is evident, a secondary appraisal process occurs in which the individual identifies his or her potential responses to the threat. Coping is the process of implementing the chosen response (Carver, Scheier, \& Weintraub, 1989).

Both the demands and resources of the environment, as well as the individual's personality characteristics that influence the appraisal of stress and available resources impact the coping process (Folkman \& Moskowitz, 2004). Specific identified coping responses, or coping dispositions, vary according to the individual's method of addressing stress. Coping 
styles frequently discussed in coping and stress literatures are problem-focused coping and emotion-focused coping (e.g., Billings \& Moos, 1981; Lazarus \& Folkman, 1984).

Coping Styles. Problem-focused coping involves dealing with the problem causing distress by utilizing various problem-solving strategies and then doing something to alter the source of the stress (Carver et al., 1989). Generally, problem-focused coping strategies (e.g., gathering information or planning), are utilized when the person feels that he or she can do something constructive to lessen the effects of the stressor(s). Whereas, emotion-focused coping (e.g., reaching out to others for emotional support) seeks to lessen the emotional distress associated with the stressor and/or situation. Emotion-focused coping strategies generally prevail when people feel that the stressor is something to endure and cannot be altered (Lazarus \& Folkman, 1984).

The literature on coping also differentiates between active and avoidant coping strategies. Active coping strategies can be either problem or emotion-focused strategies that focus on changing the nature of the stressor itself or how one assesses it. Avoidant coping styles, however, include activities designed to prevent the individual from directly addressing stressful events, such as the use of alcohol or other substances, or using different activities to take one's mind off the current problem (Carver et al., 1989).

\section{Purpose of the Study}

Recognizing the need for research on perceived stress within the university student environment, this study employed the tenets of Attachment Theory, as developed by Ainsworth and Bowlby, to study individual differences of university students as they understand and respond to their levels of perceived stress. Based on prior research, this study tested hypotheses developed from theory and prior research to better inform our understanding of the relationship 
among attachment variables, coping styles, and perceived levels of stress, and how these impact university college students. The primary question of this project asks how a student's attachment style relates to his or her level of perceived stress and the possible mediation of this relationship by the student's style of coping. This research informs both the theory and practice of treatment related to stress and adds to the literature regarding how attachment and practiced coping styles may impact an individual's understanding of his or her stress.

Research Question One. Does student's attachment avoidance and attachment anxiety predict perceived stress?

Research Question Two. The second question addressed in this study was whether the student's level of attachment avoidance and attachment anxiety are predictive of the coping strategies utilized. This question generated a number of testable hypotheses, as it aimed to examine the relationship between attachment avoidance and attachment anxiety, and the different dimensions of coping, explored further in the next chapter.

Research Question Three. The third question addressed in this study was whether the student's utilized coping strategies will predict perceived stress. In other words, does the type of coping strategy utilized explain additional variance in the perceived stress above and beyond variance explained by attachment style? 


\section{CHAPTER II}

\section{REVIEW OF THE LITERATURE}

\section{Attachment Theory}

As discussed in the previous chapter, the origins of research into attachment can be traced back to the work of ethnologist Konrad Lorenz, as he explored the principle of imprinting in animals (Hess, 1973). Lorenz's (1937) observations of how newly hatched ducklings and goslings bonded with the first moving object they encountered provided the foundational description of imprinting as we understand it today. These descriptions of imprinting as an instinctive bond between newborn and caregiver, regardless of species, reinforced the modern understanding of how behavioral patterns evolve; specifically the concept that, while behavior patterns are mostly innate, they can be triggered and influenced through environmental stimuli (Hess, 1973). Lorenz's work with the phenomenon contributed not only to understanding how these innate behaviors play into the adaptation of the organism, but also into the further exploration of how behavioral patterns not only develop in early life, but continue throughout maturation (Hess, 1973). In his efforts to extend the theory of imprinting to human social bonds, John Bowlby (1969/1982) proposed that imprinting was both an instinctive process, as well as a pattern of behavior activated to avoid perceived environmental threats.

Attachment Theory as we understand it today was largely developed by John Bowlby (1969/1982, 1988), who supplied the outline of the theory, and Mary Ainsworth (Ainsworth, Blehar, Waters, \& Wall, 1978), who supplied the early empirical support. Combining the insights of several disciplines including ethology, developmental psychology, psychoanalysis, and cognitive psychology, Attachment Theory offers an explanation of the mechanism and importance of emotional bonding between children and their primary caregivers and the impact 
of these initial experiences on subsequent relationships (Mikulincer \& Shaver, 2003). While much of the initial study on Attachment Theory focused on infancy and childhood, the theory seeks to offer a comprehensive, life-span understanding of healthy relational development. In fact, work from the last two decades has brought Attachment Theory into the realm of adult relationships, including romantic connections (e.g., Ainsworth, 1989; Hazan \& Shaver, 1987).

The premise of Attachment Theory is that attachment behavior is an innate, biological process, and evolutionarily adaptive (Bowlby, 1969/1982). Theoretically, the attachment behavioral system is one of several instinctive evolutionarily adaptive behavioral systems that guide our behaviors from birth, helping to ensure species survival. The activation and termination of each behavioral system follows projected patterns in all individuals. Mikulincer and Shaver (2003) provide a summary of the six common components of behavioral systems: 1) a specific biological function that increases likelihood of survival and successful reproduction, 2) a set of activating triggers, 3 ) a set of commutable behaviors that designate the primary strategy for attaining a specific goal, 4) a particular goal that reflects the necessary change to deactivate the system, 5) the cognitive operations necessary to navigate the system, and 6) specific neural links, either inhibitory or excitatory, with other behavioral systems. In the attachment behavioral system, for example, as a survival-ensuring mechanism activated by a perceived internal or external threat, the goal is to achieve proximity to an attachment figure that can provide safety and a secure base, thus deactivating the system. Once the attachment behavioral system is deactivated, other systems then have the opportunity to begin. Examples of other specific behavioral systems are exploration, caregiving, and relationships.

The goal of the behavioral attachment system is to cultivate survival-enhancing relationships for the benefit of infant, vulnerable members of the group (Bowlby, 1969/1982). 
The attachment behavioral system can be defined by its mechanism of seeking out and sustaining proximity to other persons. Using a variety of available behaviors, an individual who experiences a threat will reach out to the attachment figure with the aim of bringing that person into closer connection. Individuals perform attachment behaviors in the context of important relationships. First appearing in infancy in the frame of the caregiver-child relationship, the attachment system later operates in multiple contexts, including romantic relationships, interactions with superiors, and friendships. The strongest activation of attachment behaviors is in response to stress. Examples of stressful situations faced by infants that activate the attachment system are personal factors, such as fatigue, hunger, illness, and discomfort or pain. As an example of the adaptive nature of attachment behaviors, by maintaining proximity to the caregiver during the activation of the attachment behavioral system (i.e., crying when a loud noise is heard or clutching the caregiver in the presence of a stranger), the infant increases the chance of survival. Human infants are vulnerable for an extended period, even compared to other primates, thus the protection and care elicited by these behaviors helps to ensure survival and eventual reproduction.

In adults, activation of the attachment behavioral system also occurs in response to significant changes, either internal or external, and serves the purpose of eliciting support and comfort from others to reinforce coping and adjustment to experienced difficulties. During adulthood, attachment figures may include individuals outside of primary caregivers, such as romantic partners and friends, groups, institutions or symbolic/religious figures (e.g., God). In addition, context-specific situations may provoke the development of attachment relationships (Mikulincer \& Shaver, 2003), such as between a client and his/her therapist. These various attachment relationships are conceived as hierarchically organized, with the classification of 
long-term ongoing relationships as primary. For example, while a child may have attachment to both mother and father, the connection to one parent may be more dominant than the other. While the goal of attachment behaviors is to seek comfort and security with the attachment figure, the achievement of this goal is dependent on the actual response of the attachment figure to the individual. For example, Bowlby (1969/1982) specified that attachment figures need to be responsive to the signals of distress and provide a safe haven for the individual. The provision of a safe haven is when attachment figures provide reassurance, comfort, and/or help (Feeney \& Collins, 2004). When caregivers appropriately provide a secure base to which the individual can return for support and comfort, this permits the deactivation of the attachment behavioral system and the activation of the exploratory system in the individual. Thus, the ideal responsive caregiving from an Attachment Theoretical view balances the provision of comfort (i.e., safe haven) with the reassurance and support of exploration (e.g. secure base). When not met, and caregiving is insufficient, not all individuals develop secure attachments.

With sensitive and available caregiving, the provision of a safe haven and secure base, the infant's security needs are met and other systems, like the exploratory system, have the opportunity to activate. When the attachment system remains activated, possibly due to a lack of sufficient comforting response from the caregiver, other systems are unlikely to actuate and the individual experiences insecurity. According to Attachment Theory, the experience of this security or insecurity in early caregiver-child relationships becomes internalized; resulting in “internalized dispositions that largely determine a person's resilience and vulnerability to stressful life events" (Lopez \& Brennan, 2000, p. 284). These internalized inclinations are also referred to as working models of self and others. As Bowlby (1969/1982) conceptualized 
attachment as an active evaluative process, in which people are evaluating information about the attachment relationship, the attachment figure's responses, and the variable impact of different attachment cues as they occur, this information is stored as mental representations and contributes to individual nuances in attachment behavior. These working models include information about one's own sense of worth and desirability and expectations of others' sensitivity and trustworthiness, helping individuals to process information and organize behavior in the context of attachment. These internal working models of self and others impact behavioral, cognitive, and affective processes by providing guidance about what can be expected from others, how to interpret interactions, and how memories of attachment-related events are stored (Bowlby, 1980). Once internalized, the experiences of threat or safety become working models that are core aspects of one's personality, and serve as templates for behavior in later relationships, which is why they are often conceptualized as trait-like and stable over time (Kirkpatrick \& Hazen, 1994).

Two additional constructs: hyper-activation and deactivation of the attachment system, referred to as secondary attachment strategies, are also important to the viability of the attachment system (Main, 1990). When initial distress signaling does not result in the provision of appropriate caregiving, individuals must search for alternative strategies to help meet attachment needs. One of these alternatives is a hyper-activating strategy that magnifies proximity-seeking attempts. This happens simultaneously while maintaining the activation of the attachment behavioral system. Another alternative strategy is the deactivation of the attachment system without having achieved attachment security; in other words, overriding one's need for attachment. These strategies have psychological and social costs to the individual, 
including hindering the ability to develop mature, lasting relationships in adulthood and the ability to cope with difficulty (Mikulincer \& Shaver, 2003).

The work of Ainsworth and her colleagues (1978) helped to illustrate these theoretical constructs through their investigation of these behaviors in children in a laboratory situation. Briefly summarized, the experiment involved exposing children to a stressful scenario by separating and reuniting them with their mother. Based on observations of the various behavior patterns witnessed in child participants in this series of studies, researchers described three categories of attachment: secure, avoidant, and anxious/ambivalent. Secure children exhibited distress upon separation but recovered quickly and greeted the mother with joy and affection, able to resume exploration quickly upon the return. Avoidant children demonstrated a deactivating style, showing little distress upon separation and avoiding contact with the caregiver at reuniting. Anxious/ambivalent children, utilizing a hyper-activating strategy, exhibited extreme distress upon separation and contradictory responses upon reuniting, such as hugging at one moment and resisting attempts to comfort in another. A fourth type found later in duplicating the same methodology, was named disorganized, and includes components of both the deactivating and hyper-activating styles (Main \& Hesse, 1990). This work, and the ongoing research efforts in Attachment Theory, has provided substantial and consistent evidence that, based on the quality of early experiences with primary caregivers, people develop specific attachment styles that influence their actions in relationships throughout the rest of their life.

Limitations of Attachment Theory. Although much of the research completed since the beginning of Attachment Theory has validated many of the basic concepts of the theory, some limitations may impact its applicability. One of the limitations identified is the lack of longitudinal research on the stability of attachment constructs. One concern with this limitation 
is that even if attachment research were more widely conducted, we would not expect to find strongly fixed relationships between early and later attachment, given that the theory allows for flexibility within attachment organization based on experiences throughout life (Lopez, 1995). Shaver and Norman (1995) noted there have been compelling, long term prospective studies done to support the stability of attachment patterns. For example, Grossman and Grossman (1991) found that elements of peer relationships at age 11 years are assessable from attachment classifications identified at 12 months. Other relatively shorter prospective studies have found relative continuity in attachment patterns. Main, Kaplan and Cassidy (1985) reported the results of a study with 40 infants, 12-18 months old, evaluated using the Strange Situation protocol and then followed up at 6 years of age to evaluate attachment patterns. They found a correlation of $r$ $=.76$ between attachment to the mother at 12 months and at 6 years. Conversely, the correlation between attachment to the father at 18 months and at 6 years was only $r=.30$, signifying much lower stability for this relationship and evidence of both the stability and flexibility of this construct. While further longitudinal studies will help clarify the conditions under which attachment patterns are created and either remain steady or change, the literature does include sufficient longitudinal work to support the theory's basic tenets at present.

A second limitation is a lack of understanding as to how cultural variables may contribute to an individual's attachment patterns (Pistole \& Watkins, 1995). While Attachment Theory considers the development of attachments to be a universal experience, critics argue that a more nuanced understanding of how cultural variables can impact the formation and styles of attachment relationships is needed. Such variables as sex, ethnicity, sexual orientation, socioeconomic status, and disability may impact the way attachments are begun and upheld. Main (1990) reviewed the research on cross-cultural studies of attachment, finding that, while 
some of the early comparison research raised questions in response to cultural variations in the prevalence of particular attachment patterns, the current evidence demonstrates much greater variations within as opposed to between cultures. Furthermore, Main posited that the psychological mechanisms used to sustain attachment organizations seem to be similar across cultures. While future research will hopefully address these concerns, current evidence supports the cross-cultural utility of Attachment Theory.

Another criticism of Attachment Theory is the question of applicability of the theory beyond the initial parent-child bond. Bartholomew and Thompson (1995) questioned the appropriateness of applying Attachment Theory to a wide range of relationships, such as romantic and peer relationships. These relationships, they argued, while important may not take on all the characteristics of the original attachment relationships. As Shaver and Mikulincer (2007) demonstrated in their review of relationship functioning from an attachment theory perspective, adults tend to look to romantic and peer attachment figure for three central provisions of attachment: proximity maintenance, safe haven, and secure base, particularly in the face of distress. Thus, it is reasonable to continue to study the nuances of applying attachment theory to any and all relationships, as there is a foundation on which to extend it to varied adult relationships.

Finally, some researchers have raised concerns regarding the measurement of attachment variables (see, for example: Bartholomew \& Thompson, 1995; Lopez, 1995). Given questions with the use of both survey as well as interview-based instruments, comparison of studies can be challenging. Additionally, several different survey methodologies and instruments have been used to study the constructs, separating bodies of studies on the theory, making it difficult to synthesize findings. 
In summary, as with any theory, there are limitations to Attachment Theory and areas where further empirical evidence is needed. However, the existing literature is supportive of the primary tenets of attachment theory and no significant threats to the validity in applying Attachment Theory to relationships have been identified and supported by empirical research. Furthermore, as Lyddon (1995) suggested, the use of Attachment Theory has many benefits:

“... one strength of attachment theory as a potential metaperspective for counseling psychology lies in its integrativeness - its capacity to bring biological (structural), psychological (cognitive/affective), and social dimensions of experience to bear on our understanding of the developmental dynamics of self change and self stability over the life span.” (pp. 480)

Conceptualization and measurement of adult attachment. Following the original work from Ainsworth and colleagues (1978), many formulations of the basic theory have emerged. As a result, numerous methods of measurement for these attachment styles in adulthood have been developed and used in the literature. As previously noted, Attachment Theory has been repeatedly criticized for lacking a consistent measurement approach. The available measurement formulations include both taxonomic (e.g., Hazan \& Shaver, 1987) and dimensional models (e.g., Brennan, Clark, \& Shaver, 1998) for understanding variance in attachment patterns. Continuing from Ainsworth's early findings, some of the initial self-report measures of attachment were categorical in nature. For example, Hazan and Shaver (1987) extended the premises of childhood attachment into the arena of adult relationships when they developed first-person paragraphs representing each attachment type identified in the Ainsworth studies (i.e., secure, anxious, and avoidant). As a form of self-identification, individuals are presented with these three paragraphs with different descriptions of interpersonal behaviors and experiences, and are then asked to choose which pattern of behavior best represents them in relationships (see Figure 1). 
Attachment Style

Avoidant

Anxious-ambivalent

Secure

\section{Description}

I am uncomfortable being close to others; I find it difficult to trust them completely, difficult to allow myself to depend on them. I am nervous when anyone gets too close, and often, love partners want me to be more intimate than I feel comfortable being.

I find that others are reluctant to get as close as I would like. I often worry that my partner doesn't really love me or won't want to stay with me. I want to get very close to my partner, and this sometimes scares people away.

I find it relatively easy to get close to others and am comfortable depending on them. I don't often worry about being abandoned or about someone getting too close to me.

Figure 1: Hazan and Shaver (1987) Descriptions of Adult Attachment

Another widely used taxonomic conceptualization of these styles was developed by Bartholomew (1990; Bartholomew \& Horowitz, 1991) for adult application. Based on selfclassification of the individual's working models for self and others (see Figure 2), this model presents four different attachment styles: secure, preoccupied, dismissive, and fearful. These four styles have been utilized for classifying individuals in many studies of attachment. These typological conceptualizations assume that the early attachment-related experiences of the individual lead to qualitatively different subsets of people, identifiable by their unique characteristics. This approach uses the learned internal working models of self and other as points of reference, assessing the individual's perception of him or herself with their expectations of others (Bartholomew \& Horowitz, 1991). 


\begin{tabular}{|c|c|c|c|}
\hline \multirow{4}{*}{$\begin{array}{l}\text { Model of Other } \\
\text { (Avoidance) }\end{array}$} & \multicolumn{3}{|c|}{$\begin{array}{l}\text { Model of Self } \\
\text { (Dependence) }\end{array}$} \\
\hline & & $\begin{array}{l}\text { Positive } \\
\text { (Low) }\end{array}$ & $\begin{array}{c}\text { Negative } \\
\text { (High) }\end{array}$ \\
\hline & $\begin{array}{c}\text { Positive } \\
\text { (Low) }\end{array}$ & $\begin{array}{c}\text { CELL I } \\
\text { Secure } \\
\text { Comfortable with } \\
\text { intimacy and } \\
\text { autonomy }\end{array}$ & $\begin{array}{c}\text { CELL II } \\
\text { Preoccupied } \\
\text { Preoccupied with } \\
\text { relationships }\end{array}$ \\
\hline & $\begin{array}{c}\text { Negative } \\
\text { (High) }\end{array}$ & $\begin{array}{c}\text { Dismissing } \\
\text { Dismissing of } \\
\text { intimacy } \\
\text { Counter-dependent }\end{array}$ & $\begin{array}{c}\text { Fearful } \\
\text { Fearful of intimacy } \\
\text { Socially avoidant }\end{array}$ \\
\hline
\end{tabular}

Figure 2: Model of Adult Attachment, Adapted from Bartholomew \& Horowitz (1991)

While taxonomic models of attachment (i.e., secure, preoccupied, dismissive) hold some merit, recent empirical work has found support for more dimensional conceptualization of the attachment constructs. Brennan and colleagues (1998) argued that typological conceptualizations are inappropriate, citing findings from Ainsworth and colleagues' original study that two underlying quantitative dimensions, anxiety and avoidance, could consistently predict the three attachment types. They extended discussion of these findings to Hazan and Shaver's (1987) categories. Furthermore, Brennan and colleagues (1998) argued that Bartholomew's (1990) models of self and others are interpretable along these quantitative dimensions, such that a negative model of self relates to anxiety and a negative model of other relates to avoidance. To garner support for the validity of this argument, they collected all existing self-report measures of attachment and, from these, identified 323 non-redundant items representing 60 separate attachment-related constructs. They administered these specific items 
to a large sample of students $(n=1086)$ and factor analyzed the responses. They found two higher-order factors corresponding to the dimensions of avoidance and anxiety.

Furthermore, they created a self-report measure to assess these empirically supported dimensions (Experiences in Close Relationships; Brennan et al., 1998). To design a measure from the 323 original items, they identified the 36 items with highest absolute value correlations with the two factors. These 36 items shaped two new scales that were highly correlated with parent scales ( $r=.95$ for both), not with each other $(r=.11)$. While Brennan et al (1998) successfully reproduced Bartholomew and Horowitz's (1991) four types from these scales using clustering procedures, they contend that it is unnecessary and inappropriate to do so noting, "categorization of research participants is unnecessary when dimensional measures are available; and some power and precision are lost when categories rather than continuous scales are used" (p. 68). From their work, it seems likely that there are two dimensions underlying the variety of attachment constructs characterized in the body of attachment literature.

Another measure designed to assess underlying, continuous dimensions of adult attachment is the Attachment Style Questionnaire (ASQ; Feeney, Noller, \& Hanrahan, 1994). The ASQ is a 40 item self-report measure that classifies adult attachment on a five-factor scale; the classifications include confidence, discomfort with closeness, need for approval, preoccupation with relationships, and relationships as secondary. While the scale scores are consistent with the secure, avoidant, and anxious-ambivalent attachment types reported by Hazan and Shaver (1987), this format also provides a rich assessment of attachment styles as individuals are not required to ascribe to all characteristics of a category, as in the forced choice paragraph models, such as the Relationship Questionnaire (Bartholomes \& Horowitz, 1991). Instead, individuals may select the degree to which each dimension is represented in their lives 
by answering the questions related to each classification. Researchers can utilize the ASQ to assess each of the five dimensions separately, or the scales can be selected and used to represent levels of secure and insecure attachment, as in other, taxonomic models. Specifically, research conducted utilizing the ASQ demonstrated great consistency with Bartholomew and Horowitz's (1991) four group model of attachment in respondents (Feeney et al., 1994).

For the purposes of this study, the operationalization of adult attachment involved the two continuous dimensions of attachment avoidance and attachment anxiety, as individual reporting of levels of these dimensions appear to consistently represent how an individual sees themselves and others in relationships. As the Experiences in Close Relationships (Brennan et al., 1998) directly assesses these dimensions, without requiring additional sifting of the data, as with the ASQ, this measure was utilized. While there is some critique of using this measure with a young adult population, as it is written and oriented toward assessing romantic relationships (Fraley, Waller, Brennan, 2000), it was the hope of this researcher to assess all available students across age and relationship status in the university environment. This measure provided a snapshot of student attachment constructs at the time of collection.

Given the diversity of conceptualization and measurement of attachment, interpretation and comparison of the literature can be challenging (Bartholomew \& Shaver, 1998). A question that has become apparent from this heterogeneous landscape of attachment research is whether attachment constructs are dimensional or typological in nature. In an attempt to answer this difficult question, Fraley and Waller (1998) took up this issue, arguing that even though the attachment field largely relies on typological approaches to measurement, there is minimal evidence supporting the validity of this approach. To contribute an empirical test of the validity of using dimensional versus typological measures, they used two different analytic procedures 
that can examine the taxonomic vs. continuous nature of attachment data. The results of both analyses revealed no evidence for taxons. In other words, attachment constructs appear to be better understood as quantitative as opposed to qualitative in nature, providing additional empirical support for the dimensional conceptualization of attachment. In discussing their findings, Fraley and Waller (1998) identified three primary issues related to the use of taxonomic measures for attachment researchers. First, using measures based on typological conceptualizations undermines the validity of attachment research by restricting the types of questions we can ask participants. Secondly, the use of these measures undermines reliability, as can be discerned in the high rates of instability of attachment types. Thirdly, using categories limits the statistical power available to detect true effects. Therefore, Fraley and Waller found no evidence for the ongoing use of taxonomic conceptualizations of attachment.

In conclusion, a typological, or categorical, approach to conceptualizing and measuring the constructs of attachment is not appropriate given the available data. Instead, a dimensional approach that considers individual differences in anxiety and avoidance is more applicable and allows for greater statistical power, reliability, and validity in attachment-based research.

\section{Stress}

In defining the concept of stress, some researchers have used response-based definitions which focus on physiological responses (e.g., increased heart rate, sweating) as indicators of stress (Selye, 1956; Wolff, 1953). Other researchers have used stimulus-based definitions that focus on specific stimuli, events, or situations (e.g., natural disasters, illness, economic concerns) as sources of stress (Holmes \& Rahe, 1967). However, Lazarus (1966) argued that stress should be defined as a relationship between a person and the environment in which the individual appraises the situation as one that represents threat or harm and challenges available resources. 
This conceptualization takes into consideration the subjectivity of individual responses to specific stimuli and distinguishes between stress (i.e., the psychological experience) and a stressor (i.e., any real or perceived event that may be interpreted as a threat). The assignment of a certain stimulus as stressful depends on the individual's cognitive and affective assessment of the situation.

Researchers distinguish between three types of stress: eustress, neustress, and distress (Seaward, 2006). Situations categorized as eustress are enjoyable and tend to encourage individuals toward an optimal level of health or performance (e.g., in love). Any kind of sensory stimulus perceived as inconsequential or unimportant refers to neustress (e.g., news about events from far away, separate from daily life). Distress refers to the negative appraisal of an event as threatening to one's mental, physical, spiritual and/or emotional well-being. Often abbreviated to the more commonly used term stress, distress refers to the psychological and physiological response to stressors (Seaward, 2006).

According to the Institute of Medicine, there are four major categories of stressors (Elliot \& Eisdorfer, 1982). First, acute, time limited stressors are those that represent a potential, immediate threat, like bungee jumping or being caught speeding. Second, stressor sequences refer to an ongoing series of events that result from an initial event, such as a dealing with the death of a loved one or divorce. Third, chronic intermittent stressors are those that reoccur periodically, such as completing income taxes or last-minute business trips. Finally, chronic stressors are those that persist for an extended period of time, such as ongoing job stress, disabilities, or family conflict. However, the primary categorizations of stressors are generally either acute or chronic, and research indicates that these two forms of stress have different effects 
on individuals. For example, chronic stress seems to have a greater impact on physical health than acute, time limited stressors (McEwen \& Lasley, 2005).

The physical experience of stress is the individual's response to a stressor, whether real or perceived (Wolfe, 1953). The physiological stress experience consists of a wide range of physical responses that occur in direct response to a perceived stressor that disrupts the individual's equilibrium. When the a person perceives a change or threat in the environment, the body responds by activating the sympathetic nervous system, including the endocrine, immune, nervous and cardiovascular systems, in effort to prepare to address the stressor. The process of the activated sympathetic system, one part of the autonomic nervous system, is also referred to as the fight-or-flight response, in which the body experiences a cascade of physiological changes in response to a stressor (Goldberger, \& Breznitz, 1993).

When in the presence of a stressor, the first part of the system activated is the hypothalamic-pituitary-adrenal (HPA) axis; once triggered, the HPA system produces and releases steroid hormones as the hypothalamus stimulates the pituitary gland, which in turn excites the adrenal glands to produce the body's primary stress hormone: cortisol (Goldberger, \& Breznitz, 1993). Cortisol acts as the primary neurochemical in this process, organizing the different systems throughout the body to respond quickly to the triggering event. Cortisol aids the body in maintaining steady supplies of energy by converting stores of blood sugar, allowing the body to fuel changes in the circulatory, immune, and muscular systems. In addition to the release of cortisol, the HPA system also activates the adrenal medulla, which secretes the neurotransmitter epinephrine or adrenaline, which prepares the body for action in the fight-orflight response. With the release of epinephrine, the area of the brain that controls emotional response, the amygdala, is activated which prompts the release of the neuropeptide $S$ protein, 
exciting an emotional response and sense of urgency to the present stressor. The physiological responses to these chemicals include increased heart rate and blood pressure, decreased appetite, sweating, decreased sleep, tensed muscles, dry mouth, decreased short-term memory, and rapid, shallow breathing (Contrada, \& Baum, 2010).

While the activation of the sympathetic nervous system allows for the body to respond to the present stressor(s), the body cannot sustain this state for extended periods of time; once the stressor is no longer perceived as a threat, the body's parasympathetic nervous system engages to return physiological conditions to their normal state (Goldberger, \& Breznitz, 1993). When activated, the parasympathetic system, the complimentary portion of the autonomic nervous system, stimulates the rest-and-digest process of the stress response, also known as the relaxation response (Contrada, \& Baum, 2010). As the body's systems return to normal, the heightened levels of cortisol in the blood stream circulate back to the pituitary gland and hypothalamus, inhibiting the further release of the hormone, effectively turning off the HPA axis response to the stressor (Goldberger, \& Breznitz, 1993). This results in the body's muscles relaxing, salivation resuming, appetite returning, the decreasing heart rate, and the return of the body's elimination processes (Contrada, \& Baum, 2010). Of note, while the activation of the amygdala during the body's stress response contributed to emotional responsiveness in the moment, the neurotransmitters present also signaled the hippocampus to store the emotional experience of the stressor in long-term memory. This evolutionary response allows for increased survival, as the memories stored during that time consolidate during recovery, and contribute to future patterns of interpretation of and reaction to stressors (Contrada, \& Baum, 2010). These emotional and physiological reactions cause several changes throughout the body, resulting in 
both long and short-term effects; these effects are further impacted by the nature and ongoing presence of the stressor.

Consequences of Stress. Researchers have documented the numerous physical and psychological consequences of stress consistently over the last several decades, suggesting that stress can lead to sickness and disease through an over-responsive autonomic nervous system (elevated stress hormones) or a suppressed (dysfunctional) immune system (e.g., Borysenko, 1987). Some nervous-system related disorders may first appear as mild stress-related symptoms, but can lead to ongoing, serious health problems if undetected or untreated. These may include tension headaches, migraine headaches, bronchial asthma, temporomandibular joint dysfunction (TMJ), coronary heart disease, and irritable bowel syndrome (Seaward, 2006). Some illnesses resulting from suppressed immunity include the common cold and influenza, allergies, rheumatoid arthritis, various ulcers and colitis, and cancer (Seaward, 2006). Other studies linking stress to a dysfunctional immune system provide evidence that stress delays the healing of wounds (Kiecolt-Glaser \& Glaser, 1995), speeds the process of aging (Graham, Christian, \& Kiecolt-Glaser, 2006), and increases susceptibility to infections and autoimmune disease (Kiecolt-Glaser, McGuire, Robles, \& Glaser, 2002).

Although many different factors play a role in such associations, researchers believe that an important element in the connection between stress processes and these epidemiological concerns is the social aspect of a person's life (Cohen, 1988). There is a large and growing body of epidemiological research suggesting that those individuals who lack or do not access social support are at an increased risk for physical and mental health problems (Cohen, 2004; House, Landis, \& Umberson, 1988). Specifically, both the quality and quantity of social relationships related to mortality (House, Landis, \& Umberson, 1988), indicating that the perception or use of 
social support in the face of stressful conditions is associated with positive effects on mental and physical health. Researchers have suggested that actively engaging in social support alleviates some of the wear and tear from stress on the body's physiological systems, as interpersonal interactions can provide both nurturance and the opportunity to access resources outside of the individual (McEwen, 1998). This support may come in the form of emotional (e.g., empathy, trust, and caring), informational (e.g., advice), instrumental (e.g., loaning money or services), or appraisal (e.g., evaluative feedback) support, and have been found to be beneficial when received, as well as perceived as accessible (Tardy, 1985).

However, if in times of stress social support is not available or accessed, the individual is without those resources that provide a type of buffer from the stressor (Cohen, 2004; House, Landis, \& Umberson, 1988). As social interactions can help distract individuals from focusing on problems, as well as aid in addressing the stressor itself, personal belief about one's own social support can have a significant impact on health and well-being (Cohen, 2004).

Finally, researchers have repeatedly shown stress to be associated with various psychological disorders (Tennant, 2006; Turner, Wheaton, \& Lloyd, 1995), substance abuse (Brennan \& Moos, 1990), and suicidality (Dean \& Range, 1996). Researchers across multiple disciplines have reached the general agreement that there is a continuous bidirectional relationship between one's psychological and social environment (Sharf, 2004). Research has linked low levels of social support in conjunction with chronic stress to negative mental health outcomes, including anxiety and depression (DeLongis, Folkman, \& Lazarus, 1988). In fact, many counseling theories suggest most mental health problems are the end result of environmental stressors, whether acute crisis experiences (e.g., abuse, rape, bereavement, or 
major life changes) or chronic stressors (e.g., conflict with family or friends, financial difficulties, or ongoing job stress) (Sharf, 2004).

Stress theories. As research on stress has evolved, the conceptualization has become more specific, leading to three theoretical perspectives on the mechanisms of stress: (1) stimulusoriented theory, (2) response-oriented theory, and (3) interactionist theory (Bee \& Bjorklund, 2004). The first, stimulus-oriented theory, focuses on an actual event as a stimulus for stress and does not reflect individual interpretation or perception of the event. This perspective proposes that the potential for stress is present in the environment and, thus, an external force (Spielberger \& Sarason, 1986). The external event stimulates, pressures, and/or impacts the individual person and results in a change or adaptation to the environment.

The second theory, response-oriented stress theory, focuses on how the individual responds to the environment. Within this conceptualization, the initial definition of stress was an individual's subjective response to environmental events that demand change, coping, and adaptation (Holmes \& Rahe, 1967). For example, Selye (1976) conceptualized stress as the individual's response to any event or situation that required a change in the individual. Any positive event resulting in change was called eustress and, in contrast, any negative change was called distress. Stress places pressure on an individual's cognitive, social, emotional, and physical status, a phenomenon called personal distress. These demands for change challenge individuals' ability to maintain physiological homeostasis and social and emotional stability (Aronson, Wilson, \& Akert, 2003; Holmes \& Rahe, 1967; Selye, 1976). Thus, this approach focuses strictly on the person's response. Response-oriented theory, used in conjunction with stimulus-oriented theory, created the third stress theory, interactionist theory. 
In interactionist stress theory, stress is the result of an interaction between the person and the event. For example, Lazarus and Folkman (1987) stated that stress results from the personal appraisal of the event and the appraisal of resources used to cope with the event. There are two processes involved in the appraisal process, the primary appraisal and the secondary appraisal. In primary appraisal, the person determines if the event or situation represents harm/loss, threat, or challenge. If so, the person engages in secondary appraisal, in which the person determines whether he or she has the resources to handle the stressor. As the perception of environmental pressures increase, stress feelings increase and might be manifested in psychological symptoms. Denial, withdrawal from reality, and avoidance are examples of psychological responses. This cognitive appraisal process represents a crucial link between stress and coping, and helps to explain why the terms stress and coping are rarely used without the other. The ongoing, dynamic reciprocity between the person and the environment is a transaction that results in a new state (Lazarus \& Folkman, 1987). Thus, another name for this theory is transactional stress theory.

After the identification of transactional stress theory, Breznitz and Goldberger (1993) examined differences between cognitive appraisal and automatic appraisal. Cognitive appraisal is deliberate, purposeful, and well thought-out. Not well-planned, automatic appraisals might result in the "fight or flight" response in the face of environmental pressures. Appraisals might be based on previous experiences including excessive anger or fear, might be unrealistic, and might reflect a stable coping response. Each of these stress models has addressed how stress operates upon a person. The interactionist stress perspective (Lazarus \& Folkman, 1987) combines the views of stress as a stimulus and the person's stimulus perception and is, therefore, more comprehensive, examining both the individual and the environment. 
Measurement of Stress. Researchers have measured stress with both objective indicators of stressful events and subjective indicators of the individual's perception of events. Objective measures typically assess the physical reaction, occurrence and frequency of certain events, assumed by most to be stressful. Researchers may weight these events, based on their assessment of which events are more difficult to handle. Biological measurements of stress include the measurement of cortisol levels in the saliva or blood; and recording physiological reactions such as changes in heart rate, galvanic skin resistance, respiration and temperature, prior to, during, and following the presentation of a stressor during stressor exposure (Contrada, $\&$ Baum, 2010). In addition to the recording of changes in physical response, there are many self-report versions of life-event scales, originally developed by Holmes \& Rahe (1967), which are used to produce a cumulative stress score (Cohen, Kamarck, \& Mermelstein, 1983).

The primary advantages of objective measures center on their convenience and simplicity. For example, objective measures of stress allow researchers to approximate outcome risks, both physical and psychological, associated with these specific events. In addition, the administration and scoring of these measures are relatively simple. Finally, the use of objective measures reduces bias in the perceptions and reporting of events. (Cohen et al., 1983).

Some of these advantages in reliability, however, may also become disadvantages from a validity standpoint, depending on the utilized conceptual definition of stress. Different individuals may perceive a specific event in many different ways. The basis of objective measures of stress is the assumption that the stressor itself is the cause of pathological outcomes for the individual. Lazarus' transactional view of stress $(1966,1977)$, on the other hand, suggests a more complex person-environment interaction, in which an individual's cognitive appraisal of the event and his or her coping resources determine the response to or outcome of 
the event, rather than the event itself. From this context, it is more reasonable to measure one's appraisal of potentially stressful situations than the frequency of such events (Cohen et al., 1983).

Consistent with this perspective, researchers have attempted to measure the perception of stress in a number of ways. Some have modified the life-events scales, like those from Holmes and Rahe's original work (1967), to allow participants to rate the stressfulness of each experienced event. Although these modifications somewhat increased the predictability of these measures, it would seem they still do not capture significant sources of stress not included on the scale (e.g., chronic stress, nonspecific worry or anxiety, vicarious stress from friends and family, and concern about future events). Other researchers have made efforts to measure individuals' subjective responses to specific stressors. However, this approach raises additional concerns, including the possible confounding of the stressor with the response, misattributing the stress to a particular source, and assuming that a stress response is only associated with one specific event rather than some combination of factors, such as chronic stress, daily difficulties, or cumulative stress (Cohen et al., 1983).

In response to these difficulties with measurement, Cohen, Kamarck, and Mermelstein (1983) developed a global measure of perceived stress, intended to measure the degree to which one evaluates life situations as stressful. The Perceived Stress Scale (Cohen, Kamarck, \& Mermelstein, 1983) does not ask about specific events, but instead inquires as to the degree to which individuals find their lives to be uncontrollable, unpredictable, and overloading. Research has repeatedly noted these three components as the core aspects of stress experiences (Averill, 1973; Lazarus, 1966, 1977; Seligman, 1975). This instrument is considered to be a better predictor of health outcomes than previously used objective measures (i.e., life event scales), 
because it is designed to measure an individual's cognitive appraisal of experience, rather than the objective occurrence of events. In addition, it is a more global measure that accounts for other potential confounding sources of stress, such as daily difficulties, chronic stress, and preoccupation with future events (Cohen et al., 1983).

\section{Coping}

Coping involves the thoughts and behaviors individuals employ to moderate the internal and external pressures of events perceived as stressful (Lazarus \& Folkman, 1984). Coping mechanisms are used during times of adversity where the ability to endure the stress relies greatly on the individual's adaptiveness (Lazarus \& Folkman, 1984). Specifically, coping has been defined as the "constantly changing cognitive and behavioral efforts to manage specific external and/or internal demands that are appraised as taxing or exceeding the resources of that person" (Lazarus \& Folkman, 1984, p. 141). When stressors are present, various strategies are utilized to address either the stressor itself or subsequent emotions in order to maintain the individual's psychological balance (Lazarus \& Folkman, 1984).

Before coping is engaged, the two-part appraisal process from Lazarus and Folkman's (1984) transactional stress theory is employed, and the individual attempts to answer two questions regarding the stressor: "Am I in trouble or being benefitted, now or in the future, and in what way?" and "What if anything can be done about it?" (1984, p.31). The interaction of this primary and secondary appraisal shapes the degree of stress, as well as the strength and quality of the individual's emotional response, acting as a mediator between the stress reactions and coping process (1984).

Lazarus and Folkman (1987) identified two primary types of coping strategies utilized following the appraisal process: emotion-focused and problem-focused. When individuals 
employ emotion-focused coping, their behaviors are oriented more towards changing the emotional response(s) to the event. An example would be the individual trying to change how he or she feels about the stressor. In contrast, when employing problem-focused coping, the individual's actions are oriented towards changing the distressing situation itself. An example of problem-focused coping would be defining the problem and following a plan of action to change the event. Research has found emotion-focused coping to be more associated with psychological distress, while problem-focused coping has typically been associated with less distress (Ben-Zur, 2005).

Carver, Scheier, and Weintraub (1989) challenged that the problem-focused/emotionfocused distinction in Lazarus and Folkman's (1984) model is too limited a description of how individuals deal with stressors, suggesting instead an overlap exists between the two coping strategies. They also believed that different behaviors exist within the problem-focused and emotion-focused factors than were initially described by Lazarus and Folkman. In response, Carver, Scheier, and Weintraub (1989) proposed a model that integrated the Lazarus model with a model of behavioral self-regulation. This led to the development of thirteen distinct scales based on functional, and less functional, coping strategies. Carver and colleagues defined Active coping as behaviors intended to reduce or remove a stressor. They described Planning as strategies for handling present stressors. Suppression of competing activities included behaviors devoted to removing distractions to focus solely on the stressor at hand. Restraint coping involves creating time and space to think about the stressor. Seeking social support (instrumental type) involves seeking advice or further guidance about the stressor from others. Carver and colleagues' model considered these strategies functional. Seeking social support (emotional type), includes getting sympathy or understanding from others. Venting involves 
focusing on emotions involved in attending to the stressor, allowing for the expression of the individual's emotions. Identified as functional in the short-term, Carver and colleagues described these coping strategies as potentially dysfunctional if, used in the long-term, the strategies increased distress. Behavioral disengagement and Mental disengagement, or selfdistraction, are two strategies identified as dysfunctional, as they both involve the individual disengaging from the stressor.

Carver and colleagues (1989) also included four additional scales. One type of emotionfocused coping strategy, Positive reframing and growth, is when the individual focuses on managing the distressing emotion instead of coping with the stressor itself. Another emotionfocused strategy, turning to Religion and faith, is also interpretable as an active response to the stressor. While Denial as a coping strategy can help to minimize distress, Carver and colleagues described it as typically dysfunctional, as the individual engages by ignoring the stressor. A functional strategy, Acceptance, is when the individual aims to accept the reality of the stressor, indicating the individual's attempts to deal with the stressor head-on.

With the more nuanced understanding of different types of coping strategies, the categorization of these methods has expanded beyond simply problem-focused and emotionfocused, having moved to consider those to be approach oriented coping strategies, as opposed to avoidant coping (Carver et al., 1989). Avoidant coping involves efforts the individual makes to escape from dealing with the stressor. These strategies are often emotion-based, as the attempt being made is to avoid the feelings of distress triggered by the stressor, though the individual may also make a literal effort to behave as though the stressor does not exist to achieve the same result. Just as emotion-focused coping strategies are more often associated with distress, avoidance based methods are also positively tied to distress and may result in negative 
consequences, as these strategies do nothing about the stressor's existence or eventual emotional and cognitive impact to the individual (Aldwin \& Revenson, 1987; Billings \& Moos, 1981). However, there is some indication that avoidance coping may be effective in coping with shortterm stressors (e.g., temporary pain, noise, time-limited uncomfortable medical procedures; Carver et al., 1989), as they are useful in providing a brief opportunity to escape from the situation.

As research has identified different methods of coping to impact emotional wellbeing and decrease distress, researchers have utilized this information to create interventions that increase the effectiveness of coping to deal with stress (Folkman \& Moskowitz, 2004). In the ongoing need for research on coping, the mission of understanding and harnessing coping efficacy is still one of the most confounding (Somerfield \& McCrae, 2000). In identifying effective coping methods for different populations, a contextual approach appears to be the best choice (i.e. Lazarus, 1966; Moos \& Holahan, 2003), as this perspective puts forth that no one particular coping method is intrinsically good or bad (Lazarus \& Folkman, 1984). As such, the individual must evaluate the adaptive characteristics of coping processes in the specific context of the stressor, keeping in mind that circumstances may change, resulting in a once effective coping strategy becoming ineffective later in the same scenario (Folkman \& Lazarus, 1985). Evaluating coping from a contextual perspective calls for two key components. The individual must choose first, important personal goals or outcomes and, second, must consider the quality of fit between the situation itself and the coping strategies (Folkman \& Moskowitz, 2004).

Measurement of Coping. In measuring the construct of coping, the decision to assess either dispositional or episodic coping has been a primary issue of concern (Carver, 1997; Folkman, 1992; Stone \& Kennedy-Moore, 1991). Whether persons continually make use of the 
same coping strategies across situations, or assess each stressor and respond in an idiosyncratic manor has been a point of discussion in the research for some time. The alternative of a trait versus a state approach to coping has implications for the development and utilization of measures. Researchers need to create dispositional or trait measures according to high psychometric standards, though this means that these assessments may not be able to account for coping strategies across different categories (Folkman, 1992). Whereas situational measures are beneficial in studying individuals who cope with the same kind of stress at different points in time, focusing on the specific strategies across categories, used at different times (Stone \& Kennedy-Moore, 1992). However, if it is possible to better ascertain adaptation to stress outcomes by dispositional coping measures than by state-oriented assessments that could explain the greater leaning in the research towards these measures (Folkman, 1992).

Another point of question is in the use of either real-life or hypothetical situations in framing measures. Specifically, the scenario of a stressful event and the individual's appraisal of the stressor influence how a person chooses to cope in the moment. Asking individuals to imagine possible scenarios, while potentially improving internal validity of the measure, lacks the realism of reflecting on personal experience in actual events, and can limit responses to more state-oriented results (McCrae, 1984). In response to this concern, some authors (Carver, 1997) have developed coping measurement scales usable as either a trait or state measure of how individuals respond to stressors, depending on the research at hand. Both the COPE (Carver, Scheier, \& Weintraub, 1989) and Brief COPE (Carver, 1997) were developed to be used in either context, so that participants can consider a particular, provided stressor, or reflect on their typical strategies when responding. 
One additional question concerning the measurement of coping regards the extent to which cultural factors influence coping approaches. Researchers have demonstrated that problem-focused coping is strongly associated with positive psychological outcomes, while emotion-focused and avoidance strategies are frequently been related to lower levels of mental health (Ben-Zur, 2005; Endler \& Parker, 1990; Seiffge-Krenke, 1993). However, the emphasis on action-oriented and problem-focused coping within coping research may indicate cultural bias (Bandura, 1982; Dunahoo et al., 1998), as both of these concepts are accentuated and valued by characteristically individualistic cultures (Yeh, Arora $\& W u, 2006)$. It is possible that previous coping research has not focused on using diverse or representative samples of the population that may have found alternatives to problem-focused coping to be adaptive. It is also possible that placing a greater emphasis on the context of coping will reveal situations where emotion-focused and/or avoidance coping are found to be more adaptive.

\section{Empirical Research in Attachment Theory and Stress}

According to interactionist or transactional stress theory discussed above, stress results when an individual interacts with the environment. This interaction might result in stress when individuals appraise the demands of their environments and perceive their resources as insufficient to cope with the demands of environmental events. Stress activates the attachment system (Mikulincer, Birnbaum, Woodis, \& Nachmias, 2000). When experiencing stress, the attachment system determines how one reacts to stress based on previously acquired working models (Collins \& Feeney, 2004; Larose \& Soucy, 2005). As previously discussed, working models are internal cognitive representations of attachments and are based on previous interactions between the individual and the caregiver (Perrine, 1998). Working models provide the frameworks for individuals' reactions to stress. Positive reactions to stress include 
communication, seeking support from others, and active problem solving. Negative reactions to stress include anger, blaming others, and using avoidance mechanisms such as denial (Howard \& Medway, 2004). When individuals experience stress, attention is diverted to feeling worthless and overwhelmed (Nounopoulos, Ashby, \& Gilman, 2006) and these thoughts exacerbate the stress reaction (Mikulincer et al., 2000). The attachment system influences how a person copes with stress (Mallinckrodt \& Wei, 2005). Thus, positive reactions to stress were found as consequences of secure adult attachments and negative reactions to stress as the consequences of insecure adult attachments.

Stress, Coping and Attachment Relationships in College. Adult attachments direct one's interpretations of potentially stressful events and one's reaction to these events (Simpson $\&$ Rholes, 1998). For example, adults whose attachments are insecure or high in anxiety were more likely to perceive events as stressful and threatening and react with less effective coping mechanisms than securely attached adults. In a more secure adult attachment, each person perceived available support from the other member of the relationship when it was needed (Cutrona et al., 1994; Howard \& Medway, 2004). Individuals' specific attachment systems are at the base of this interaction. The attachment system is enacted when the individual perceives stress from the environment (Collins \& Feeney, 2004; Mikulincer et al., 2000). Therefore, securely attached adults might reach out for support when confronted with stressful events. The basis for perceived support and safety is the belief that one is loved and valued by others (Collins \& Feeney, 2004) and that, in stressful times, their support is reliable. Securely characterized adult attachment provides a safety net when people experience stress and adversity in their environment. These individuals are typically more effective in problem solving, more selfconfident in trying different solutions, and experience a more positive self-concept. 
The college environment holds many new demands and opportunities for students, which may include academic work, test preparation, living environment-based social interaction, and an increased focus on time-management. Securely attached students are more likely to succeed in the face of multiple demands than students with higher levels of attachment anxiety and/or avoidance (Collins \& Feeney, 2004). Those students are likely to be more optimistic and, thus, have higher expectations for themselves in the environment. Exploratory behavior also increases in secure adult attachment relationships, and these students are more likely to seek out and try possible solutions for stressful situations than anxious and/or avoidant students. Secure adult attachment provides resources and strategies to cope with stress and, thus, increase the chances of academic and interpersonal success in college.

As previously discussed, research has found negative associations between stress and attachment in college students (Bradford \& Lyddon, 1993; Howard \& Medway, 2004; Kemp \& Neimeyer, 1999; Kenny \& Donaldson 1991; Kotler, Buzwell, Romeo, \& Bowland, 1994; Lopez \& Gormley, 2002; Mallinckrodt \& Wei, 2005; McCarthy, Lambert, \& Moller, 2006; McCarthy, Moller, \& Fouladi, 2001; Mikulincer \& Florian, 1998; Perrine, 1998; Rholes \& Simpson, 2004; Scharfe \& Cole, 2006; Solberg \& Villarreal, 1997; Vogel \& Wei, 2005). Similar conclusions were found throughout the research: secure adult attachment reduces stress and provides positive strategies for coping with stress; insecure attachment is associated with stress and negative outcomes. Bradford and Lyddon (1993) found that current parental attachment predicted psychological distress in college students. Insecure attachment was positively associated with distress, and secure attachment was negatively associated with distress. Bradford and Lyddon suggested that a secure base established by a secure adult attachment enabled college students to adapt to the environment more readily than students with an insecure attachment. Kemp and 
Neimeyer (1999) also found that insecure attachment was positively associated with psychological distress. This research found insecure, preoccupied attachments positively related to distress and psychological symptoms among four-year college students. In their research at a large university, McCarthy et al. (2001) found lower attachment scores related to higher stress scores; conversely, higher attachment scores related to lower stress scores. For example, if a student, characterized as insecurely attached, and striving for autonomy at college had parents who became overprotective, the student's stress scores increased (McCarthy et al., 2001).

Perrine (1998) examined perceived stress and retention in four-year undergraduate college student as a function of attachment, finding that students with securely characterized attachment reported less perceived stress than those with insecure attachments. Additionally, securely attached students were less likely to leave college and consistently reported higher grade point averages. In their investigation of the relationship between attachment and stress in college students, Kenny and Donaldson (1991) found that insecurely attached students also reported lacking social competence and higher stress levels. Conversely, Vogel and Wei (2005) found that students with avoidant attachment denied the experience of stress, and were less likely to seek help than students with more anxious attachments. This contributed to the concern that these avoidantly-attached students may not access or receive the necessary assistance to thrive in the college environment (Kuh et al., 2006).

Bowlby $(1980,1988)$ proposed that attachment was likely to change in reaction to stressful events. Scharfe and Cole (2006) examined both moderator and mediator effects of attachment and found that stress mediated the stability of attachment among four-year college seniors. The assessment of senior students occurred in two phases. In the first phase, investigators examined whether interpersonal events changed the association between attachment 
at both the first and second assessment. The second phase examined if stress acted as a mediator between attachment at both the first and second assessment. Research confirmed Bowlby's proposition when specific indexes of distress such as anxiety and depression changed the relationship between the first and second attachment assessments. The status of a relationship also changed attachment stability (Scharfe \& Cole, 2006).

Lopez and Gormley (2002) investigated the stability and change in adult attachment and their correlation with self-confidence, coping, and distress patterns during students' first years of college. The first years of college were highly stressful as students moved into a new environment, possibly far from attachment figures, and adapted to the rigors of college courses. In October and April of the freshman year, undergraduates completed six scales including the Relationship Questionnaire (RQ; Bartholomew \& Horowitz, 1991) and the shortened version of the Experiences in Close Relationships (ECR; Brennan, Clark, \& Shaver, 1998). Findings indicated that attachment styles were only moderately stable over the first year of college and that current attachments related to stress levels. Stable secure attachment correlated with high scores in self-confidence. Students who changed from insecure to secure attachment showed no differences in the area of self-confidence. However, students who changed from secure attachments to insecure attachments showed diminished coping or moderately high stress. Stress increased as attachment declined and vice-versa.

Research also indicated that four-year college students with an avoidant attachment style denied that they experienced stress. Avoidantly-attached students were less likely to seek help than anxiously attached students who acknowledged stress and were more likely to seek help (Vogel \& Wei, 2005). Thus, avoidantly-attached students might not receive needed assistance and their performance might reflect this lack (Vogel \& Wei, 2005). This denial of the stress 
experience also related to patterns of affect regulation, with multiple studies finding attachment shapes the way individuals appraise, cope with, and adjust to stress (Kotler, Buzwell, Romeo, \& Bowland, 1994; Mikulincer \& Florian, 1998; Rholes \& Simpson, 2004). Securely attached individuals were found to more positively appraise their ability to cope with stressful situations in a constructive manner, whereas avoidantly attached individuals under-reacted to stressors, and did not take advantage of social support as a form of coping, and anxiously attached individuals tended to overreact to stressors and utilize maladaptive coping behaviors (Kotler, Buzwell, Romeo, \& Bowland, 1994; Mikulincer \& Florian, 1998; Rholes \& Simpson, 2004).

Low parental attachment positively correlated with stress symptoms and stress produced emotions among four-year college students. Secure attachment was associated with lower levels of stress symptoms and lower levels of stress-produced emotions than insecure attachment (McCarthy et al., 2006). As secure attachment increased, stress symptoms and stress-produced emotions declined. If college students have avoidant adult attachments or feel uncomfortable asking questions of faculty, interacting with other students in groups, or giving class presentations, then they might achieve less academically, earn lower grade-point averages, and complete fewer courses successfully than securely attached students.

Frequently found in the attachment literature is the term social support. Cohen (1986) suggested that researchers examine how social support received in relationships alters the relationship between stress and its outcomes. Research indicated that adult attachment quality was synonymous with social support sources (Kenny \& Rice, 1995). Cohen (1986) specifically defined social support as one's interpersonal relationships. Other researchers have referred to social support as relationship support linked to maternal attachment (Sroufe, Egeland, Carlson, \& Collins, 2005). Sroufe and colleagues (2005) conceptualized attachment as a larger 
organizational construct encompassing specific elements of social support. Other researchers used perceived parental social support (Cutrona et al., 1994) to describe parental attachment. A study from Cutrona and colleagues (1994) used the anxiety subscale of the Adult Attachment Scale (Collins \& Read, 1990) as a measure of parental support. Cutrona et al. defined social support as an overall framework for specific advantages derived from relationships with others. Among these advantages were guidance, reliable alliance, attachment, and reassurance of worth. These advantages also described the qualities of secure relationships (Kenny \& Donaldson, 1991; Kobak, 1999; Mattanah, Hancock, \& Brand, 2004). Solberg and Villarreal (1997) defined social support as including both parental and peer support. In a previous study, Cutrona and colleagues (1994) identified self-efficacy as an outcome of secure attachment. Solberg and Villarreal (1997) described social support as a buffer activated in stressful times to reduce the negative stress impact. This description matched that given for attachment systems during stressful times (Mikulincer et al., 2001; Kuh et al., 2006). Thus, research has defined social support synonymously with attachment.

The application of attachment theory to adult attachment is still a relatively new approach in need of much exploration. As attachment style derives from social experiences throughout the life span, there is constant growth and change in relationships. Also, as discussed, research has shown stress to have an impact on attachment (Bowlby, 1980; Collins \& Feeney, 2004). In looking at the effects of stress and anxiety, a growing amount of the research on stress has focused on the college student population, looking at how students cope in response to stress and how emotions regulate in the presence of stress (Watson \& Sinha, 2008). In examining the relationship between the stress and attachment, some researchers have looked at attachment style corresponding to partners' reported reactions to stress in their relationship (Roisman, Clausell, 
Holland, Fortuna, \& Elieff, 2008). However, for the most part, researchers have focused more on coping strategies used in response to stress in relationships more so than to general adult attachment in the college student population. As of yet, more study is still needed with regard to the interaction of these variables on overall relationships within the college population.

\section{Summary and Research Questions}

Given reflection on the importance of perceived community connectedness and accessibility in impacting the development of the student in the college environment, there is a need to understand further the variables that impact the university student experience (Kuh et al., 2006). This study intended to aid in our understanding of the perceived stress experience of university students by examining how attachment and coping styles relate to the interpretation of and response to stress. Attachment theory has shown utility for providing a framework for the study of stress and provides the basis for this investigation. This study explored how attachmentrelated variables relate to students' perceived stress and coping behaviors.

It was the hope of this author that this investigation would aid in our understanding of stress within the university student population. If, as a field, we can better understand what variables contribute to the perception of stress, this could potentially lead to a better understanding of how to work within the stress-response system. It is possible that we could apply this increase in understanding to clinical practice, in better being able to identify ways to help students understand how they experience stress and how to adjust to stress, which could potentially benefit academic and personal success.

This study addressed three questions with regard to how students' attachment styles relate to their experience of stress and utilization of coping strategies. Each question and the related hypotheses are listed below, along with tables outlining the hypotheses. 
Research Question 1. Does student level of attachment avoidance and attachment anxiety predict perceived stress?

Hypothesis 1: Attachment anxiety and attachment avoidance will explain a significant amount of variance in students' perceived stress above and beyond demographic variables. Specifically, higher perceived stress is expected to correlate positively to attachment anxiety.

Research Question 2. Is student level of attachment avoidance and attachment anxiety predictive of utilized coping strategies?

Hypothesis 2a: Attachment variables will explain a significant amount of variance in utilized coping strategies above and beyond demographic variables.

Hypothesis 2b: Both attachment avoidance and attachment anxiety will be negatively correlated to problem-focused coping strategies, including active coping, use of instrumental support, and planning behaviors. Hypothesis 2c: Attachment avoidance will be negatively correlated to emotion-focused coping strategies, including the use of emotional support, substance use, humor, venting, positive reframing, self-blame, and turning to religion.

Hypothesis 2d: Attachment anxiety will be positively correlated to emotion-focused coping strategies.

Hypothesis 2e: Attachment avoidance will be positively correlated to avoidant coping strategies, including self-distraction, behavioral disengagement, and denial. 
Hypothesis 2f: Attachment anxiety will be negatively correlated to avoidant coping strategies.

Research Question 3. Does the type of coping strategy utilized predict the student's perceived stress?

Hypothesis 3a: Utilized coping strategies will explain a significant amount of variance in students' perceived stress above and beyond attachment variables.

Hypothesis 3b: There will be a significant, negative correlation between problem-focused coping strategies and perceived stress level.

Hypothesis 3c: There will be a significant, positive correlation between emotion-focused coping strategies and perceived stress level.

Hypothesis 3d: There will be a significant, negative correlation between avoidant coping strategies and perceived stress level. 


\section{CHAPTER III}

\section{METHODOLOGY}

\section{Research Design}

A cross-sectional design utilizing multiple regression was used to investigate the interaction of adult attachment and coping strategies as it impacts perceived stress levels among university students (Heppner, Wampold, \& Kivlighan, 2008). Specifically, hierarchical multiple regression was used to determine the particular contribution of each construct (i.e., attachment avoidance and attachment anxiety, and coping strategies) on perceived stress, and how they interact with each other.

\section{Participants}

The population of interest in this study included students 18 years of age or older attending West Virginia University and living in the Morgantown, West Virginia area and its environs. Participants were recruited from all currently enrolled students at West Virginia University via online and flyer advertisements available to all students, as well as advertisements disseminated throughout various academic departments. For inclusion in this study, only data from individuals who reported currently attending West Virginia University full-time or parttime were included. No students were excluded from the study based on gender, age, or racial background. Demographic details of participants are outlined in the next chapter.

In order to determine the number of students to be recruited, I conducted an a priori power analysis using G*Power (Faul, Erdfelder, Buchner, \& Lang, 2009). Based on a hierarchical multiple regression model with 19 independent variables (e.g., age, gender, year in school, attachment anxiety, attachment avoidance, and 14 dimensions of coping), power set at .80 , and alpha $=.05$, it was determined that 153 participants would be necessary to detect a 
medium effect size $\left(\mathrm{f}^{2}=.15\right.$, Cohen, 1988). The decision of using a medium effect size was made based on medium effect sizes observed in prior research examining attachment variables to predict stress-related phenomena (McCarthy, Moller, \& Fouladi, 2001; McCarthy, Lambert, \& Moller, 2006). While statistical analysis through $G *$ Power suggested a minimum number of 153 participants, given the potential for data loss, incomplete protocols, and participant attrition, I sought to enroll and collect data to a maximum of 300 student participants. Initial data collection yielded a total of 214 cases and, after cleaning the data, final sample included 174 cases.

\section{Procedures}

After obtaining approval for the study from West Virginia University's Institutional Review Board (IRB), advertisements were placed for the study throughout the West Virginia University campus. These advertisements were disseminated throughout campus in both online and flyer formats (see Appendix A). The online advertisements were posted through the Mountaineer Information Xpress (MIX) and Daily Athenaeum websites, while the flyers were posted in student-populated areas, including the Mountainlair, the Student Health and Wellness Building, the Daily Athenaeum, and in residence halls. The advertisements invited students to take part in a study examining the stress and coping of university students, and included a brief description of the study, a description of the incentives offered to participants, and a link to the survey. The advertisements advised that all West Virginia students are eligible to participate, permitting only one entry per student.

Due to sporadic initial responding, additional recruiting procedures were put into place in order to obtain a satisfactory $n$ based on the power analysis discussed above. An amendment was submitted to West Virginia University's IRB, seeking permission to email academic departments throughout the university, requesting assistance in sharing study advertisement information with 
students. Once approved, all academic departments throughout West Virginia University's 15 colleges and schools were listed into a random number generator, and one third of the departments, a total of 37 , were chosen to be contacted. Of those, 10 departments responded that the information had been shared with students; no follow-up was received from the other departments. The email sent to academic departments included information on the study, as well as the advertisement to be shared with students; departments were encouraged to share the information with students via email, departmental advertisements, and/or in class advertisement. The advertisement included in the email was the advertisement written originally for the Mountaineer Information Xpress (MIX) and Daily Athenaeum websites; additionally, in the event departments elected to share the information with students via in class advertisement, a recruitment script was included with the email (Appendix B).

Students who chose to participate selected the directed link provided in the advertisement to connect via Qualtrics, an online site for electronic survey research that enables anonymous online participation. The first page of the survey included willing participant information and instructions for students to answer as honestly as possible (Appendix C). This page also included notification of the option to enter a gift card drawing after completing the protocol. Students were directed to indicate their consent by clicking the "Next" button, agreeing to complete the surveys. The following pages contained a demographic questionnaire and the utilized measures, including the Perceived Stress Scale (Cohen \& Williamson, 1988), the Experiences in Close Relationships Questionnaire (Brennan et al., 1998), and the Brief COPE Inventory (Carver, 1997). Once the student completed the survey, he or she had the option to enter a drawing to win one of ten $\$ 20$ Amazon e-gift cards. If they chose to enter the drawing, they were instructed to send an email to the researcher at a specified email address with "Enter 
Drawing" in the subject line and his or her name in the email body. No other personal information was required or requested. Participants who selected this option were notified that the drawing would be conducted by random number generator after all responses were collected, at which time the code for the e-gift cards would be emailed to the winners. No identifying information was attached to the surveys and, as students sent the drawing entry email separately, information about individuals who entered the drawing was not associated with their responses.

\section{Instrumentation}

Demographics. The first measure asked participants to answer questions regarding personal status. The author developed this demographic questionnaire. Questions pertained to participants' gender, age, year in school, full- or part-time student status, relationship status, and race/ethnicity (see Appendix D). As only currently enrolled university students were included in data analysis, the student status question on this measure was used to assist in the exclusion process. For this item, participants chose which answer best fit their enrollment status: either full- or part-time enrollment, or currently auditing course(s) only as either student or faculty. Any participants that selected the auditing option were excluded from data analysis. Exclusions based on this information will be discussed in the following chapter.

Perceived Stress Scale (PSS). The Perceived Stress Scale (Cohen, Kamarck, \& Mermelstein, 1983) measures perceived stress for a situation or an event. The PSS items measure current feelings of stress. For example, Item 2 in the PSS asked, "In the last month, how often have you felt you were unable to control the important things in your life?" Respondents were instructed to answer based on their feelings and thoughts during the previous month. Thus, the PSS was used to measure how college students in the proposed study perceive stress. Cohen and Williamson (1988) initially examined the 10-item version of the PSS using 
2,388 participants from across the U.S. representative of the 1980 census data. Higher scores on the PSS indicated higher amounts of perceived stress (see Appendix E). The responses were marked on a 5-point Likert-type scale. On the PSS, items ranged from 0 (almost never) to 4 (very often). The PSS has an internal consistency of $\alpha=.85$ and a two day test-retest reliability of $r=.85$ (Cohen \& Williamson, 1988). The PSS also demonstrated concurrent validity with the items on the Life Satisfaction Scales (LSS; Neugarten, Havighurst, \& Tobin, 1961). Coefficient alpha reliability ranged from $\alpha=.84$ to $\alpha=.86$ in three samples (Cohen et al., 1983).

Experiences in Close Relationships (ECR). This study used the Experiences in Close Relationships (Brennan et al., 1998) to assess adult attachment quality; this 36-item self-report questionnaire consists of two subscales: avoidance (or discomfort with closeness and depending on others) and anxiety (or fear of rejection and abandonment). Brennan and colleagues (1998), as discussed in chapter 2, conducted a factor analysis of all attachment-related items from multiple questionnaires to examine the underlying structure of attachment. Their examination resulted in a 36-item measure with two 18 item scales, reflecting the underlying dimensions of attachment anxiety and attachment avoidance (see Appendix F). As responses on this measure directly relate to scores for the constructs of attachment anxiety and attachment avoidance being assessed, the ECR was chosen for this study. This measure asks respondents to consider and rate their feelings and behaviors in the context of how they typically relate to others by responding to items such as "I worry a fair amount about losing my partner" (i.e., attachment anxiety) and "I don't feel comfortable opening up to romantic partners" (i.e., attachment avoidance).

The ECR yields continuous scores on the two 18-item subscales (Brennan et al., 1998). Respondents are asked to rate responses to each question on a 7-point Likert-type scale, where 1 $=$ disagree strongly and $7=$ agree strongly. The attachment anxiety scale consists of the 18 
evenly numbered items (e.g., 2, 4, 6) and the avoidance scale consists of the 18 oddly numbered items (e.g., 1, 3, 5). It is important to note that items 3, 15, 19, 22, 25, 27, 29, 31, 33 and 35 were reverse keyed before being included in calculations. These items are phrased negatively; therefore, on answers to these items, a high rating represents a low level of anxiety or avoidance, rather than a high level. In order to reverse score the ten items, SPSS was instructed to transform these data points (i.e., a high score of 6 became a low score of 2). Once these items were reverse keyed, the scores for the 18 items on each subscale were averaged to find the mean score for the scale. This method provides a mean anxiety and avoidance score for each respondent.

In their original investigation, Brennan et al. (1998) found the scales to have adequate internal consistency with a coefficient alpha of $\alpha=.91$ for anxiety and $\alpha=.94$ for avoidance. A more recent investigation using these scales found similar, firm coefficient alphas of $\alpha=.92$ for attachment anxiety and $\alpha=.93$ for attachment avoidance (Noftle \& Shaver, 2006). Brennan and colleagues found these two scales were only mildly correlated with one another $(r=.11)$, demonstrating they are relatively independent measures of attachment-related styles. Additionally, Brennan and colleagues provided evidence of convergent and divergent validity for both scales, providing data demonstrating these scales correlated in theoretically expected ways with concepts related to attachment anxiety and attachment avoidance. For example, the attachment anxiety scale was highly positively correlated with proximity seeking and need for approval in relationships. The attachment avoidance scale was found to be positively related to fearfulness and negatively related to trust in relationships. Therefore, these two scales appear to have adequate psychometric properties to be used in this study.

As discussed in chapter 2, there are some concerns for utilizing the ECR with a young adult population, particularly as it is oriented toward romantic relationships (Fraley, Waller, \& 
Brennan, 2000). Some other measures have been developed to assess the underlying dimensions of adult attachment, including the Attachment Style Questionnaire (ASQ; Feeney, Noller, \& Hanrahan, 1994). The ASQ is a 40-item self-report measure that classifies adult attachment on a five-factor scale; the classifications include confidence, discomfort with closeness, need for approval, preoccupation with relationships, and relationships as secondary. Researchers can utilize the ASQ to assess each of the five areas separately, or the scales can be selected and used, through combination, to represent levels of secure and insecure attachment, as in taxonomic models, as well as to represent the two attachment constructs of avoidance and anxiety. Specifically, several groups of researchers have combined items from the five classifications to assess these two dimensions of attachment from the ASQ (Alexander, Feeney, Hohaus, \& Noller, 2001; Feeney et al., 1994; Strahan, 1995). When utilizing the ASQ to assess the avoidance and anxiety constructs, researchers are required to load different items from each classification to define a score for each construct; however, it should be noted that the items significantly loading on each of these dimensions has not been consistent across studies (Feeney et al., 1994).

The ECR was chosen, as it directly assesses the continuous dimensions of attachment avoidance and attachment anxiety without any further manipulations or sifting of the data. In addition to providing scores for the two underlying constructs of attachment, it was also possible to examine participant responses in relation to reported relationship status, to determine potential confounding by participants' lack of romantic involvement and/or experience. Implications of these potential limitations were further considered in the discussion of the results below.

Brief COPE. This study used the Brief COPE (Carver, 1997) to assess the coping styles utilized by participants. The Brief COPE is a shortened 28 -item version, taken directly from the full 60-item COPE (Carver et al., 1989). Both the Brief and full COPE are multidimensional 
instruments designed to assess which cognitive and behavioral strategies individuals utilize to manage the demands of daily life. The Brief COPE contains fourteen 2-item subscales that measure 14 conceptually distinct aspects of coping (see Appendix G). The subscales are identified as Active Coping, Planning, Acceptance, Positive Reframing, Religion, Humor, Using Emotional Support, Using Instrumental Support, Self-distraction, Venting, Denial, Behavioral Disengagement, Self-blame, and Substance Use. Items on this measure can be presented in a retrospective situation context, a concurrent situational context, or a dispositional context. Also, subscales can be selectively chosen and administered by researchers according to the focus of interest. For the purposes of this study, all subscales were utilized and items were presented to reflect a dispositional context. In studying reliability of the internal structure of the Brief COPE scales, Carver (1997) administered the measure as part of a large battery to a community sample of survivors following Hurricane Andrew. The battery was administered at three separate assessments: three to six months following Hurricane Andrew, at which time 168 participants were sampled; then again six months later, at which time 124 of the original participants were sampled; and finally one year later, at which time 126 of the original participants were sampled. From these assessments, Carver (1997) conducted a factor analysis and identified nine distinct factors: first, with Active Coping, Planning, and Positive Reframing loading onto a single factor (with the addition of one item from the Acceptance subscale); then, with Using Emotional and Instrumental Support loading onto a single factor; next with Self-distraction and Venting loading onto a single factor; then, with Denial and Self-Blame loading onto a single factor; and finally with Substance Use, Religion, Humor, Behavioral Disengagement, and the other item from the Acceptance scale each loading onto individual factors. These factors each had eigenvalues greater than 1.0 and, together, accounted for $72.4 \%$ of the variance. Additionally, through 
reliability analyses, Carver (1997) determined that the alpha reliabilities, averaged across the three administrations, all met and/or exceeded a value of $\alpha=.50$, which was minimally acceptable. Specifically, even though each subscale has only two items, all subscales exceeded an alpha of $\alpha=.60$, except for the subscales of Venting, Denial, and Acceptance.

Consistent with the understanding that coping styles can be categorized by developing different higher order constructs (Carver et al., 1989; Lazarus \& Folkman, 1984), previous research has combined the subscales to create three higher order subscales: problem-focused, emotion-focused, and avoidant styles of coping (Horwitz, Hill, \& King, 2011; Wilson, Pritchard, \& Revalee, 2005). I have provided a table below, outlining these higher order scales, including the subscales included in each and an example item for each individual subscale.

Table 3.1

Higher Order Subscales for the Brief COPE

\begin{tabular}{|c|c|c|}
\hline $\begin{array}{l}\text { Higher Order } \\
\text { Subscale }\end{array}$ & Subscale Included & Example Item \\
\hline \multirow{2}{*}{$\begin{array}{l}\text { Problem- } \\
\text { Focused }\end{array}$} & Active Coping & $\begin{array}{l}\text { "I have been taking action to try to make the situation } \\
\text { better" }\end{array}$ \\
\hline & Use of Instrumental Support & "I've been getting help and advice from other people" \\
\hline \multirow[t]{2}{*}{ Coping } & Planning & "I have been thinking hard about what steps to take" \\
\hline & Using Emotional Support & "I’ve been getting emotional support from others" \\
\hline Emotion- & Substance Use & $\begin{array}{c}\text { "I've been using alcohol or other drugs to make myself } \\
\text { feel better" }\end{array}$ \\
\hline Focused & Humor & "I've been making jokes about it" \\
\hline \multirow{4}{*}{ Coping } & Venting & "I've been expressing my negative feelings" \\
\hline & Positive Reframing & $\begin{array}{c}\text { "I've been looking for something good in what is } \\
\text { happening" }\end{array}$ \\
\hline & Self-Blame & "I've been criticizing myself" \\
\hline & Religion & "I've been praying or meditating" \\
\hline \multirow{3}{*}{$\begin{array}{l}\text { Avoidant } \\
\text { Coping }\end{array}$} & Self-Distraction & "I've been turning to work or other activities to take \\
\hline & Behavioral Disengagement & $\begin{array}{l}\text { my mind off things" } \\
\text { "I've been giving up the attempt to cope" }\end{array}$ \\
\hline & Denial & "I've been refusing to believe that it has happened" \\
\hline
\end{tabular}


Research suggests these higher order subscales of coping relate to attachment, specifically replicating some of the earlier work on attachment, reflecting attachment styles. It is expected that attachment style will relate directly to the types of coping utilized, with positive correlations between more secure attachments and higher reporting of more problem-focused coping styles such as active and planning. This comes from a study of first year college students, which demonstrated securely attached students reported a greater sense of agency, fewer problems, less depression, and less self-splitting than more insecurely attached students (Lopez \& Gormley, 2002). Avoidantly attached individuals were more likely to cope using avoidant strategies, such as denial and behavioral disengagement, while anxiously attached individuals were more likely to utilize coping strategies that manifested more difficulties and emotional responses, such as substance use and venting (Lopez \& Gormley, 2002). Additionally, an adolescent study from Howard and Medway (2004) found attachment security negatively related to emotion-focused coping methods, such as substance use.

As with the 60-item COPE, researchers can present items in the Brief COPE in a retrospective and situational context, or, as I used it in this study, a dispositional context. For the purposes of this study, the primary analysis was used to examine the higher order subscales of Problem-Focused Coping, Emotion-Focused Coping, and Avoidant Coping styles. Additionally, I ran a secondary analysis to determine the contribution of the individual subscales to the variance observed in perceived stress related to coping strategies.

In completing the Brief COPE, respondents were asked to rate their responses to each question on a 4-point Likert-type scale, where $1=$ "I haven't been doing this at all" and $4=$ "I've been doing this a lot." The individual subscales are scored by summing the raw score for each item in the subscale. The different broader coping styles (e.g., Emotion-Focused Coping) are 
calculated by summing the appropriate subscales within each domain, with higher scores indicating more use of that particular coping style. Participants' scores for each of the three broader coping styles were used in the data analysis.

\section{Data Analytic Techniques}

Hierarchical multiple regression analysis was utilized to determine the roles of the predictor variables, namely attachment anxiety, attachment avoidance, and different coping strategies to observed variance in the criterion variable, perceived stress. I considered the suitability of this strategy in light of recommendations for the use of this procedure based on a review and critique of its use in the existing literature (Petrocelli, 2003). Also, statisticians recommend this type of analysis when the research design contains sets of predictors, as the researcher can enter predictors in blocks according to an order that is based on theoretical and/or logical considerations (Tabachnick \& Fidell, 2007). The purpose of hierarchical multiple regression is to examine the change in the amount of variance explained in the dependent variable(s) by the independent variables added in later stages of the total regression analyses. The aim of this study, as outlined in the three research questions and corresponding hypotheses described previously, was to determine the significance of additional variance in students' perceived stress, the dependent or criterion variable, that may be explained by the independent or predictor variables of attachment constructs and coping strategies. Therefore, hierarchical multiple regression was selected for data analysis. Petrocelli (2003) described the use of this approach as suitable for testing theoretically derived hypotheses, as it is used to explore the importance of a predictor variable by "how much it adds to the prediction of a criterion, over and above that which can be accounted for by other important predictors" (p. 10). 
Specifically, following the examination of bivariate correlations to establish the existence of relationships between the predictor and criterion variables, a series of regression equations was computed to address the three research questions. The different predictor variables were entered in a specified order, to observe and account for the different amounts of variance contributed by each variable type. In order to control for the variance contributed by gender and relationship status, the first group of predictors entered included responses to these demographic questions. The second group of predictors entered were the attachment variables, including attachment avoidance and attachment anxiety, as several studies have found that attachment dimensions were predictive of psychological distress in college students (Bradford \& Lyddon, 1993; Kemp \& Neimeyer, 1999; McCarthy, Moller, \& Fouladi, 2001; Perrine, 1998; Scharfe \& Cole, 2006; Solberg \& Villarreal, 1997). The third group of predictors entered were the three coping styles of interest (i.e., Problem-focused, Emotion-focused, and Avoidant). I also conducted a secondary analysis looking at the specific coping strategies utilized to determine the impact of any specific subscale on perceived stress. For this analysis, coping styles were entered in the third group as multiple studies have found that attachment characteristics shape the way individuals appraise, cope with, and adjust to stress (Kotler, Buzwell, Romeo, \& Bowland, 1994; Mikulincer \& Florian, 1998; Rholes \& Simpson, 2004). Additionally, I conducted a secondary analysis in which I entered the individual coping strategies in the third group to determine any specific contribution of the individual subscales to the variance observed in perceived stress. I have provided tables below, outlining this process, specifically the order in which the variables were entered into both of the hierarchical regression equations. 
Table 3.2

Hierarchical Multiple Regression Model 1 Variable Entry

\begin{tabular}{cc}
\hline Predictor Variable Blocks & Variables in Each Block \\
\hline Block One & Demographic Variables: \\
Gender and Relationship Status & Attachment Constructs: \\
Block Two & Attachment Avoidance and Attachment Anxiety \\
Block Three & Coping Styles: \\
& Problem-Focused, Emotion-Focused, and Avoidant \\
\hline
\end{tabular}

Table 3.3

Hierarchical Multiple Regression Model 2 Variable Entry

\begin{tabular}{cc}
\hline Predictor Variable Blocks & Variables in Each Block \\
\hline Block One & Demographic Variables: \\
Gender and Relationship Status & \\
Block Two & Attachment Constructs: \\
Block Three & Attachment Avoidance and Attachment Anxiety \\
& Distinct Coping Strategies: \\
& Active Coping, Planning, Acceptance, Positive Reframing, \\
Religion, Humor, Using Emotional Support, Using Instrumental \\
Support, Self-distraction, Venting, Denial, Behavioral \\
Disengagement, Self-blame, and Substance Use
\end{tabular}




\section{CHAPTER IV}

\section{RESULTS}

This chapter presents the results of the statistical analyses used to evaluate the research hypotheses. The first section describes the initial review of the data, including the data screening and preliminary analysis, as well as how missing data were handled. The second section includes the descriptive statistics for participants, as well as the criterion and predictor variables. Finally, the third section summarizes the results of the hierarchical multiple regression analysis, utilized to determine the amount of variance in the criterion variable, perceived stress, that could be accounted for by sets of predictor variables, including attachment avoidance and attachment anxiety, and coping styles.

\section{Preliminary Analyses}

All statistical analyses were performed using the Statistical Package for the Social Sciences (SPSS 23.0) for Windows. One benefit of the online data collection platform Qualtrics is that the platform includes an automated process through which a data file is generated and exported directly from the raw response data, which significantly reduced the risk of error associated with manual data entry. To ensure consistency, response patterns in the exported data file were also visually inspected.

All predictor and criterion variables were screened for the underlying assumptions of linearity, normality, and homoscedasticity, as well as for multivariate outliers. Normality, linearity, and homoscedasticity of variables were visually examined using histograms, and skewness and kurtosis statistics, and were found to meet the assumptions of multivariate analysis. Additionally, a matrix of correlation coefficients was reviewed to study bivariate 
correlational relationships. The data were also examined for missing data. Transformations were applied to variables as necessary, discussed below.

\section{Missing Data}

Prior to completing the planned analyses, data were examined for completeness. A total of 214 cases were collected through Qualtrics to complete the initial data set. Of these, two cases $(.9 \%)$ met exclusion criteria of not being currently enrolled as a full or part-time student at West Virginia University; therefore, these were excluded from further analysis. Of the remaining 212 cases, $38(17.7 \%)$ had more than $10 \%$ missing data. These 38 cases were examined to determine any possible patterns in the missing data. Three of these 38 cases had no response to any of the survey questions, after answering yes to the informed consent at the start of the study. These cases were removed from further analyses. The remaining 35 cases were subjected to further analysis to explore patterns of missingness. The majority of these cases, $65.71 \%(n=23)$ discontinued responding to survey questions following the Demographic survey, not completing any of the included measurements; $20 \%(n=7)$ stopped responding to the survey questions during or after the first questionnaire, leaving two of the survey measures incomplete; and $14.29 \%(n=5)$ discontinued responding prior to completing the final survey. In all of these 25 cases, the missing data appeared to be attributable to attrition during completion of the study.

After this review, steps were taken based on best practice recommendations for treating missing data (Schlomer et al., 2010) as 13 of the remaining 174 cases had less than $9 \%$ missing data. Specifically, one case was missing data on seven items, one case was missing data on three items, six cases were missing data on two items, and 25 cases were missing data on one item. First, a visual examination showed no obvious patterns of missingness across these cases and variables. Second, Little's MCAR test was conducted utilizing the Missing Values Analysis 
function in SPSS 23.0. The results of this review indicated that it is likely the data are missing completely at random (Little's MCAR test: $\chi 2=2324.033, d f=2227, p=.074$ ), as significance was greater than .05 (Tabachnick \& Fidell, 2007). Instead of removing these cases from subsequent analyses, which is not recommended when data are missing at random and the proportion of missing cases is considered small, the missing values were imputed using expectation maximization, which is fitting when data are missing at random. Expectation maximization is a mathematical procedure used for finding maximum likelihood estimates of missing values for incomplete case data; the algorithm used allows for parameter estimation of unobserved variables in statistical models, by utilizing the observed data points in the case. This method has been found superior to alternative methods of addressing missing data, including mean substitution and multiple imputation (Schlomer et al., 2010; Tabachnick \& Fidell, 2007).

\section{Tests for Univariate and Multivariate Normal Assumptions}

In examining univariate and multivariate assumptions, the Kolmogorov-Smirnov test was used to assess the assumption of normality for the dependent variable. The assumption of normality was found $(d f=174, p=.200)$, therefore it is presumed that perceived stress is normally distributed within this sample. Additionally, the normality of the criterion variable, perceived stress, was examined using Levene's test of homogeneity of variance. Participant

responses for perceived stress were found to be normally distributed, as Levene's test of equality of error variances was not violated. To assess for the presence of multivariate outliers in the primary predictor variables in the data set, the Mahalanobis statistic was utilized. In evaluating the seven predictor variables, and with a $p<.001$ criterion for the Mahalanobis distance, no outliers were detected among the 174 cases; therefore no additional cases were deleted prior to conducting the proposed regression analyses. 


\section{Descriptive Statistics}

Complete descriptive data on the 174 remaining participants are recorded in Table 4.1, below. While initial data collection yielded 214 cases, after cleaning and deleting cases with missing data, as discussed above, the final sample included 174 cases. Of the 174 participants, 25.3\% $(n=44)$ identified as male and $74.7 \%(n=130)$ identified as female. Participants ranged in age from 18 to 50 with a mean age of 23.63 , and a mode of 18 . When asked to identify their

Table 4.1

Participant Demographic Characteristics $(n=174)$

\begin{tabular}{|c|c|c|}
\hline Demographic Covariates & $n(\%)$ & Mean $(S D)$ \\
\hline Age & & $23.63(6.284)$ \\
\hline \multicolumn{3}{|l|}{ Sex } \\
\hline Female & $130(74.7 \%)$ & \\
\hline Male & $44(25.3 \%)$ & \\
\hline \multicolumn{3}{|l|}{ Race/Ethnicity } \\
\hline Caucasian & $151(86.8 \%)$ & \\
\hline African-American & $7(4 \%)$ & \\
\hline Asian & $6(3.4 \%)$ & \\
\hline Latino/Latina & $5(2.9 \%)$ & \\
\hline Native American & $1(.6 \%)$ & \\
\hline Other & $4(2.3 \%)$ & \\
\hline \multicolumn{3}{|l|}{ Relationship Status } \\
\hline Single & $70(40.2 \%)$ & \\
\hline $\begin{array}{c}\text { In a committed relationship, } \\
\text { Not living together }\end{array}$ & $57(32.8 \%)$ & \\
\hline $\begin{array}{c}\text { In a committed relationship, } \\
\text { Living together }\end{array}$ & $26(14.9 \%)$ & \\
\hline Married & $21(12.1 \%)$ & \\
\hline \multicolumn{3}{|l|}{ Year in School } \\
\hline Freshman & $32(18.4 \%)$ & \\
\hline Sophomore & $17(9.8 \%)$ & \\
\hline Junior & $19(10.9 \%)$ & \\
\hline Senior & $27(15.5 \%)$ & \\
\hline 5 years + undergraduate & $9(5.2 \%)$ & \\
\hline Graduate & $70(40.2 \%)$ & \\
\hline \multicolumn{3}{|l|}{ Student Status } \\
\hline Full-time & $152(87.4 \%)$ & \\
\hline Part-time & $22(12.6 \%)$ & \\
\hline
\end{tabular}


race/ethnicity, $86.8 \%(n=151)$ identified as Caucasian; $4 \%(n=7)$ identified as AfricanAmerican; 3.4\% $(n=6)$ identified as Asian; 2.9\% $(n=5)$ identified as Latino/Latina; $0.6 \%(n=$ 1) identified as Native American; and 2.3\% $(n=4)$ identified as Other; of those who identified as Other, three respondents included specifications for their identified race/ethnicity, including "biracial", "mixed", and "two or more races". Participants were also asked to identify their current relationship status. A majority of students, $40.2 \%(n=70)$ identified as currently single; $32.8 \%$ $(n=57)$ identified as currently in a committed relationship, though not living together; $14.9 \%(n$ $=26)$ identified as currently in a committed relationship and living together; and $12.1 \%(n=21)$ identified as currently married.

In order to better understand the sample, participants were also asked to indicate their year in school and student status. With regard to year in school, 40.2\% $(n=70)$ participants were graduate students; $18.4 \%(n=32)$ were freshman; $9.8 \%(n=17)$ were sophomores; $10.9 \%$ $(n=19)$ were juniors; $15.5 \%(n=27)$ were seniors; and $5.2 \%(n=9)$ were fifth year or more undergraduate students. Participants were also asked to identify their student status as either full-time or part-time. The majority of participants, $87.4 \%$ identified as currently full-time students $(n=152)$ while $12.6 \%(n=22)$ identified as part-time, currently enrolled in less than 12 credit hours for undergraduate students or 8 credit hours for graduate students.

Means, standard deviations, range, skewness, and kurtosis for all utilized predictor and criterion variables are shown below in Table 4.2. This table includes information on the higher order coping styles (Problem-Focused, Emotion-Focused, and Avoidant), as well as the 14 different coping strategies. Additionally, bivariate correlations between the explored variables are reported in Table 4.3. This includes the primary variables of analysis, including demographic variables (Sex and Relationship Status), attachment dimensions (Avoidance and 
Anxiety), higher order coping styles (Problem-Focused, Emotion-Focused, Avoidant), and perceived stress. Results from the correlational analysis included findings on variable(s) investigated further in the hierarchical multiple regression analysis. Additionally, potentially relevant confounds in the sample, including differences in sex ratio and relationship status, were examined through the multivariate procedures. 
Table 4.2

Descriptive Statistics for Criterion and Predictor Variables

\begin{tabular}{|c|c|c|c|c|c|}
\hline Variable & Mean & $\mathrm{SD}$ & Range & Skewness & Kurtosis \\
\hline \multicolumn{6}{|l|}{ Criterion } \\
\hline Perceived Stress & 28.28 & 8.696 & $0-56$ & .042 & -.391 \\
\hline \multicolumn{6}{|l|}{ Demographics } \\
\hline Sex & 1.25 & .436 & $1-2 \mathrm{a}$ & 1.147 & -.692 \\
\hline Relationship Status & 1.99 & 1.020 & $1-6_{b}$ & .718 & -.632 \\
\hline \multicolumn{6}{|l|}{ Attachment } \\
\hline Avoidance & 2.8549 & 1.18874 & $0-7$ & .741 & .008 \\
\hline Anxiety & 3.7160 & 1.11959 & $0-7$ & -.075 & -.287 \\
\hline \multicolumn{6}{|l|}{ Coping Styles } \\
\hline $\begin{array}{l}\text { Problem-Focused } \\
\text { Coping }\end{array}$ & 17.20 & 3.383 & $0-24$ & -.122 & -.044 \\
\hline $\begin{array}{l}\text { Emotion-Focused } \\
\text { Coping }\end{array}$ & 32.79 & 6.320 & $0-56$ & .181 & .292 \\
\hline Avoidant Coping & 11.76 & 2.905 & $0-24$ & .774 & 1.118 \\
\hline \multicolumn{6}{|l|}{ Coping Strategies } \\
\hline Active Coping & 5.89 & 1.358 & $0-8$ & -.220 & -.487 \\
\hline Planning & 6.04 & 1.375 & $0-8$ & -.498 & -.140 \\
\hline Acceptance & 6.04 & 1.393 & $0-8$ & -.636 & .212 \\
\hline Positive Reframing & 5.87 & 1.520 & $0-8$ & -.562 & -.054 \\
\hline Religion & 3.98 & 2.106 & $0-8$ & .664 & -.941 \\
\hline
\end{tabular}


Table 4.2 (cont).

\begin{tabular}{|c|c|c|c|c|c|}
\hline Humor & 5.08 & 1.919 & $0-8$ & .053 & -1.042 \\
\hline $\begin{array}{l}\text { Using Emotional } \\
\text { Support }\end{array}$ & 5.30 & 1.750 & $0-8$ & -.104 & -.755 \\
\hline $\begin{array}{l}\text { Using Instrumental } \\
\text { Support }\end{array}$ & 5.26 & 1.780 & $0-8$ & -.087 & -.883 \\
\hline Self-Distraction & 5.90 & 1.527 & $0-8$ & -.415 & -.403 \\
\hline Venting & 4.68 & 1.619 & $0-8$ & .185 & -.675 \\
\hline Denial & 2.70 & 1.194 & $0-8$ & 1.814 & 2.972 \\
\hline $\begin{array}{l}\text { Behavioral } \\
\text { Disengagement }\end{array}$ & 3.16 & 1.439 & $0-8$ & 1.274 & .960 \\
\hline Self-Blame & 4.83 & 1.809 & $0-8$ & .175 & -.917 \\
\hline Substance Use & 3.04 & 1.670 & $0-8$ & 1.554 & 1.451 \\
\hline
\end{tabular}

Note. $\mathrm{n}=174$. The following codes apply to the categorical variables of Sex and Relationship Status.

a. $1=$ female, $2=$ male

b. $1=$ Single; $2=$ In a committed relationship, not living together; $3=$ In a committed relationship, living together; $4=$ Married; 5 = Separated or Divorced; $6=$ Widowed 
Table 4.3

Correlations of Predictor and Criterion Variables for Coping Styles

\begin{tabular}{|c|c|c|c|c|c|c|c|c|}
\hline Variables & 1 & 2 & 3 & 4 & 5 & 6 & 7 & 8 \\
\hline \multicolumn{9}{|l|}{ 1.Sex } \\
\hline 2.RelaStat & $-.266 * *$ & & & & & & & \\
\hline 3.Att-Avoid & $.262 * *$ & $-.326 * *$ & & & & & & \\
\hline 4.Att -Anx & .007 & $-.298 * *$ & .138 & & & & & \\
\hline 5.Cope-Prob & -.083 & .042 & $-.277 * *$ & -.111 & & & & \\
\hline 6.Cope-Emo & -.051 & -.107 & .007 & $.201 * *$ & $.390 * *$ & & & \\
\hline 7.Cope-Avoid & .023 & $-.327 * *$ & $-.270 * *$ & $.345^{* *}$ & -.046 & $.302 * *$ & & \\
\hline 8.PercStress & -.047 & $-.171 *$ & .094 & $.550 * *$ & -.134 & $.237 * *$ & $.436^{* *}$ & \\
\hline
\end{tabular}




\section{Regression Analyses}

For all analyses discussed in this section, each solution was screened for the likelihood of violations of homoscedasticity using residual scatterplots. Examinations of the scatterplots for each regression equation found no significant deviations from this assumption.

Question 1. Does student level of attachment avoidance and attachment anxiety predict perceived stress? To examine this first hypothesis, that attachment avoidance and attachment anxiety would explain a significant proportion of the variance in perceived stress in students, above and beyond demographic variables, the bivariate correlations between the criterion variable, perceived stress, and the proposed independent variables was examined. As shown in Table 4.3, while attachment avoidance was not found to be significant $(r=.094, p=.219)$, attachment anxiety was found to be significant $(r=.550, p<.001)$ in relation to perceived stress.

Question 2. Is student level of attachment avoidance and attachment anxiety predictive of utilized coping strategies? To examine the hypothesis, that attachment avoidance and attachment anxiety would explain a significant variance in utilized coping styles, the bivariate correlations between coping styles and the proposed independent variables was examined. These results are depicted in Table 4.4, to address the sub-hypotheses to research question 2.

Table 4.4

Research Question 2 Observed Relationships

\begin{tabular}{cccc} 
& & Criterion Variables & \\
\hline & Problem-Focused & Emotion-Focused & Avoidant Coping \\
Predictor Variables & Coping Strategies & Coping Strategies & Strategies \\
\hline Attachment Avoidance & $r=-.277, p<.001^{*}$ & $r=.007, p=.924$ & $r=-.270, p<.001^{*}$ \\
Attachment Anxiety & $r=-.111, p=.146$ & $r=.201, p=.008$ & $r=.345, p<.001^{*}$ \\
\hline
\end{tabular}

As predicted in hypothesis $2 \mathrm{~b}$, a negative relationship exists between attachment avoidance and Problem-Focused coping strategies $(r=-.277, p<.001)$, as well as between attachment anxiety 
and Problem-Focused coping strategies $(r=-.111, p=.146)$; however, only the relationship between attachment avoidance and Problem-Focused coping strategies was found to be significant. Hypothesis $2 \mathrm{c}$ predicted a negative relationship would exist between attachment avoidance and Emotion-Focused coping strategies; while this inverse was observed $(r=.007, p$ $=.924$ ), it was not found to be significant. As predicted in hypothesis $2 \mathrm{~d}$, a positive relationship between attachment anxiety and Emotion-Focused coping strategies was found, $(r=.201, p$ $=.008$ ), and found to be significant. Hypotheses $2 \mathrm{e}$ and $2 \mathrm{f}$ predicted that the relationship between attachment avoidance and Avoidant coping strategies would be positive, while the relationship between attachment anxiety and Avoidant coping strategies would be negative. In fact, the inverse of these hypotheses was found, and both found to be significant. Attachment avoidance and Avoidant coping strategies were found to have a significantly negative relationship ( $r=$ $-.270, p<.001)$, and attachment anxiety and Avoidant coping strategies were found to have a significantly positive relationship $(r=.345, p<.001)$. These surprising and unpredicted results will be thoroughly examined in the next chapter.

Question 3. Does the type of coping strategy utilized predict the student's perceived stress? To examine this hypothesis, that the style of coping strategy utilized would explain a significant proportion of the variance in perceived stress, the bivariate correlations between the criterion variable, perceived stress, and the independent variables was examined. These results are depicted in Table 4.5, to address the sub-hypotheses to research question 3.

Table 4.5

Research Question 3 Observed Relationships

Predictor Variables

Criterion Variable: Perceived Stress

$\begin{array}{cc}\text { Problem-Focused Coping Strategies } & r=-.134, p=.079 \\ \text { Emotion-Focused Coping Strategies } & r=.237, p=.002 \\ \text { Avoidant Coping Strategies } & r=.436, p<.001 *\end{array}$


As predicted, in hypothesis $3 b$, there was a negative relationship between Problem-Focused coping strategies and perceived stress $(r=-.134, p=.079)$, though it was not found significant. The significant positive relationship between Emotion-Focused coping strategies and perceived stress $(r=.237, p=.002)$, as predicted in hypothesis $3 \mathrm{c}$, was found. While the negative relationship between Avoidant coping strategies and perceived stress predicted in hypothesis $3 \mathrm{~d}$ was, in fact, found to be positive $(r=.436, p<.001)$, it was also found to be significant.

\section{Hierarchical Multiple Regression Analyses}

Given that relationships between the criterion and independent variables were found, as described above, the hierarchical multiple regression analyses were performed with the data as planned. Results from the hierarchical regression analyses, including values for change in $R^{2}$ $\left(\Delta R^{2}\right)$, unstandardized regression coefficients $(B)$, standard errors $(S E B)$, and standardized coefficients $(\beta)$ at each step and for the final model are recorded below, in Tables 4.6 and 4.7, respectively. Perceived stress was the DV and three sets of IVs were entered in a predetermined order: (1) Demographics, (2) attachment, (3) Coping, both higher order styles and distinct strategies. Hierarchical multiple regression analysis was used to investigate the relative contributions of these three sets of IVs, and the unique contribution of each individual IV, to variance in students' perception of stress. In order to assess the predicted relationships, two separate hierarchical regression analyses were performed.

The first, depicted in Table 4.6, utilized the higher order coping styles of ProblemFocused coping, Emotion-Focused coping, and Avoidant coping for the third IV. In the first step of the model, the demographic variables of sex and relationship status were added. Together, these variables accounted for some variance in perceived stress, $R^{2}=.039, F(2,171)=3.430, p$ $<.05$. The standardized partial regression coefficient for relationship status, $\beta=-.198, t(173)=$ 
$-2.543, p<.05$, indicated this variable was a unique contributor to the variance in perception of stress. In the second step, the attachment avoidance and attachment anxiety variables were added. This set of variables accounted for a significant amount of variance in perceived stress, $R^{2}=.307, F(2,169)=32.690, p<.001$. The standardized partial regression coefficient for attachment anxiety, $\beta=.542, t(173)=8.032, p<.05$, indicated that after controlling for demographic variables and attachment avoidance, attachment anxiety was a unique contributor to the variance in perceived stress, with each standard deviation increase on attachment anxiety predicting an increase of .542 standard deviations on perceived stress. The standardized partial regression coefficient for attachment avoidance, $\beta=.030, t(173)=.432, p=.666$, was not found to be a statistically significant contributor to variance in perceived stress in this second step.

Table 4.6

Hierarchical Multiple Regression Analysis-1 for Prediction of Perceived Stress $(n=174)$

\begin{tabular}{|c|c|c|c|c|c|c|c|c|}
\hline \multirow[b]{2}{*}{ Variable } & \multirow[b]{2}{*}{$R^{2}$} & \multirow[b]{2}{*}{$\Delta R^{2}$} & \multicolumn{3}{|c|}{ At Entry Into Model } & \multicolumn{3}{|c|}{ Final Model } \\
\hline & & & $B$ & $S E B$ & $\beta$ & $B$ & $S E B$ & $\beta$ \\
\hline Block 1: Demographics & .039 & $.039 *$ & & & & & & \\
\hline Sex & & & -1.990 & 1.552 & -.100 & -.722 & 1.283 & -.036 \\
\hline \multicolumn{9}{|l|}{ Relationship } \\
\hline Status & & & -1.687 & .663 & $-.198 *$ & .325 & .593 & .038 \\
\hline \multicolumn{9}{|l|}{ Block 2: Emotional } \\
\hline Closeness & .307 & $.268 * *$ & & & & & & \\
\hline Avoidance & & & .218 & .506 & .030 & -.425 & .504 & -.058 \\
\hline Anxiety & & & 4.207 & .524 & $.542 *$ & 3.382 & .521 & $.435 * *$ \\
\hline Block 3: Coping Styles & .396 & $.090 * *$ & & & & & & \\
\hline $\begin{array}{l}\text { Problem } \\
\text { Focused }\end{array}$ & & & -.368 & .180 & $-.143^{*}$ & -.368 & .180 & $-.143 *$ \\
\hline Emotional & & & .174 & .098 & .127 & .174 & .098 & .127 \\
\hline Avoidant & & & .808 & .210 & $.270 * *$ & .808 & .210 & $.270 * *$ \\
\hline $\begin{array}{l}\text { Note. Full Model: } F(7, \\
(2,169)=32.690, p<. \\
\text { Step 3: } \Delta F(3,166)=8 \\
{ }^{*} p \leq .05,{ }^{* *} p \leq .01\end{array}$ & $\begin{array}{l}66)= \\
1 \\
19, p\end{array}$ & $\begin{array}{l}15.575 \\
.001\end{array}$ & & & & & & ep 2: $\Delta F$ \\
\hline
\end{tabular}


In the final step, the higher order coping style variables (Problem-Focused, Emotion-Focused, Avoidant) were added as the third IV in the equation. As can be seen, the third step of the model also accounted for a significant amount of variance in perceived stress above and beyond demographic and attachment variables, $\left.R^{2}=.396, \Delta R^{2}=.090, F(3,166)=8.219, p<.001\right)$. The Avoidant coping standardized partial regression coefficient, $\beta=.270, t(173)=3.845, p<.001$, indicated that after controlling for demographic variables, attachment avoidance, and attachment anxiety, Avoidant coping was a significantly unique contributor to variance in perceived stress, with each standard deviation increase on Avoidant coping predicting an increase of .27 standard deviations for perceived stress. Additionally, Problem-Focused coping was a unique contributor to variance in perception of stress, with a standardized partial regression coefficient of $\beta=.143, t$ $(173)=-2.040, p<.05 ;$ this means each standard deviation increase on Problem-Focused coping predicts a decrease of -.143 standard deviations for students' perception of stress. Also of note, after the third step of the model, attachment anxiety remained a significant predictor of variance in the DV, even with the standardized regression coefficient reduced from $\beta=.542$ to $\beta=.435$.

The second hierarchical regression analysis utilized the 14 individual coping strategies as the third IV, to observe any particular impact of specific coping strategies. The results are shown below, in Table 4.7. As observed in the first hierarchical multiple regression, the demographic variables added in the first step accounted for some variance in perceived stress, $R^{2}=.039, F(2$, $171)=3.430, p<.05$, and the standardized partial regression coefficient for relationship status, $\beta$ $=-.198, t(173)=-2.543, p<.05$, indicated this variable was a unique contributor to the variance in perceived stress. The attachment variables added in step 2, as in the first analysis, accounted for a significant amount of variance in perceived stress, $R^{2}=.307, F(2,169)=32.690, p<.001$. Specifically, the standardized partial regression coefficient for attachment anxiety, $\beta=.542, t$ 
$(173)=8.032, p<.05$, indicated this variable, after controlling for demographic variables and attachment avoidance, was a unique contributor to the variance in perceived stress. The standardized partial regression coefficient for attachment avoidance, $\beta=.030, t(173)=.432, p=$ .666 , was not found to be a statistically significant contributor to variance in perceived stress.

Table 4.7

Hierarchical Multiple Regression Analysis-2 for Prediction of Perceived Stress $(n=174)$

\begin{tabular}{|c|c|c|c|c|c|c|c|c|}
\hline \multirow{2}{*}{ Variable } & \multirow[b]{2}{*}{$R^{2}$} & \multirow[b]{2}{*}{$\Delta R^{2}$} & \multicolumn{3}{|c|}{ At Entry Into Model } & \multicolumn{3}{|c|}{ Final Model } \\
\hline & & & $B$ & $S E B$ & $\beta$ & $B$ & $S E B$ & $\beta$ \\
\hline Block 1: Demographics & .039 & $.039 *$ & & & & & & \\
\hline Sex & & & -1.990 & 1.552 & -.100 & -1.744 & 1.369 & -.087 \\
\hline Relationship & & & & & & & & \\
\hline Status & & & -1.687 & .663 & $-.198 *$ & .196 & .611 & .023 \\
\hline Block 2: Emotional & & & & & & & & \\
\hline Closeness & .307 & $.268 * *$ & & & & & & \\
\hline Avoidance & & & .218 & .506 & .030 & -.807 & .524 & -.110 \\
\hline Anxiety & & & 4.207 & .524 & $.542 *$ & 2.642 & .528 & $.340 * *$ \\
\hline Block 3: Coping & & & & & & & & \\
\hline Strategies & .494 & $.187 * *$ & & & & & & \\
\hline Active Coping & & & -.537 & .496 & -.084 & -.368 & .180 & $-.143 *$ \\
\hline Planning & & & .348 & .492 & .055 & .174 & .098 & .127 \\
\hline Acceptance & & & -.632 & .437 & -.101 & .808 & .210 & $.270 * *$ \\
\hline PosReframing & & & -.070 & .417 & -.012 & -.070 & .417 & -.012 \\
\hline Religion & & & -.183 & .263 & -.044 & -.183 & .263 & -.044 \\
\hline Humor & & & -.206 & .290 & -.046 & -.206 & .290 & -.046 \\
\hline Emot-Support & & & -.874 & .505 & -.176 & -.874 & .505 & -.176 \\
\hline Instru-Suport & & & .438 & .481 & .090 & .438 & .481 & .090 \\
\hline Self-Detraction & & & .529 & .384 & .093 & .529 & .384 & .093 \\
\hline Venting & & & .291 & .412 & .054 & .291 & .412 & .054 \\
\hline Denial & & & .060 & .494 & .008 & .060 & .494 & .008 \\
\hline BehavDisen & & & 1.076 & .487 & $.178 *$ & 1.076 & .487 & $.178 *$ \\
\hline Self-Blame & & & 1.320 & .362 & $.275 * *$ & 1.320 & .362 & $.275^{* *}$ \\
\hline Substance Use & & & .427 & .385 & .082 & .427 & .385 & .082 \\
\hline
\end{tabular}

Note. Full Model: $F 14,155)=4.096, p<.001 ;$ Step 1: $F(2,171)=3.430, p=.035 ;$ Step 2: $\Delta F$ $(2,169)=32.690, p<.001$

Step 3: $\Delta F(14,155)=4.096 . p<.001 .^{*} p \leq .05,{ }^{* *} p \leq .01$. 
In the third step, the 14 individual coping strategies were added, including active coping, planning, acceptance, reframing, religion, humor, use of emotional support, use of instrumental support, self-distraction, venting, denial, behavioral disengagement, self-blame, and substance use. As can be observed, the third block containing the distinct coping strategies accounted for a significant amount of variance in perceived stress above and beyond demographic and attachment variables, $\left.R^{2}=.494, \Delta R^{2}=.187, F(14,155)=4.096, p<.001\right)$. An examination of the standardized partial regression coefficients found that the coping strategy self-blame was a statistically significant contributor to variance in perceived stress at entry into the model, with a standardized partial regression coefficient of $\beta=.275, t(173)=3.646, p<.001$. This means each standard deviation increase on the strategy of self-blame predicts an increase of .275 standard deviations for students' perception of stress. Also, the coping strategy behavioral disengagement was a unique contributor to variance in perceived stress at entry into the model, with a standardized partial regression coefficient of $\beta=.178, t(173)=2.209, p<.05$. In the final model, these coping strategies continued as a statistically significant contributors to variance, with a standardized partial regression coefficients remaining at $\beta=.275$ for self-blame and $\beta=.178$ for behavioral disengagement. Additionally, in the final model, the coping strategy acceptance was a statistically significant contributor to variance in the DV, with a standardized partial regression coefficient of increasing from $\beta=-.101$ at entry to to $\beta=.270, t(173)=-1.447$, $p<.001$. Similarly, in the final model, the coping strategy active coping was a unique contributor to variance in perceived stress, with a standardized partial regression coefficient decreasing from $\beta=-.084$ to $\beta=-.143, t(173)=-1.083, p<.05$. Also of note, after the third step of the model, attachment anxiety remained a significant predictor of variance in the DV, even with the standardized regression coefficient reduced from $\beta=.542$ to $\beta=.340$. 


\section{Additional Regression Analyses}

To further explore any possible relationships found between sex, relationship status, attachment avoidance, and perceived stress, additional analyses were run involving these variables. As demonstrated in Table 4.3, significant correlations were found between the predictor variables of sex and relationship status $(r=-.266, p<.001)$, attachment avoidance and sex $(r=.262, p<.001)$, and attachment avoidance and relationship status $(r=-.326, p<.001)$. However, only relationship status was found to have a significant relationship with the criterion variable, perceived stress $(r=-.171, p=.024)$. To better assess the unique impact of the three predictor variables on the variable of perceived stress, a stepwise regression analysis was run. Stepwise regression analyses are utilized in an effort to identify the best predictive model with the included predictor variables, based on the data collected (Petrocelli, 2003). In running the stepwise regression analysis, entering sex, relationship status, and attachment avoidance as the predictor variables and perceived stress as the criterion variable, only relationship status was included in the overall analysis, resulting in a simple linear regression. Relationship status accounted for $2.9 \%$ of the variance in perceived stress $(F=5.197, d f=1,172, p=.024)$. Sex $(p$ $=.202)$ and attachment avoidance $(p=.595)$ were excluded from the analysis, as the $\mathrm{p}$-values for these predictor variables were not found to be statistically significant.

In an effort to better understand the relationship between these predictor variables, an additional analysis was run, utilizing the demographic variables of sex and relationship status as predictor variables, and attachment avoidance as the criterion variable. This was done in an effort to tease out any potential impact of the demographic variables on attachment avoidance. The demographic variables were found to account for $13.9 \%$ of the variance in attachment avoidance $(F=13.813, d f=2,171, p<.001)$. An examination of the standardized beta weights 
found that only relationship status was a unique predictor of attachment avoidance $(\beta=-.275, p$ $<.001)$, whereas sex $(\beta=.189, p=.011)$ was not.

\section{Summary of Results}

In summary, the proposed research hypotheses were partially supported by the results. As predicted, a positive relationship was found between attachment anxiety and perceived stress. The predicted negative correlations between the attachment variables and Problem-Focused coping strategies were also observed, as well as the negative correlation between ProblemFocused coping and the perception of stress. Also, a positive relationship was found between Emotion-Focused coping strategies and perceived stress. With regard to the hierarchical multiple regression analysis, the proposed loading of variables when using both the higher order coping style variables as well as the distinct coping strategies in the third block accounted for a statistically significant amount of the variance in perceived stress.

Several unpredicted findings were also observed in the results. Specifically, attachment avoidance was not found to be significantly related to the perception of stress. The inverse of predicted relationships between the attachment variables and Emotion-Focused and Avoidant coping strategies were found. Attachment avoidance found to be positively related to EmotionFocused coping strategies, while attachment anxiety found to be negatively related to EmotionFocused coping strategies. With regard to Avoidant coping strategies, attachment avoidance was found to be positively related, while attachment anxiety was found to have a negative relationship. Additionally, Avoidant coping strategies were found to be positively related to the perception of stress, though this relationship was predicted to be negative. These findings, along with the implications of these results, will be examined in detail in the subsequent chapter. 


\section{CHAPTER V}

\section{DISCUSSION}

In this study I hoped to contribute to the current research regarding a range of variables primarily drawn from attachment theory (Bowlby, 1969/1982), that may contribute to perceived stress in university and college students. As Attachment Theory describes the way in which individuals' early experiences with caregivers impact their behavior in relation to the environment, and to others, attachment relationships direct an individual's interpretations of potentially stressful events, as well as an individual's reaction to these events (Simpson \& Rholes, 1998). An individuals' specific attachment systems are at the base of this interaction, as the basis for perceived support and safety is the belief that one is loved and valued by others (Collins \& Feeney, 2004) and that, in stressful times, their support is reliable (Collins \& Feeney, 2004). The university environment holds many demands and opportunities for students, which include academic work, test preparation, living environment-based social interaction, and an increased focus on time-management. Individuals who report lower levels of attachment avoidance and attachment anxiety are more likely to succeed in the face of these multiple demands than students with higher levels of attachment anxiety and/or avoidance (Collins \& Feeney, 2004). Those students are likely to be more optimistic and, thus, have higher expectations for themselves in the environment. Additionally, more secure adult attachment provides resources and strategies to cope with stress and, thus, increase the chances of academic and interpersonal success in college. In addition, I hoped to show that specific coping styles defined by Carver, Scheier, and Weintraub (1989) would also show a relationship with perceived stress. 
Hierarchical multiple regression analyses were utilized to determine if variability in perceived stress in this population is related to specific characteristics in the sample such as sex and relationship status; as well as specific constructs that underlie attachment theory, including the constructs of avoidance and anxiety in attachment relationships; and also different types of coping styles (i.e., Problem-Focused Coping, Emotion-Focused Coping, and Avoidant Coping). In this chapter I will explore and discuss the meaning and implications of the previously reported results, with particular focus on those relationships that were found to be significant. Additionally, limitations of the current study are reviewed, potential directions for future research, and clinical implications are explored.

\section{Summary of Results}

Attachment and perceived stress. The first research question explored whether general attachment avoidance and attachment anxiety in university students would relate to perceived stress. The results of this analysis suggest that attachment variables are helpful in explaining variability in students' reporting of perceived stress. Based on past research that found relationships between stress and attachment variables (Howard \& Medway, 2004; Kenny \& Donaldson, 1991; Lopez \& Gormley, 2002; Mallinckrodt \& Wei, 2005; McCarthy et al., 2006; McCarthy et al., 2001; Perrine, 1998; Scharfe \& Cole, 2006; Solberg \& Villarreal, 1997; Sroufe et al., 2005; Vogel \& Wei, 2005), it was expected that higher levels of attachment avoidance and/or anxiety would relate to higher levels of reported perceived stress. This expectation was partly supported by the results, as attachment anxiety was found to be significantly, positively related to perceived stress, while attachment avoidance was not found to be related at a significant level. The significant finding for anxiety is consistent with the understanding that individuals more likely to perceive events as stressful also report higher levels of attachment 
anxiety (Howard \& Medway, 2004; Mikulincer et al., 2000). As attachment theory informs us, individuals turn to the internal working models formed in early attachment relationships to understand current experiences, and to form their interpretations of events (Bowlby, 1980). Individuals with higher levels of anxiety in their attachment relationships often exhibit lower levels of self-confidence, as well as hyper-activation of support seeking in relationships, as these individuals likely did not receive consistent and sufficient care or comfort in their early relationships; these individuals more often view themselves as needing support from others in addressing difficulties (Kirkpatrick \& Hazen, 1994). For individuals with higher levels of attachment anxiety, the perception of stressful events might be seen as threatening to the self and to relationships with others, as opposed to a challenge to be dealt with, as those with lower levels of attachment anxiety (Perrine, 1998). Therefore, it is likely that the variable of attachment anxiety was important in explaining differences in university students' perception of stress, as these individuals experience more reactivity to perceived threat.

In exploring the non-significant finding for attachment avoidance as it relates to perceived stress among the sample, some researchers have found that those who identify with greater levels of avoidance in their attachments deny the experience of stress (Kuh et al., 2006; Vogel \& Wei, 2005). This corresponds to early attachment research that described those falling under the avoidant style as disengaged in the face of distressing experiences, such as in Ainsworth's (1978) Strange Situation. Individuals who report higher levels of attachment avoidance often deactivate the instinctive attachment system response in the face of distress, as the early experiences that shaped internal working models were based on a lack of comfort and support from primary care givers. The earliest experiences for these individuals often involved not achieving attachment security during experiences of discomfort, resulting in a distrust of 
receiving support (Mikulincer \& Shaver, 2003). As the internal working model was based in not receiving support in the face of stress, the distressing event(s) are often dismissed as nonsignificant, so as to minimize the potential need for support and the resulting increased experience of anxiety that feeling a need for more support could generate (Perrine, 1998).

Much of the early research exploring attachment avoidance and attachment anxiety as it relates to the perception of stress combined individuals with higher levels of the two attachment variables under the broader category of insecure attachment (Feeney, 1999; Howard \& Medway, 2004; Mallinckrodt \& Wei, 2005; Mikulincer \& Florian, 1998; Mikulincer \& Shaver, 2003). This category was used in comparison to those individuals characterized as having secure attachment, reporting lower levels of attachment anxiety and attachment avoidance. As discussed, those reporting higher levels of attachment avoidance are likely to experience discomfort in expressing difficulties to others, as well as trusting and depending on others (Hazan \& Shaver, 1987). Those individuals may also face obstacles in acknowledging struggles or perceived weaknesses. Prior research supported the prediction of this study, that both attachment avoidance and attachment anxiety would be positively related to the perception of stress, as individuals reporting less secure attachment also report lower levels of self-esteem, less utilization of support in dealing with stress, and unworthy of affection (Perrine, 1998). As participants in this study reporting higher levels of attachment avoidance did not, as expected, also endorse higher levels of perceived stress, it is possible that the combination of both attachment variables, under the broader category of insecure attachment, was influenced by the relationship between attachment anxiety and the perception of stress. Other researchers examining the delineation between attachment avoidance and attachment anxiety, in relation to 
the experience of stress, have found similar results (Kuh et al., 2006; Vogel \& Wei, 2005). This is an area worthy of further exploration.

Attachment and coping style. The second research question examined in this study was whether levels of attachment avoidance or anxiety would be related to the style of coping strategies utilized by university students. It was predicted that, given the theoretical applicability and previous findings supporting a relationship between attachment dynamics and coping styles (Lopez \& Gormley, 2002; McCarthy et al., 2006; Mikulincer \& Florian, 1998; Rholes \& Simpson, 2004; Vogel \& Wei, 2005), students' levels of attachment avoidance and attachment anxiety would be predictive of their coping styles. Specifically, it was predicted that a there would be an inverse relationship between both attachment avoidance and attachment anxiety and Problem-Focused coping styles. This expectation was supported by the results, with the significant correlations between attachment avoidance and Problem-Focused coping being negative. Based on the understanding that problem-focused strategies are utilized more often by those reporting less distress (Ben-Zur, 2005), this finding was expected. Specifically, individuals reporting lower levels of attachment avoidance and attachment anxiety, and who were considered securely attached, also typically report a greater sense of control and mastery of their environment, as well as competence in social and academic settings (Bernier et al., 2004). As Problem-Focused coping strategies are utilized when the person feels that he or she can do something constructive to lessen the effects of the stressor(s), those who perceive themselves as more effective in their environment employ coping behaviors that are oriented towards changing the distressing situation itself.

With regard to Emotion-Focused coping, it was predicted that there would be a direct relationship with attachment anxiety and an inverse relationship with attachment avoidance. 
However, both the relevant correlations were found to be positive, with a significantly positive relationship being observed between Emotion-Focused coping and attachment anxiety. This corresponds to previous findings that individuals reporting higher levels of attachment anxiety were more likely to seek help for perceived stress than those reporting lower attachment anxiety (Vogel \& Wei, 2005). As observed in this study, participants who reported higher levels of attachment anxiety also reported higher levels of Emotion-Focused coping strategies, accessing support for perceived stress. As Emotion-Focused coping strategies are utilized in an effort to lessen the emotional distress associated with the situation, these strategies are most often used when the individual perceives the stressor as something that cannot be altered, and must be endured (Lazarus \& Folkman, 1984). This perception could come from a factual assessment of the distressing situation; it can also be the result of having fewer emotional and cognitive resources to address distress, leading to a greater reliance on reassurance from others (Bernier et al., 2004; Mikulincer et al., 2000).

As higher levels of attachment avoidance correspond to a lesser acknowledgment of distress, the observed positive correlation between attachment avoidance and Emotion-Focused coping was unexpected, indicating that those with more avoidant attachments avoid closeness with and reliance on others (Bernier et al., 2004). As these individuals are more emotionally distant and skeptical of trust in relationships, they find it difficult to depend on others, as is necessary in engaging in more Emotion-Focused coping strategies (Perrine, 1998). As previous research has demonstrated, those individuals endorsing higher levels of attachment avoidance experience a discomfort in expressing difficulties to others (Hazan \& Shaver, 1987). Therefore, it was predicted participants reporting higher levels of avoidance would endorse less use of Emotion-Focused coping strategies, as the experience has to be acknowledged to then utilize 
coping strategies aimed at changing the emotional response(s) to stressful events (Ben-Zur, 2005). However, several Emotion-Focused coping strategies, specifically substance use, selfblame, and humor, are intended to relieve the psychological distress of the situation, without necessarily engaging with and relying on others for support (Carver, Scheier \& Weintraub, 1989). Therefore, it is possible this observed positive relationship was greatly shaped by these less functional strategies, more so than the overall style of coping. It is also possible that the unexpectedly positive correlation found between Emotion-Focused coping and attachment avoidance is attributable to the non-significant finding discussed above, between attachment avoidance and perceived stress.

Finally, with regard to Avoidant coping, a direct relationship was expected with attachment avoidance and an inverse relationship was predicted with attachment anxiety. The direction of these predictions was found to be in reverse, though both results were statistically significant. Those reporting higher levels of attachment avoidance also reported less utilization of avoidant coping strategies. This could be attributed to the observation that those individuals self-reporting higher levels of attachment avoidance also report less distress (Ben-Zur, 2005; Kotler, Buzwell, Romeo, \& Bowland, 1994; Kuh et al., 2006; Mikulincer \& Florian, 1998; Rholes \& Simpson, 2004) and, therefore, report less utilization of any coping tools, including avoidant strategies. While avoidant coping strategies, at the base, function to provide escape from dealing with the stressors present, they are also often emotion-based, as the attempt being made is to avoid the feelings of distress triggered by the stressor (Aldwin \& Revenson, 1987). As those individuals who report higher levels of attachment avoidance are often hesitant to acknowledge and/or engage their emotional response to distressing situations, it is also probable 
that they are less likely to endorse disengaging from their stressor(s) in this way (Billings \& Moos, 1981). Therefore, while this finding was not predicted, it is not completely surprising.

Additionally, as those reporting higher levels of attachment anxiety reported greater levels of perceived stress, these individuals might also endorse increased use of a variety of coping strategies, including avoidant approaches. As individuals with higher levels of attachment anxiety internalized early, inconsistent, experiences in attachment relationships, these individuals are also more likely to engage in a multitude of coping strategies, as a way of hyperactivating the attachment system to elicit a response from their attachment figures (Kirkpatrick \& Hazen, 1994). Though the utilization of avoidant coping strategies was not predicted to be directly related to those participants reporting higher levels of attachment anxiety, it is possible individuals who endorsed higher levels of anxiety in attachment relationships also experience difficulty engaging with distressing situations, as they already expect inconsistent responses from others and from the environment (Ainsworth, 1989; Bartholomew, 1990). Additionally, avoidance based coping methods are positively tied to distress, and may result in negative consequences, as these strategies do nothing about the stressor's existence, nor the eventual emotional and cognitive impact to the individual (Carver et al., 1989). Overreliance on these kinds of coping strategies may attribute to short-term relief, though lead to long-term increased distress, as the situation is not dealt with effectively when first experienced.

As multiple studies have found attachment shapes the way individuals appraise, cope with, and adjust to stress (Kotler, Buzwell, Romeo, \& Bowland, 1994; Mikulincer \& Florian, 1998; Rholes \& Simpson, 2004), it was expected that Avoidant coping strategies, those aimed at escaping dealing with stressful scenarios, would have a direct relationship with attachment avoidance and an inverse relationship with attachment anxiety. Given that those individuals 
avoidantly attached tend to under-react to stressors, and have difficulty taking advantage of social support as a form of coping, it was expected that they would also endorse coping strategies reflecting the struggle to acknowledge and address distress, instead of employing less active, dysfunctional coping strategies. For individuals reporting higher levels of attachment anxiety, it was expected those persons, with a tendency to overreact to stressors would report less utilization of strategies designed to diminish the stressor, as these strategies are less likely to evoke a supportive response from others (Kotler, Buzwell, Romeo, \& Bowland, 1994; Rholes \& Simpson, 2004). While the opposite of these predictions was found in this sample, it is possible that these results were impacted by the emotion-based nature of Avoidant coping strategies, as these strategies, while aimed to disengage from the stressor, also come about as a means to diminish the experience of distress that has been triggered (Carver et al., 1989). Additionally, as adult attachments direct one's interpretations of potentially stressful events and one's reaction to these events (Simpson \& Rholes, 1998), those reporting higher levels of attachment avoidance may be less likely to acknowledge distress, as well as any types of coping strategies utilized in the face of stress. Those reporting higher levels of attachment anxiety may engage a variety of means to cope with perceived distress, some strategies designed to elicit a response from others, as well as other approaches that attempt to disengage from the situation, given uncertainty of the provision of support through attachment figures.

Coping style and perceived stress. The third research question posited that the style of coping strategies utilized was predictive of levels of perceived stress in a sample of university students. As prior research has demonstrated coping styles have support for being representative of how individuals perceive stress (Collins \& Feeney, 2004; Cutrona et al., 1994; Howard \& Medway, 2004; Mikulincer et al., 2000), it was expected that different styles of coping would be 
positively and negatively related to the level of stress was perceived. Specifically, it was predicted that individuals reporting greater utilization of Problem-Focused and Avoidant coping strategies would report less perceived distress, while students reporting greater utilization of Emotion-Focused coping strategies would report greater levels of perceived distress. The predicted relationships with Problem-Focused and Emotion-Focused coping were found, though only the positive relationship with Emotion-Focused coping was significant. Interestingly, a significantly positive relationship was found with Avoidant coping and the perception of stress, suggesting that participants in this study reporting greater levels of distress also reported greater utilization of Avoidant coping strategies, including self-distraction, behavioral disengagement, and denial. Avoidant coping strategies, while utilized as a means to distance oneself from the stress, are emotion-based in nature, as the individual must first acknowledge the distress to then diminish the experience (Carver et al., 1989). While these individuals are actively working to deny any distress experienced, it is also possible that they experience a greater level of perceived stress over time, as these strategies do nothing about the stressor's existence or impact (Aldwin \& Revenson, 1987; Billings and Moos, 1981). Given that early experiences shape how a person interprets his/her ability to address distressing situations, both in accessing support through attachment relationships and through self-reliance (Simpson \& Rholes, 1998), these internal working models can also shape what methods of coping one feels are accessible and beneficial over time. The significant relationships with Emotion-Focused and Avoidant coping would suggest that, while students are willing to acknowledge heightened levels of distress at some point in their experience of the stressor(s), they are more likely to use coping strategies that are designed to distance themselves from actively processing and/or resolving the distress. This could be due to learned behaviors in early experiences, including learned helplessness, as well as 
in the provision of intermittent support over time (Solberg \& Villarreal, 1997). If an individual feels that he or she will not receive support in addressing a stressor, or may receive support at a later time, that person may employ inactive coping strategies designed to remove themselves from the stressor, until such a time that support can be gained, or the distress is no longer avoidable.

Hierarchical regression analyses. The hypotheses of this study posited that, when the attachment and coping variables were entered in a specified order, the full regression model would account for significant variability in students' reported perception of stress. This prediction was supported as both hierarchical analyses, the first using coping styles and the second utilizing the 14 distinct coping strategies, accounted for a significant amount of variability in students' perception of stress. In both instances, attachment anxiety was found to be significantly related to the perception of stress, as expected from previously discussed analyses. With regard to coping, the overall Avoidant coping approach was found to be significantly related; however, when the higher order coping styles were broken down into the distinct coping behaviors, self-blame, an Emotion-Focused coping strategy, and acceptance, a non-categorized coping strategy, were found to be significant. In examining the differing contributions of coping styles and strategies in the third step of both analyses, after controlling for the demographic and attachment variables, there was no identifiable pattern, even though the overall Avoidant coping style had the only significant relationship with the perception of stress. As this relationship parallels the results of the third research question, it is possible that the strategies comprising this style, self-distraction, behavioral disengagement, and denial, together reflect a less functional style of coping with perceived stress (Carver, Scheier, \& Weintraub, 1989), even when students are willing to acknowledge heightened levels of distress. In exploring 
the significant relationships of the self-blame and acceptance coping strategies, it is possible that the use of negative self-talk in self-blame as a form of addressing higher levels of distress also acts as a less functional approach to moderating the stress experience. With acceptance, it is plausible that this functional strategy aimed at accepting the reality of the stress, is helpful in addressing the initial distress provoked when confronting the stressor in the moment. Each of the types of coping most strongly related to students' perceived stress is a style of coping that may be useful in the short-term, but are considered less functional with long-term use, as each provides a brief opportunity to escape from, or share, the pain, without addressing the emotional or cognitive impact of the stressor (Lazarus \& Folkman, 1987). This corresponds to the idea that individuals with higher levels of anxiety in attachment relationships will often utilize strategies aimed at eliciting a response from others, as a way to garner support and attention, with or without actively engaging with the sources of the distress (Aldwin \& Revenson, 1987; Lopez \& Gormley, 2002). These results support the argument that the perception of stress is not only impacted by greater attachment anxiety, but also by the chosen coping approach in the face of that distress.

Exploratory regression analyses. As some significant relationships were found among the utilized demographic variables and attachment avoidance in the initial analyses that were not reflected in the overall hierarchical regression analyses, analyses were completed to explore any existing relationships among these variables, as well as with these variables and perceived stress. In exploring the impact of these predictor variables on the perception of stress, only relationship status was found to have a significant, inverse relationship with the perception of stress in the sample. Previous research has established a connection between more secure adult attachments and the increased perception and utilization of available support from others, particularly in 
relationships (Cutrona et al., 1994; Howard \& Medway, 2004). While individuals' specific attachment systems are at the base of this interaction, it is possible that those study participants in established romantic relationships were more likely to access the support systems in place, decreasing their perception of current stress.

In completing this stepwise regression analysis, though sex, relationship status, and attachment avoidance were all entered as predictor variables for perceived stress, only relationship status was included in the final analysis. The variables of sex and attachment avoidance were excluded from the regression as non-significant relationships were found among the variables. With regard to the non-significant relationship between sex and perceived stress, previous research has proposed that the perception of stress exhibits a normal distribution in relation to sex (Cohen, Kamarck \& Mermelstein, 1983; Cohen \& Williamson, 1988); therefore, this finding, while not exhibiting significance, is not entirely unexpected. In considering possible reasons for the exclusion of attachment avoidance in these results, as previously discussed those individuals who report greater levels of attachment avoidance are less likely to acknowledge levels of stress, as this could include expressing their difficulties to others and utilizing support to address distress (Hazan \& Shaver, 1987; Kuh et al., 2006; Vogel \& Wei, 2005).

An additional analysis was run in an effort to better understand the relationships that exist between the demographic variables and the variable of attachment avoidance, as not all variables were significantly related to the perception of stress. While the two demographic variables together contributed to variability in the reported levels of attachment avoidance among participants, in this exploration, only relationship status was found to be a unique predictor of attachment avoidance, with an inverse relationship. As prior research has found no significant 
relationship between sex and the distribution of attachment variables (Bartholomew, 1990; Bartholomew \& Horowitz, 1991; Bradford \& Lyddon, 1993; Collins \& Feeney, 2004; Feeney, 1999; Kenny \& Rice, 1995), the lack of a significant predictive relationship between sex and reported levels of attachment avoidance in this sample was not surprising. Given that previous research, as discussed, has outlined the connection between the utilization of support in relationships and lower levels of attachment avoidance (Collins \& Read, 1990; Feeney, 1999; Howard \& Medway, 2004; Mallinckrodt \& Wei, 2005; McCarthy et al., 2006; Scharfe \& Cole, 2006; Solberg \& Villarreal, 1997; Vogel \& Wei, 2005), as those with greater attachment avoidance are less likely to acknowledge distress nor access support to address stress related concerns, this finding is not surprising. Additionally, as those reporting lower levels of attachment avoidance are also likely to report more positive experience of and utilization of support in romantic relationships (Cutrona et al., 1994; Howard \& Medway, 2004; Mikulincer \& Florian, 1998), those respondents currently in romantic relationships had a greater likelihood of reporting lower levels of attachment avoidance. Given these findings, it is possible that current relationship status acts as a moderator in the perception of stress, as those student participants currently engaged in a romantic relationships were more likely to report lower levels of attachment avoidance, and greater utilization of support, perhaps through their romantic partners.

\section{Clinical Implications and Future Research}

The primary purpose of this study was to explore the individual difference variables that impact perceived stress in a sample of university students from the perspective of attachment theory. Considered overall, the results from this study provided good support for the model, as tested. While it was hypothesized that both attachment avoidance and attachment anxiety in this sample of university students would relate to coping styles, it was found that only attachment 
anxiety had a significant relationship. Theoretically, the lack of significant findings related to attachment avoidance could suggest that more work needs to be done to explore the specific relationship between attachment avoidance and the perception of stress. While there is a significant body of research connecting the theories of attachment and stress, the majority of existing research focuses largely on comparing secure and insecure attachment patterns. The findings of this study would support the beginning movement in the research to further explore the relationship between the distinct variables of attachment avoidance and attachment anxiety, in relation to the perception of stress. Through this exploration, it is possible to develop a better understanding of the roles of these individual attachment dimensions in an individual's understanding and experience of stress.

Given the strong relationships found in this study between Emotion-Focused coping and Avoidant coping styles and the perception of stress, future research can be used to explore what other characteristics of university students may impact utilized coping style. Given the relationship between Emotion-Focused and Avoidant coping styles and the perception of stress in study participants, and given that more research is focusing on the exploration of how students cope in response to stress and how emotions regulate in the presence of stress (Roisman, Clausell, Holland, Fortuna, \& Elieff, 2008; Watson \& Sinha, 2008), clinicians working with the university student population need to become more aware of the emphasis on more or less functional coping strategies in addressing heightened levels of stress. Additionally, findings from this study important to the therapeutic treatment of students include the importance of understanding students' attachment dimensions and the relationships between those dynamics and the comfort with utilization of specific coping strategies. 
It would also be beneficial to replicate this study with larger and more representative samples, again with students from various other universities, in order to reduce the potential for restriction of range in the variables of interest. Additionally, it could be helpful to examine whether students' perceptions of their attachment dynamics and coping styles is consistent with similar reporting from others' perspectives (i.e., parents, romantic partners, peers). Given that self-reporting is sometimes biased by the individual's limited self-perception and desire to appear more socially desirable in answering, expanding the data collection to include measures outside of self-report could further substantiate the results of this, or further, studies.

\section{Strengths}

This study was designed to explore the specific variables that influence perceived stress in a sample of university students. Specifically, I hoped to further the understanding of how different variables of adult attachment and coping come together in the perception of stress. The majority the previous research studying the connection between adult attachment and perceived stress focused on the differences between secure and insecure forms of attachment. While recent research has begun to delineate between the elements of insecure attachment, specifically attachment anxiety and attachment avoidance, the majority of studies continue to find similar results for both dimensions, despite the unique elements of each variable. In this study, it was my hope that differentiation would be observed between attachment anxiety and attachment avoidance, as they related to the perception of stress, aligning more directly with the elements of attachment theory. This was the case as, while not all predicted relationships were found in the data analysis, a distinct difference in the role of attachment avoidance was observed, particularly in relation to the emotional experience of stress and the utilization of emotion-focused strategies of coping. In the present study, the relationship between attachment avoidance and perceived 
stress was not significant; however, the indirect effect of attachment avoidance on the perception of stress through different approaches to coping led to an observable change. It is possible that the impact of attachment avoidance on perception of stress is observable through the employment of certain forms of coping; particularly in the negative relationships between attachment avoidance and Problem-Focused and Avoidant coping.

Additionally, previous research exploring the connection between coping strategies and perceived stress has largely focused on the two primary types of coping strategies proposed by Lazarus and Folkman (1987): emotion-focused and problem-focused. As the study of coping has been expanded in more recent years to differentiate between functional and dysfunctional strategies, a third category of coping has emerged, avoidant coping. As avoidant coping, like attachment avoidance within attachment theory, has not been as thoroughly examined as the original styles of coping, there is limited research to aid in the understanding of the role of avoidant coping strategies. Therefore, I hoped to contribute to the study of this coping strategy. Though predictions were made based on prior research, none of the predicted relationships for avoidant coping were observed, even though all observed relationships, with both attachment variables and perceived stress, were found to be significant within this sample. Previously limited understanding of avoidant coping categorized these strategies purely as dysfunctional, and as a way to distance for distress. However, the largely emotion-based nature of these approaches (self-distraction, behavioral disengagement, denial) contends that an individual must acknowledge distressing circumstances to then diminish the impact. The results of this study further highlight the need for exploring the specific role of avoidant coping strategies, as individuals reporting a greater utilization of these strategies may also experience a greater level of perceived stress, which was not previously assumed. 


\section{Limitations}

It is important to note that several limitations exist within this research. First, the nature of the sampling procedure utilized may limit the generalizability of the findings in a few ways. Given the use of internet and advertising recruitment within the university, as well as the selfselected nature of the sample, there may be unidentified differences that characterize those that chose to participate in the study, setting them apart from the broader West Virginia University student population. While I made efforts to recruit from the entire university population, utilizing multiple methods of recruitment in a variety of areas, there may be students who do not actively engage in the different areas of advertisement. Also, it is possible that students who chose to participate in the survey on perceived stress may share individual differences that relate to the variables of interest in this study. For example, it is possible that individuals who chose to participate in stress-related research are more aware of their own experience of stress than other university students. Additionally, there may be significant differences in individuals who dropped out of the survey prior to completion of all included measures. Finally, given the selfselected nature of those who comprise the study sample, it is possible that a restriction of range in the measured variables exists, and could limit the power to detect effects within this student sample. For example, samples of university students tend to self-report higher levels of perceived stress, and this can limit the statistical power to identify effects. To further explore these concerns, these results would need to be replicated in other samples of university students to provide additional support for the generalizability of these results to the West Virginia University, and other university student populations.

Second, while there are theoretical reasons to support the assumption of directionality between the variables in this study, as explored in earlier chapters, the survey design does not 
allow for the examination of causal relationships between the variables. For that reason, while significant relationships among the variables do exist, the specific direction of the relationships did not always emerge as predicted, suggesting other factors may be at work, which would require further study to understand.

Another limitation comes from the cross-sectional nature of the research design. This design prohibits the researcher's ability to examine any developmental changes that may occur in the variables studied, including coping styles and strategies. Given that attachment is conceptualized as a developmental process that is somewhat flexible over time, it is possible that university students' perception of stress may vary over time both with the utilization of specific coping strategies, as well as over the course of one's university career.

Lastly, a limitation that could impact the applicability of the study is that the measurement of all variables was done via self-report assessments. This method of measurement can be impacted by issues outside of those being studied, including impression management and social desirability. Additionally, this style of measurement is limited to the perceptions of the participants involved, and their reflections on their behavior other than observations of their actual behaviors and interactions. To the extent that individuals' self-perceptions are, in fact, representative of their actual behavior and styles, is unknowable at this time. Given the selfreported nature of the constructs explored in this study, the desire to be perceived as utilizing more functional coping strategies may have shaped the scores on the coping measurement. As evidence to support this proposition, the means on the majority of coping strategies considered to be functional fell near the upper range of the scales, indicating that students were more likely to characterize themselves as utilizing strategies that were more active in addressing distress themselves or through engaging the support of others. It is, therefore, difficult to determine to 
what extent these self-ratings reflect actual styles of coping. Future studies could also benefit from utilizing various methods to measure the included variables, such as adding biological observations of stress or collateral reports on attachment and utilized coping responses.

\section{Conclusion}

In this study, an attachment framework was utilized to predict the perceived stress of a sample of students at West Virginia University. Aspects of attachment theory, along with utilized coping styles, were found to be a strong predictor of the level of perceived stress. The implications of this study suggest that a better understanding of individuals' attachment dynamics and chosen coping strategies may be useful in furthering the understanding of individual experience of distress in the university environment. By having a better understanding of how these variables potentially affect the perception of stress in university students, counseling center and community clinicians may be able to more effectively identify and address stress processes and factors that could lead to enhancing coping with stressful situations experienced in the college environment, improving the quality of life of university students. 


\section{References}

Ainsworth, M. S., Blehar, M. C., Waters, E., Wall, S. (1978). Patterns of Attachment: A Psychological Study of the Strange Situation. Oxford, England: Lawrence Erlbaum.

Ainsworth, M. D. S. (1989). Attachments beyond infancy. American Psychologist, 44, 709- 716.

Andrews, B., \& Wilding, J. M. (2004). The relation of depression and anxiety to life-stress and achievement in students. British Journal of Psychology, 95(4), 509-521.

Aldwin, C.M., \& Revenson, T.T. (1987). Does coping help? A reexamination of the relation between coping and mental health. Journal of Personality and Social Psychology, $53,337-478$.

Alexander, R., Feeney, J., Hohaus, L., \& Noller, P. (2001). Attachment style and coping resources as predictors of coping strategies in the transition to parenthood. Personal Relationships, 8, 137-152.

Aronson, E., Wilson, T. D., \& Akert, R. M. (2003). Social psychology. New York: Prentice-Hall.

Averill, J.R. (1973). Personal control over aversive stimuli and its relationship to stress. Psychological Bulletin, 80, 286-303.

Bandura, A. (1982). Self-efficacy mechanism in human agency. American Psychologist, 37(2), $122-147$.

Bartholomew, K. (1990). Avoidance of intimacy: An attachment perspective. Journal of Social and Personal Relationships, 7, 147-178.

Bartholomew, K., \& Horowitz, L. M. (1991). Attachment styles among young adults: A test of a four-category model. Journal of Personality and Social Psychology, 61, 226-244. 
Bartholomew, K. \& Shaver, P. R. (1998). Methods of assessing adult attachment: Do they converge? In J. A. Simpson \& W. S. Rholes (Eds.) Attachment Theory and Close Relationships (pp. 25-45). New York: Guilford.

Bartholomew, K. \& Thompson, J. M. (1995). The application of attachment theory to counseling psychology. The Counseling Psychologist, 23, 484-490.

Bee, H., \& Bjorklund, B. R. (2004). The journey of adulthood. Upper Saddle River, NJ: Prentice Hall.

Ben-Zur, H. (2005) Coping, distress, and life events in a community sample. International Journal of Stress Management, 12, 188-196.

Bernier, A., Larose, S., Boivon, M., \& Soucy, N. (2004). Attachment state of mind: Implications for adjustment to college. Journal of Adolescent Research, 19, 783-806.

Billings, A.G., \& Moos, R.H. (1981). The role of coping responses and social resources in attenuating the impact of stressful life events. Journal of Behavioural Medicine, 4, 139157.

Brennan, P. L., \& Moos, R. H. (1990). Life stressors, social resources, and late-life problem drinking. Psychology and Aging, 5, 491-501.

Breznitz, S., \& Goldberger, L. (1993). Stress research at a crossroads. In L. Goldberger \& S. Borysenko, M. (1987). The immune system: An overview. Annals of Behavioral Medicine, 9, 310.

Bowlby, J. (1969/1982). Attachment and loss: Vol. 1. attachment. New York: Basic Books. Bowlby, J. (1980). Attachment and loss: Vol. 3. Sadness and depression. New York: Basic Books. 
Bowlby, J. (1988). A secure base: Parent-child attachment and healthy human development. New York: Basic Books.

Bradford, E., \& Lyddon, W. J. (1993). Current parental attachment: Its relation to perceived psychological distress and relationship satisfaction in college students. Journal of College Student Development, 34, 256-260.

Brennan, K. A., Clark, C. L., \& Shaver, P. R. (1998). Self-report measurement of adult attachment an integrative overview. In J. A. Simpson \& W. S. Rholes (Eds.), Attachment theory and close relationships (pp. 46-76). New York: Guilford Press.

Carver, C. (1997). You want to measure coping but your protocol's too long: Consider the brief COPE. International Journal of Behavioral Medicine, 4, 92-100.

Carver, C. S., Scheier, M. F., Weintraub, J. K. (1989). Assessing coping strategies: A theoretically based approach. Journal of Personality and Social Psychology, 56, 267283.

Chemers, M. M., Hu, L., \& Garcia, B. F. (2001). Academic self-efficacy and first-year college student performance and adjustment. Journal of Educational Psychology, 93, 55-64.

Cohen, S. (1986). Cognitive processes as determinants of environmental stress. In C. D. Spielberger \& I. G. Saronson (Eds.), Stress and Anxiety: vol. 10: A sourcebook of theory and research (pp. 65-82). Washington: Hemisphere Publishing Corporation.

Cohen, J. (1988). Statistical power analysis for the behavioral sciences ( $2^{\text {nd }}$ ed.). Hillsdale, NJ: Erlbaum.

Cohen, S. (2004). Social relationships and health. American Psychologist 59(8), 676-684.

Cohen, S, Kamarck, T, \& Mermelstein, R. (1983). A global measure of perceived stress. Journal of Health and Social Behavior, 24, 385-396. 
Cohen, S., \& Williamson, G.M. (1988). Perceived stress in a probability sample of the United States. In S. Spacapan \& S. Oakamp (Eds.), The social psychology of health (pp. 51-67). Newbury Park, CA: Sage.

Colin, V. L. (1996). Human attachment. New York: McGraw Hill.

Collins, N. L., \& Feeney, B. C. (2004). Working models of attachment shape perceptions of social support: Evidence from experimental and observational studies. Journal of Personality and Social Psychology, 87, 363-383.

Collins, N. L., \& Read, S. J. (1990). Adult attachment, working models, and relationship quality in dating couples. Journal of Personality and Social Psychology, 58, 644-663.

Contrada, R., \& Baum, A. (Eds.). (2010). The handbook of stress science: Biology, psychology, and health. New York, NY: Springer Publishing Company.

Corcoran, K. O., \& Mallinckrodt, B. (2000). Adult attachment, self-efficacy, perspective taking, and conflict resolution. Journal of Counseling and Development, 78, 473-483.

Cutrona, C. E., Cole, V., Colangelo, N., Assouline, S. G., \& Russell, D. W. (1994). Perceived parental social support and academic achievement: An attachment theory perspective. Journal of Personality and Social Psychology, 66, 369-378.

Dean, P. J., \& Range, L. M. (1996). The Escape Theory of Suicide and perfectionism in college students. Death Studies, 20, 415-424.

DeLongis, A., Folkman, A.S., \& Lazarus, R.S. (1988). The impact of daily stress on health and mood: Psychological and social resources as mediators. Journal of Personality and Social Psychology, 54:486-495.

De Meuse, K. P. (1985). The relationship between life events and indices of classroom performance. Teaching of Psychology, 12, 146-149. 
Dunahoo, C. L., Hobfoll, S. E., Monnier, J., Hulsizer, M. R., \& Johnson, R. (1998). There's more than rugged individualism in coping. Anxiety, Stress \& Coping, 11(2), 137.

Elliot, G. R., \& Eisdorfer, C. (1982). Stress and human health: An analysis and implications of research. A study by the Institute of Medicine, National Academy of Sciences. New York: Springer Publishing.

Endler, N. S., \& Parker, J. D. (1990). Multidimensional assessment of coping: A critical evaluation. Journal of Personality and Social Psychology, 58(5), 844-854.

Faul, F., Erdfelder, E., Buchner, A., \& Lang, A. G. (2009). Statistical power analyses using G*Power 3.1: Tests for correlation and regression analyses. Behavior Research Methods, $41,1149-1160$.

Feeney, B. C. \& Collins, N. L. (2004). Interpersonal safe haven and secure base caregiving processes in adulthood. In W. S. Rholes \& J. A. Simpson (Eds.) Adult Attachment: Theory, Research, and Clinical Implications (pp. 300-338). New York: Guilford.

Feeney, J. A. (1999). Adult attachment, emotional control, and marital satisfaction. Personal Relationships, 6, 169-185.

Feeney, J. A., \& Noller, P. (1996). Adult attachment: Sage series on close relationships. Thousand Oaks, CA: Sage Publications.

Feeney, J. A., Noller, P., \& Hanrahan, M. (1994). Assessing adult attachment. In M. B. Sperling, \& W. H. Berman (Eds.), Attachment in adults: Clinical and developmental perspectives (pp. 128-152). New York: The Guilford Press.

Folkman, S. (1992). Making the case for coping. In B.N. Carpenter (Ed.) Personal coping: Theory, research, and application (pp. 31-46). Westport, CT: Praeger. 
Folkman, S., \& Lazarus, R. S. (1985). If it changes it must be a process: Study of emotion and coping during three stages of a college examination. Journal of Personality and Social Psychology, 48, 150-170.

Folkman, S., \& Moskowitz, J. (2004). Coping: Pitfalls and promise. Annual Review Of Psychology, 55, 745-774.

Fraley, R. C. \& Waller, N. G. (1998). Adult attachment patterns: A test of the typological model. In J. A. Simpson \& W. S. Rholes (Eds.) Attachment theory and close relationships (pp. 77-114). New York: Guilford.

Fraley, R. C., Waller, N. G., \& Brennan, K. A. (2000). An item response theory analysis of selfreport measures of adult attachment. Journal of Personality and Social Psychology, 78(2), 350-365.

Goldberger, L., \& Breznitz, S. (Eds.). (1993). Handbook of stress, $2^{\text {nd }}$ Ed. New York, NY: The Free Press.

Graham, J. E., Christian, L. M., \& Kiecolt-Glaser, J. K. (2006). Stress, age, and immune function: Toward a lifespan approach. Journal of Behavioral Medicine, 29, 389-400.

Grossman, K. E. \& Grossman, K. (1991). Attachment quality as an organizer of emotional and behavioral responses in a longitudinal perspective. In C. M. Parkes, J. Stevenson-Hinde \& P. Marris (Eds.), Attachment across the life cycle (pp. 93 114). London: Tavistock/Routledge.

Hammen, C. L., Burge, D., Daley, S. E., Davila, J., Paley, B., \& Rudolph, K. D. (1995). Interpersonal attachment cognitions and prediction of symptomatic responses to interpersonal stress. Journal of Abnormal Psychology, 104, 436-443. 
Hazan, C., \& Shaver, P. (1987). Romantic love conceptualized as an attachment process. Journal of Personality and Social Psychology, 52, 511-524.

Heppner, P. P., Wampold, B. E., \& Kivlighan, D. M. (2008). Research design in counseling ( ${ }^{\text {rd }}$ ed.). Belmont, CA: Thomson Higher Education.

Hess, E. H. (1973). Imprinting: Early experience and the developmental psychobiology of attachment. New York: Van Nostrand Reinhold Co.

Holmes, T. H., \& Rahe, R. H. (1967). The social readjustment rating scale. Journal of Psychosomatic Research, 11, 213-218.

Horwitz, A. G., Hill, R. M., \&King, C. A. (2011). Specific coping behaviors in relation to adolescent depression and suicidal ideation. Journal of Adolescence, 34(5), 1077-1085.

House, J. S., Landis, K. R., \& Umberson, D. (1988). Social relationships and health. Science, $241,540-545$.

Howard, M. S., \& Medway, F. J. (2004). Adolescents' attachment and coping with stress. Psychology in the Schools, 41, 391-402.

Hudd, S. S., Dumlao, J., Erdmann-Sager, D., Murray, D., Phan, E., Soukas, N., \& Yokozuka, N. (2000). Stress at college: Effects on health habits, health status, and self-esteem. College Student Journal, 34, 217-218.

Kemp, M. A., \& Neimeyer, G. J. (1999). Interpersonal attachment: Experiencing, expressing, and coping with stress. Journal of Counseling Psychology, 46, 388-394.

Kenny, M. E., \& Donaldson, G. A. (1991). Contributions of parental attachment and family structure to the social and psychological functioning of first-year college students. Journal of Counseling Psychology, 38, 479-486. 
Kenny, M. E., \& Rice, K. G. (1995). Attachment to parents and adjustment in late adolescent college students: current status, applications, and future considerations. The Counseling Psychologist, 23, 433-456.

Kobak, R. (1999). The emotional dynamics of disruptions in attachment relationships: Implications for theory, research, and clinical intervention. In J. Cassidy \& P. R. Shaver (Eds.), Handbook of attachment theory, research, and clinical applications (pp. 21-44). New York: Guilford.

Kiecolt-Glaser, J. K., \& Glaser, R. (1995). Psychoneuroimmunology and health consequences: Data and shared mechanisms. Psychosomatic Medicine, 57, 269-274.

Kiecolt-Glaser JK, McGuire L, Robles T, Glaser R (2002). Psychoneuroimmunology: Psychological influences on immune function and health. Journal of Consulting and Clinical Psychology 70:537-547.

Kirkpatrick, L., \& Hazen, C. (1994). Attachment styles and close relationships: A four year prospective study. Personal Relationships, 1, 123-142.

Kotler, T., Buzwell, S., Romeo, Y., \& Bowland, J. (1994). Avoidant attachments as a risk factor for health. British Journal of Medical Psychology, 67(3), 237-245.

Kuh, G. D., Kinzie, J., Buckley, J.A., Bridges, B. K., \& Hayek, J. C. (2006, July). What matters to student success: A review of the literature. Paper commissioned by the National Postsecondary Education Cooperative (NPEC).

Larose, S., Bernier, A., \& Soucy, N. (2005). Attachment as a moderator of the effect of security in mentoring on subsequent perceptions of mentoring and relationship quality with college teachers. Journal of Social and Personal Relationships, 22(3), 399-415. 
Lazarus, R. S. (1966). Psychological stress and the coping process. New York, NY US: McGraw-Hill.

Lazarus, R.S. (1977). Psychological stress and coping in adaptation and illness. In Z. J. Lipowski, D. R. Lipsi, \& P. C. Whybrow (Eds.), Psychomatic medicine: Current trends pp 14-26). New York: Oxford University Press.

Lazarus, R. S., \& Folkman, S. (1984). Stress, appraisal, and coping. New York: Springer.

Lazarus, R. S., \& Folkman, S. (1987). Transactional theory and research on emotions and coping. European Journal of Personality, 1, 141-169.

Lok, C., \& Bishop, G. D. (1999). Emotion control, stress, and health. Psychology and Health, 14, 813-827.

Lopez, F. G. (1995). Contemporary attachment theory: An introduction with implications for counseling psychology. The Counseling Psychologist, 23, 395-415.

Lopez, F. G. \& Brennan, K. A. (2000). Dynamic processes underlying adult attachment organization: Toward attachment theoretical perspective on the healthy and effective self. Journal of Counseling Psychology, 47, 283-300.

Lopez, F. G., \& Gormley, B. (2002). Stability and change in adult attachment style over the firstyear college transition: Relations to self-confidence, coping, and distress patterns. Journal of Counseling Psychology, 49(3), 355-364.

Lorenz, K. (1937). On the formation of the concept of instinct. Natural Sciences, 25(19), 289300.

Lyddon, W. J. (1995). Attachment theory: A metaperspective for counseling psychology? The Counseling Psychologist, 23, 479-483. 
Main, M. (1990). Cross-cultural studies of attachment organizations: Recent studies, Changing methodologies, and the concept of conditional strategies. Human Development, 33, 4861.

Main, M. \& Hesse, E. (1990). Parents' unresolved traumatic experiences are related to infant disorganized attachment status: Is frightened and/or frightening parental behavior the linking mechanism? In M. T. Greenberg, D. Cicchetti, D., \& E. M. Cummings (Eds.) Attachment in the preschool years: Theory, research, and intervention (pp. 161-182). Chicago: University of Chicago.

Main, M., Kaplan, N., \& Cassidy, J. (1985). Security in infancy, childhood, and adulthood: A move to the level of representation. Monographs for the Society for Research in Child Development, 50, 66-104.

Mallinckrodt, B., \& Wei, M. (2005). Attachment, social competencies, social support, and psychological distress. Journal of Counseling Psychology, 52, 358-367.

Mattanah, J. F., Hancock, G. R., \& Brand, B. L. (2004). Parental attachment separation individuation, and college student adjustment: A structural equation analysis of mediational effects. Journal of Counseling Psychology, 51, 213-225.

McCarthy, C. J., Lambert, R. G., \& Moller, N. P. (2006). Preventive resources and emotion regulation expectancies as mediators between attachment and college students' stress outcomes. International Journal of Stress Management, 13, 1-22.

McCarthy, C. J., Moller, N. P., \& Fouladi, R. T. (2001). Continued attachment to parents: Its relationship to affect regulation and perceived stress among college students. Measurement \& Evaluation in Counseling and Development, 33, 198-214. 
McCrae, R. R. (1984). Situation determinants of coping responses: Loss, threat, and challenge. Journal of Personality and Social Psychology, 46, 919-928.

McEwen, B. S. (1998). Protective and damaging effects of stress mediators. New England Journal of Medicine, 338, 171-179.

McEwen, B., \& Lasley, E.N. (2002). The end of stress as we know it. Washington, DC: Joseph Henry Press.

Mikulincer, M. (1998). Adult attachment styles and affect regulation: Strategic variations in selfappraisals. Journal of Personality and Social Psychology, 75,420-435.

Mikulincer, M., Birnbaum, G., Woddis, D., \& Nachmias, O. (2000). Stress and accessibility of proximity-related thoughts: Exploring the normative and intraindividual components of attachment theory. Journal of Personality and Social Psychology, 78, 509-523.

Mikulincer, M., \& Florian, V. (1998). The relationship between adult attachment styles and emotional and cognitive reactions to stressful events. In J. A. Simpson and W. S. Rholes (Eds.), Attachment theory and close relationships (pp. 143-165). New York: Guilford Press.

Mikulincer, M., Gillath, O., Halevy, V., Avihou, N., Avidan, S., \& Eshkoli, N. (2001). Attachment theory and reactions to others' needs: Evidence that activation of the sense of attachment security promotes empathic responses. Journal of Personality and Social Psychology, 81, 1205-1224.

Mikulincer, M. \& Shaver, P. R. (2003). The attachment behavioral system in adulthood: Activation, psychodynamics, and interpersonal processes. In M. P. Zanna (Ed.), Advances in experimental social psychology (Vol. 35, pp. 53-152). San Diego, CA: Elsevier Academic Press. 
Moos, R., \& Holahan, C. (2003). Dispositional and contextual perspectives on coping: toward an integrative framework. Journal Of Clinical Psychology, 59(12), 13871403.

Moos, R. H., \& Schaefer, J. A. (1993). Coping resources and processes: current concepts and measures. In L. Goldberger \& S. Breznitz (Eds.), Handbook of stress (2nd ed., pp. 234258). New York: Free Press.

Neugarten, B. L., Havighurst, R. J., \& Tobin, S. S. (1961). The measurement of life satisfaction. Journal of Gerontology, 16(2), 134-143.

Noftle, E. E. \& Shaver, P. R. (2006). Attachment dimensions and the big five personality traits: Associations and comparative ability to predict relationship quality. Journal of Research in Personality, 40, 179-208.

Nounopoulos, A., Ashby, J. S., \& Gilman, R. (2006). Coping resources, perfectionism, and academic performance among adolescents. Psychology in the Schools, 43, 613-622.

Perrine, R. M. (1998). Stress and college persistence as a function of attachment style. Journal of the First-Year Experience \& Students in Transition, 11, 25-38.

Petrocelli, J. V. (2003). Hierarchical multiple regression in counseling research: Common problems and possible remedies. Measurement and Evaluation in Counseling and Development, 36, 9-22.

Pistole, M., \& Arricale, F. (2003). Understanding attachment: Beliefs about conflict. Journal of Counseling and Development, 81, 318-328.

Pistole, C. M. \& Watkins, C. E. (1995). Attachment theory, counseling process, and supervision. The Counseling Psychologist, 23, 457-478. 
Rholes, W. S., \& Simpson, J. A. (2004). Attachment theory: Basic concepts and contemporary questions. In W. S. Rholes \& J. A. Simpson (Eds.), Adult attachment theory, research, and clinical implications (pp. 3-16). New York: Guilford Press.

Roisman, G.I., Clausell, E., Holland, A., Fortuna, K., \& Elieff, C. (2008). Adult romantic relationships as contexts of human development: A multimethod comparison of same-sex couples with opposite-sex dating, engaged, and married dyads. Developmental Psychology, 44, 91-101.

Ross, S. E., Niebling, B. C., \& Heckert, T. M. (1999). Sources of stress among college students. College Student Journal, 33, 312-316.

Salas, E., Driskell, J. E., \& Hughes, S. (1996). Introduction: The study of stress and human performance. In J. E. Driskell \& E. Salas (Eds.), Stress and human performance (pp. 147). Mahwah, NJ: Erlbaum.

Scharfe, E., \& Cole, V. (2006). Stability and change of attachment representations during emerging adulthood: An examination of mediators and moderators of change. Personal Relationships, 13, 363-374.

Schlomer, G. L., Bauman, S., \& Card, N. A. (2010). Best practices for missing data management in counseling psychology. Journal of Counseling Psychology, 57, 1- 10.

Seaward, B. L. (2006) Managing Stress: Principles and strategies for health and well-being (5th ed.). Sudbury, MA: Jones \& Barlett.

Seiffge-Krenke, I. (1993). Coping behavior in normal and clinical samples: More similarities than differences?. Journal of Adolescence, 16(3), 285-303 
Seiffge-Krenke, I. (2006). Coping with relationship stressors: The impact of different working models of attachment and links to adaptation. Journal of Youth and Adolescence, 35(1), 25-39.

Seligman, M. E. P. (1975). Helplessness: On depression, development, and death. San Fransisco: W. H. Freeman.

Selye, H. (1956). The stress of life. New York: McGraw-Hill.

Selye, H. (1976). The stress of life (rev. ed.). New York: McGraw-Hill.

Sharf, R. S. (2004). Theories of psychotherapy and counseling: Concepts and Cases $\left(3^{\text {rd }}\right.$ ed.). Pacific Grove, CA: Brooks/Cole.

Shaver, P. R., \& Mikulincer, M. (2006). Attachment theory, individual psychodynamics, and relationship functioning. In A. L. Vangelisti and D. Perlman (Eds.), The cambridge handbook of personal relationships. New York: Cambridge University Press.

Shaver, P. R., \& Mikulincer, M. (2007). Adult attachment strategies and the regulation of emotion. In J. J. Gross (Ed.), Handbook of emotion regulation (pp. 446-465). New York: Guilford Press.

Shaver, P. R. \& Norman, A. J. (1995). Attachment Theory and Counseling Psychology: A Commentary. The Counseling Psychologist, 23, 491-500.

Shields, N. (2001). Stress, active coping, and academic performance among persisting and nonpersisting college students. Journal of Applied Biobehavioral Research, 6, 65-81.

Simpson, J. A., \& Rholes, W. S. (1998). Attachment in adulthood. In J. A. Simpson \& W. S. Rholes (Eds.), Attachment theory and close relationships (pp. 3-21). New York: Guilford Press. 
Solberg, V. S., \& Villarreal, P. (1997). Examination of self-efficacy, social support, and stress as predictors of psychological and physical distress among Hispanic college students. Hispanic Journal of Behavioral Sciences, 19, 182-201.

Somerfield, M. R., \& McCrae, R. R. (2000). Stress and coping research: Methodological challenges. American Psychologist, 55(6), 620.

Soucy, N., \& Larose, S. (2000). Attachment and control in family and mentoring contexts as determinants of adolescent adjustment to college. Journal of Family Psychology, 14, 125143.

Spielberger, C. D., \& Sarason, I. G. (1986). Stress and anxiety: A sourcebook of theory and research. Washington, DC: Hemisphere Publishing Corporation.

Sroufe, L. A., Egeland, B., Carlson, E. A., \& Collins, W. A. (2005). The development of the person: The Minnesota study of risk and adaptation from birth to adulthood. New York: Guilford Press.

Stone, A. A., \& Kennedy-Moore, E. (1991). Assessed situational coping: Potential conceptual and methodological issues. H. S. Friedman (Ed.), Hostility, coping, and health (pp. 203214). Washington, DC: American Psychological Association.

Strahan, B. J. (1995). Predictors of depression: An attachment theoretical approach. Journal of Family Studies, 1, 33-47.

Struthers, C. W., Perry, R. P., \& Menec, V. H. (2000). An examination of the relationship among academic stress, coping motivation, and performance in college. Research in Higher Education, 41, 581-592.

Tabachnick, B. G. \& Fidell, L. S. (2007). Using multivariate statistics (5th Ed.). Boston, MA: Pearson. 
Tardy, C. H. (1985). Social support measurement. American Journal of Community Psychology, 13(2), 187-202.

Tennant, C. (2002). Life events, stress and depression: a review of recent findings. Australian and New Zealand Journal of Psychiatry, 36(2), 173-182.

Turner, R. J., Wheaton, B., \& Lloyd, D. A. (1995). The epidemiology of social stress. American Sociological Review, 60, 104-125.

Vogel, D. L., \& Wei, M. (2005). Adult attachment and help-seeking intent: The mediating roles of psychological distress and perceived social support. Journal of Counseling Psychology, 52, 347-357.

Vondras, D. D., Powless, M. R., Olson, A. K., Wheeler, D., \& Snudden, A. L. (2005). Differential effects of everyday stress on the episodic memory test performances of young, mid-life, and older adults. Aging \& Mental Health, 9, 60-70.

Watson, D. C., \& Sinha, B. (2008). Emotion regulation, coping, and psychological symptoms. International Journal of Stress Management, 15, 222-234.

Wilson, G. S., Pritchard, M. E., \& Revalee, B. (2005). Individual differences in adolescent health symptoms: The effects of gender and coping. Journal of Adolescence, 28(3), 369-379.

Wolff, H. G. (1953). Stress and disease. Springfield, IL: Thomas.

Yeh, C. J., Arora, A. K., \& Wu, K. A., (2006). A new theoretical model of collectivistic coping. In P. Wong \& L. Wong (Eds.). Handbook of multicultural perspectives on stress and coping. Dallas, TX US: Spring Publications. 


\section{APPENDICES}




\section{APPENDIX A}

\section{STUDY ADVERTISEMENTS}

\section{MIX and Daily Athenaeum Advertisement:}

Opportunity to Participate in Student Research: Researchers at West Virginia University are looking for current WVU students to complete an online research survey examining the stress and coping of university students. Completion of this survey will take approximately 20 minutes. All currently enrolled students are invited to participate in this anonymous survey one time. Following completion of the survey, participants can enter a drawing to for one of ten Amazon \$20 gift cards.

For more information, please visit the following link:

\section{[LINK]}

Contact Person: Erin L. Higgenbotham, MA (ehiggenb@mix.wvu.edu; (803) 427-4078)

or James Bartee, Ph.D. (James.Bartee@ mail.wvu.edu; (304) 293-2227) from the Department of Counseling, Rehabilitation Counseling, and Counseling Psychology.

(West Virginia University’s Institutional Review Board (IRB) has approved this study.) 
Campus Flyer:

\section{Opportunity for Student Research Participation}

What: You are invited to participate in a study conducted by investigators from West Virginia University. The survey takes approximately 15-20 minutes to complete and is examining the stress and coping strategies of university students.

Who: All currently enrolled WVU students are invited to participate once. After you complete the survey, you are invited to enter a drawing for one of ten \$20 Amazon gift cards.

When: Anytime - the survey is online!

Where: [LINK]

Thanks for Your Interest!!

Contact Information:

Student Researcher: Erin L. Higgenbotham, MA

Doctoral Candidate

(304) 427-4078 / ehiggenb@mix.wvu.edu

PI: James Bartee, Ph.D., Chair and Professor

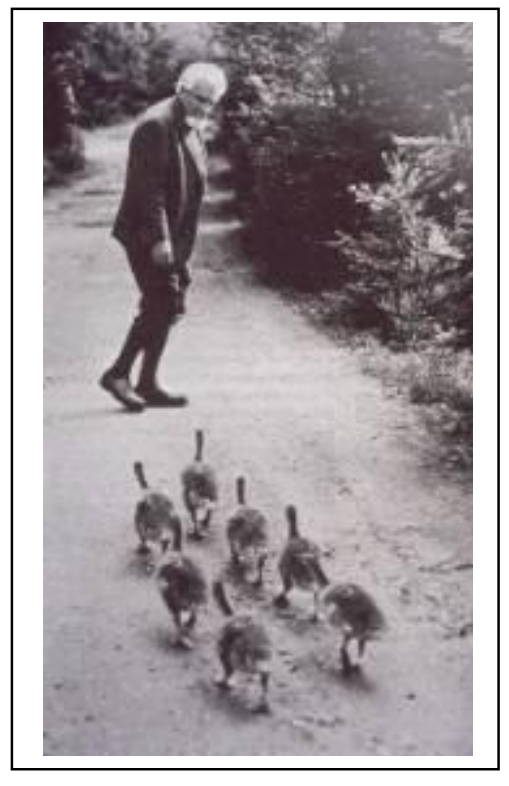

(304) 293-2227 / James.Bartee@mail.wvu.edu

Department of Counseling, Rehabilitation Counseling, \& Counseling Psychology

West Virginia University

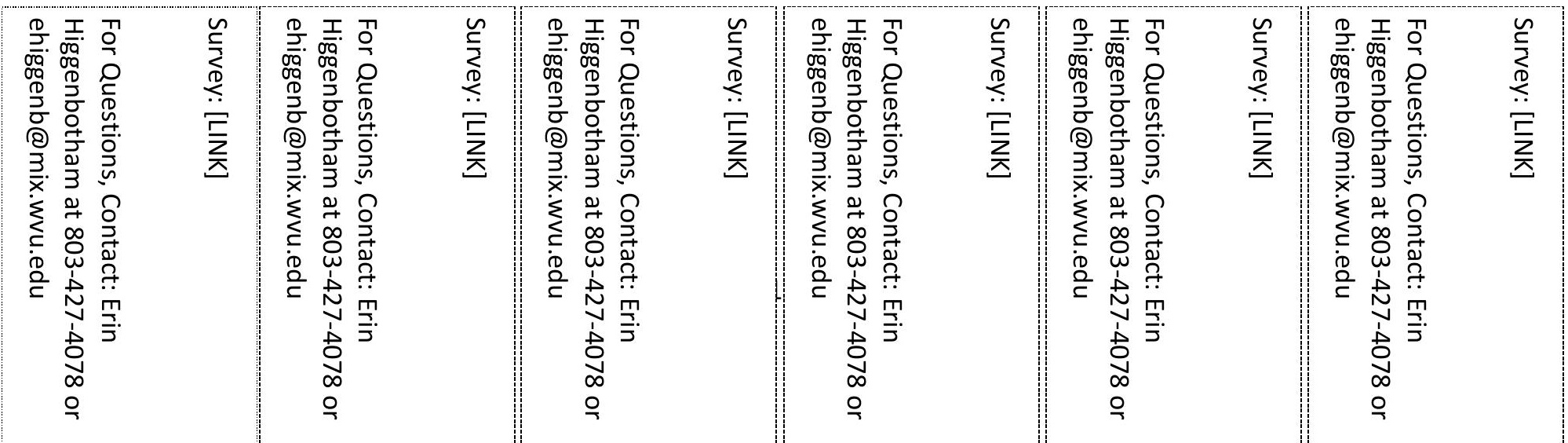




\section{APPENDIX B}

\section{ADDITIONAL RECRUITMENT MATERIALS}

\section{Email:}

Hello,

My name is Erin Higgenbotham and I am a doctoral candidate in the Counseling Psychology program here at West Virginia University. I am seeking participants for my dissertation, which focuses on stress and coping of university students. I am writing to you in hopes that you would be willing to share this information with the students in your program. Once the study has been completed and my dissertation is written, I would be very happy to share a summary of the findings with your department, should you be interested.

I am seeking responses from any and all current WVU students, 18 years of age and older. Participants will be required to complete online a demographic form and several short measures via the internet link provided. Once participants complete the survey, they have the option to enter a drawing to win one of ten $\$ 20$ gift Amazon gift cards. Drawing participants will be required to provide contact information (e-mail address) to receive the gift card, if selected. Their participation is voluntary and completely confidential.

If you have a chance, I would appreciate an email reply letting me know if you share this information with your students. This will aid in my record keeping. I look forward to hearing from you. If you have any questions about the project, please don't hesitate to contact me at the email address or phone number listed below. You may also contact my dissertation chair, Dr. James Bartee, in the Department of Counseling, Rehabilitation Counseling, and Counseling Psychology. If there is someone else I need to discuss this request with, please notify me, or forward my email to that person.

I have attached the information, and also copied it at the end of this email. Additionally, if any instructors elect to share this information with students via an in-class announcement, a script has been attached to this email for instructors to utilize.

Thank you for considering my request, and I look forward to your response.

Thank you,

Erin L. Higgenbotham, MA

Doctoral Candidate

Counseling Psychology

Email: ehiggenb@mix.wvu.edu

Phone: 803-427-4078 


\section{Advertisement in Email:}

Title: Opportunity to Participate in Student Research

You must be 18 years old or older, and a current student at West Virginia University to participate in this study. Researchers at West Virginia University are looking for participants to complete an online research survey examining the stress and coping of university students. Completion of this survey will take approximately 20 minutes. All currently enrolled students are invited to participate in this anonymous survey one time. Following completion of the survey, participants can enter a drawing to for one of ten Amazon \$20 gift cards.

For more information, please visit the following link:

\section{http://wvu.qualtrics.com/SE/?SID=SV_54rzfEkTNIMRHoN}

Contact Person: Erin L. Higgenbotham, MA (ehiggenb@mix.wvu.edu; (803) 427-4078) or James Bartee, Ph.D. (James.Bartee@mail.wvu.edu; (304) 293-2227) from the Department of Counseling, Rehabilitation Counseling, and Counseling Psychology.

(West Virginia University's Institutional Review Board (IRB) has acknowledgment of this study on file.) 


\section{Recruitment Script for In Class Advertisement Use:}

Instructors,

If you elect to share this information with your students in the classroom, please read the following recruitment script in doing so. Indicate how the advertisements have been shared with students in the final sentence, with one or more of the provided options included.

"I have the following announcement to the class asking for volunteers interested in a dissertation project out the Department of Counseling, Rehabilitation Counseling and Counseling Psychology at WVU. Counseling Psychology doctoral candidate Erin Higgenbotham has provided the following information on her study, which focuses on stress and coping in university students.

The study is open to all current WVU students, 18 years of age and older. Participants will be required to complete several short measures via the provided internet link. If you elect to participate in this study, you have opportunity to enter a drawing to win one of ten $\$ 20$ gift Amazon gift cards. Participation is voluntary and completely confidential.

If you are interested in this study, please review the information provided in the advertisement, which has been [A. posted in the department; B. provided as a handout today; C. sent to you via email]." 


\section{APPENDIX C}

\section{WILLING PARTICIPANT INFORMATION}

Principal Investigator: Erin L. Higgenbotham, M.A.

Dissertation Advisor: James Bartee, Ph.D.

Department: Counseling, Rehabilitation Counseling, and Counseling Psychology

Study Title: (Dissertation research) Attachment, Coping Style, and Perceived Stress in University Students

\section{Contact Persons:}

In the event you experience any discomfort or have any concerns related to this research, you should contact the primary investigator, Erin L. Higgenbotham, M.A. at ehiggenb@mix.wvu.edu, or call (803) 427-4078; or the research advisor, Dr. James Bartee at James.Bartee@mail.wvu.edu, or call at (304) 293-2227. If you have urgent needs associated with this research, please contact the university counseling center, Carruth Center for Psychological and Psychiatric Services at (304) 293-4431.

For information regarding your rights as a research subject, to discuss problems, concerns, or suggestions related to the research, obtain information or offer input about the research, contact the Office of Research Integrity \& Compliance at (304) 293-7073.

\section{Introduction to the Study:}

You have been invited to participate in this research study. The participation criteria, procedures for participation, and incentives will be explained in the following sections. This research is being conducted to fulfill the requirements for a doctoral dissertation in counseling psychology in the Department of Counseling, Rehabilitation Counseling, and Counseling Psychology at West Virginia University, under the supervision of Dr. James Bartee.

\section{Purposes of the Study:}

The purpose of this study is to learn more about how a student's attachment variables and the coping strategies that students use impact how they perceive stress in their environment. A total of approximately 300 participants at West Virginia University are expected to participate.

\section{Description of the Procedures:}

This study involves the completion of a demographic questionnaire and three measures of attachment variables, coping styles, and perceived stress and will take approximately 20 minutes for you to complete. You do not have to answer all the questions, and you can withdraw from participating at any time during the process of filling out the questionnaires. The criterion for participation in this study is that you are a student currently enrolled in West Virginia University. If you meet this criterion, please check the box below to proceed to the study. After completing the questionnaires online, you will be given the opportunity to email the researcher to enter a 
drawing for one of ten $\$ 20$ Amazon gift cards. After the data collection is completed, a drawing will be conducted based on the email contact you provide. If you have any questions you may contact the primary investigator, Erin L. Higgenbotham, at ehiggenb@mix.wvu.edu or call (803) 427-4078, or the research advisor Dr. James Bartee at James.Bartee@mail.wvu.edu or call at (304) 293-2227.

\section{Discomforts}

There are no known or expected risks from participating in this study, except for the mild frustration associated with answering the questions.

\section{Benefits:}

After completing the questionnaires online, you will be given the opportunity to send an email to the researcher titled "Enter Drawing" to enter a drawing for one of ten \$20 Amazon gift cards. After the data collection is completed, a drawing will be conducted based on the email contact you provided. Also, the knowledge gained from this study may eventually benefit others.

\section{Financial Considerations:}

There are no fees for participating in this study.

\section{Confidentiality:}

Any information about you that is obtained as a result of your participation in this research will be kept as confidential as legally possible. In any publications that may result from this research, neither your name nor any information from which you might be identified will be published without your consent.

\section{Voluntary Participation:}

Participation in this study is voluntary. You are free to withdraw your consent to participate in this study at any time. You do not have to answer all the questions. Refusal to participate or withdrawal will not affect your class standing or grades, or access to mental health care, and will involve no penalty to you. Refusal to participate or withdrawal will not affect your future care, or your employee status at West Virginia University.

In the event new information becomes available that may affect your willingness to participate in this study, this information will be given to you so that you can make an informed decision about whether or not to continue your participation.

I willingly agree to be in the study.
$\underline{\text { Yes }}$
№ 


\section{APPENDIX D}

\section{DEMOGRAPHIC QUESTIONNAIRE}

1. What is your gender?
a. Female
b. Male

2. What is your age?

3. What year in school are you?
a. Freshman
b. Sophomore
c. Junior
d. Senior
e. $5^{\text {th }}$ year + Undergraduate Student
f. Graduate Student

4. Are you a part-time or full-time student (as defined below)?
a. Full-time (currently enrolled in at least 12 credit hours for undergraduate or 9 credit hours for graduate)
b. Part-time (currently enrolled in less than 12 credit hours for undergraduate or 9 credit hours for graduate)
c. Auditing course(s) as student or faculty, but not enrolled for credit

5. What is your race/ethnicity?
a. African-American
b. Asian
c. Caucasian
d. Latino/a
e. Native American
f. Other (please specify)

6. What is your relationship status?
a. Single
b. In a committed relationship - not living together
c. In a committed relationship - living together
d. Married
e. Separated or Divorced
f. Widowed 


\section{APPENDIX E}

\section{PERCEIVED STRESS SCALE (PSS)}

The following questions ask you about your feelings and thoughts during the last month. In each case, you will be asked to indicate how often you felt or thought a certain way. Although some of the questions are similar, there are differences between them and you should treat each one as a separate question. The best approach is to answer each question fairly quickly. That is, don't try to count up the number of times you felt a particular way, but rather indicate the alternative that seems like a reasonable estimate. For each question, choose from the following alternatives:

$$
\begin{aligned}
& 0=\text { never } \\
& 1=\text { almost never } \\
& 2=\text { sometimes } \\
& 3=\text { fairly often } \\
& 4=\text { very often }
\end{aligned}
$$

1. In the last month, how often have you been upset because of something that happened unexpectedly?

2. In the last month, how often have you felt that you were unable to control the important things in your life?

3. In the last month, how often have you felt nervous and "stressed"?

4. In the last month, how often have you dealt successfully with irritating life hassles?

5. In the last month, how often have you felt that you were effectively coping with important changes that were occurring in your life?

6. In the last month, how often have you felt confident about your ability to handle your personal problems?

7. In the last month, how often have you felt that things were going your way? 
8. In the last month, how often have you found that you could not cope with all the things that you had to do?

9. In the last month, how often have you been able to control irritations in your life?

10. In the last month, how often have you felt that you were on top of things?

11. In the last month, how often have you been angered because of things that happened that were outside of your control?

12. In the last month, how often have you found yourself thinking about things that you have to accomplish?

13. In the last month, how often have you been able to control the way you spend your time?

14. In the last month, how often have you felt difficulties were piling up so high that you could not overcome them? 


\section{APPENDIX F}

\section{EXPERIENCES IN CLOSE RELATIONSHIPS SCALE}

The following statements concern how you feel in romantic relationships. We are interested in how you generally experience relationships, not just in what is happening in a current relationship. Respond to each statement by indicating how much you agree or disagree with it.

\begin{tabular}{ccccccc} 
Disagree Strongly & \multicolumn{3}{c}{ Neutral/Mixed } & \multicolumn{2}{c}{ Agree Strongly } \\
1 & 2 & 3 & 4 & 5 & 6 & 7
\end{tabular}

1. I prefer not to show a partner how I feel deep down.

2. I worry about being abandoned.

3. I am very comfortable being close to romantic partners.

4. I worry a lot about my relationships.

5. Just when my partner starts to get close to me I find myself pulling away.

6. I worry that romantic partners won't care about me as much as I care about them.

7. I get uncomfortable when a romantic partner wants to be very close.

8. I worry a fair amount about losing my partner.

9. I don't feel comfortable opening up to romantic partners.

10. I often wish that my partner's feelings for me were as strong as my feelings for him/her.

11. I want to get close to my partner but I keep pulling back. 
12. I often want to merge completely with romantic partners, and this sometimes scares them away.

13. I am nervous when my partners get too close to me.

14. I worry about being alone.

15. I feel comfortable sharing my private thoughts and feelings with my partner.

16. My desire to be very close sometimes scares people away.

17. I try to avoid getting too close to my partner.

18. I need a lot of reassurance that I am loved by my partner.

19. I find it relatively easy to get close to my partner.

20. Sometimes I feel that I force my partners to show more feeling, more commitment.

21. I find it difficult to allow myself to depend on romantic partners.

22. I do not often worry about being abandoned.

23. I prefer not to be too close to romantic partners.

24. If I can't get my partner to show interest in me, I get upset or angry.

25. I tell my partner just about everything.

26. I find that my partner(s) don't want to get as close as I would like.

27. I usually discuss my problems and concerns with my partners.

28. When I'm not involved in a relationship, I feel somewhat anxious and insecure. 
29. I feel comfortable depending on romantic partners.

30. I get frustrated when my partner is not around as much as I would like.

31. I don't mind asking partners for comfort, advice, or help.

32. I get frustrated if romantic partners are not available when I need them.

33. It helps to turn to my romantic partner in times of need.

34. When romantic partners disapprove of me, I feel really bad about myself.

35. I turn to my partner for many things, including comfort and reassurance.

36. I resent it when my partner spends time away from me. 


\section{APPENDIX G}

\section{BRIEF COPE}

These items deal with ways you've been coping with the stress in your life in the last 3 months. There are many ways to try to deal with problems. These items ask what you've been doing to cope with problems. Obviously, different people deal with things in different ways, but I'm interested in how you've tried to deal with them. Each item says something about a particular way of coping. I want to know to what extent you've been doing what the item says. How much or how frequently. Don't answer on the basis of whether it seems to be working or not- - just whether or not you're doing it. Use these response choices. Try to rate each item separately in your mind from the others. Make your answers as true FOR YOU as you can.

$$
\begin{aligned}
& 1=\text { I haven't been doing this at all } \\
& 2=\text { I've been doing this a little bit } \\
& 3=\text { I've been doing this a medium amount } \\
& 4=\text { I've been doing this a lot }
\end{aligned}
$$

1. I've been turning to work or other activities to take my mind off things.

2. I've been concentrating my efforts on doing something about the situation I'm in.

3. I've been saying to myself "this isn't real.".

4. I've been using alcohol or other drugs to make myself feel better.

5. I've been getting emotional support from others.

6. I've been giving up trying to deal with it.

7. I've been taking action to try to make the situation better.

8. I've been refusing to believe that it has happened.

9. I've been saying things to let my unpleasant feelings escape.

10. I've been getting help and advice from other people. 
11. I've been using alcohol or other drugs to help me get through it.

12. I've been trying to see it in a different light, to make it seem more positive.

13. I've been criticizing myself.

14. I've been trying to come up with a strategy about what to do.

15. I've been getting comfort and understanding from someone.

16. I've been giving up the attempt to cope.

17. I've been looking for something good in what is happening.

18. I've been making jokes about it.

19. I've been doing something to think about it less, such as going to movies, watching TV, reading, daydreaming, sleeping, or shopping.

20. I've been accepting the reality of the fact that it has happened.

21. I've been expressing my negative feelings.

22. I've been trying to find comfort in my religion or spiritual beliefs.

23. I've been trying to get advice or help from other people about what to do.

24. I've been learning to live with it.

25. I've been thinking hard about what steps to take.

26. I've been blaming myself for things that happened.

27. I've been praying or meditating.

28. I've been making fun of the situation. 